This PDF is a selection from an out-of-print volume from the National Bureau of Economic Research

Volume Title: Business Cycle Indicators, Volume 1

Volume Author/Editor: Geoffrey H. Moore, ed.

Volume Publisher: Princeton University Press

Volume ISBN: 0-870-14093-0

Volume URL: http://www.nber.org/books/moor61-1

Publication Date: 1961

Chapter Title: Electronic Computers and Business Indicators

Chapter Author: Julius Shiskin

Chapter URL: http://www.nber.org/chapters/c0737

Chapter pages in book: (p. 517 - 597) 


\title{
Electronic Computers and Business Indicators
}

\author{
Julius Shiskin
}

\section{The Problem}

A PRINCIPAL purpose of studying economic indicators is to determine the stage of the business cycle at which the economy stands. Such knowledge helps in forecasting subsequent cyclical movements and provides a factual basis for taking steps to moderate the amplitude and scope of the business cycle. It is of critical importance around turning points; for example, failure to recognize a downturn may lead to the adoption of policies to curb expansion when a recession is already under way. In using indicators, however, analysts are perennially troubled by the difficulty of separating cyclical from other types of fluctuations, particularly seasonal fluctuations.

This problem can be illustrated by the situation in the summer and fall of 1954, when government officials were trying to determine whether or not this country was coming out of a mild recession. The President had said earlier in the year that he would wait for several months to see whether an upturn in business activity occurred before deciding on further

Nore: Reprinted from Journal of Business, October 1957, copyright (1957) by University of Chicago (Occasional Paper 57, New York, NBER, 1957).

The writer wishes to acknowledge his obligation to Geoffrey $H$. Moore for valuable suggestions at every stage in the preparation of this paper and for contributions to recent tests and extensions of the electronic computer program. Harry Eisenpress programmed the method described in this paper for the Univac and provided helpful assistance in many other phases of the work. Gerhard Bry, Donald J. Daly, Milton Friedman, Leonard H. Lempert, Robert Lipsey, Ilse Mintz, Boris Shishkin, and Willard L. Thorp offered constructive criticisms of an earlier draft. The paper was edited by John Sibley. Sophie Sakowitz, Dorothy M. O'Brien, George Stein, Sandra Renaud, and Henry Einhorn rendered valuable statistical assistance. Thanks are also due to the staff of the Bureau of the Census and particularly to Howard C. Grieves, Morris H. Hansen, and William N. Hurwitz, for helping to get this program under way and for encouragement and practical assistance at critical stages.

EDrTOR's Note: The electronic computer program described here was started by Mr. Shiskin at the Bureau of the Census, where he is chief economic statistician. Mr. Shiskin received a Rockefeller Public Service Award for 1956-57, during which time he conducted further research on computer techniques at the National Bureau. This research was part of a larger study of the application of electronic computers to economic statistics, made possible by substantial contributions of machine and programming time from equipment manufacturers and a grant from the National Science Foundation. The particular computer program described in the present report was developed with the aid of a contribution of Univac programming and machine time from the Sperry-Rand Corporation. An advisory committee of distinguished economists and statisticians under the chairmanship of W. Allen Wallis, dean of the School of Business of the University of Chicago, helped to guide the research. 
government action to stimulate business. In the meantime debates were taking place in Congress and in the press, with many urging that vigorous contracyclical measures be taken before the country once again was engulfed in a disastrous depression.

One of the vexatious problems was to determine whether changes in business activity, from, let us say, September to October 1954 were larger or smaller than normal seasonal changes. It was easy enough to determine how the volume of business in September and October 1954 compared with September and October 1953 but that was not the question. September and October 1954 were certainly lower than the corresponding months of 1953, but that was not so important as how they compared with July and August 1954. In forecasting for the months immediately ahead, it was crucial to know whether the economy during the preceding four or five months had been rising to the levels of October 1954 or declining to them.

This problem confronts all business concerns with large seasonal fluctuations. Decisions are often necessary on price and inventory policy, commitments to make capital expenditures, and so on. Such decisions must be based upon forecasts of the volume of business in the months ahead, often for the country at large as well as one's own company. Officials of business concerns sometimes cannot tell, on the basis of raw data, whether their own business is in a rising or declining stage, and they are making forecasts of the future without knowing whether their business has been getting better or worse in the immediate past.

Knowledge of the seasonal pattern in the sales of its products (as well as of the materials it purchases) is also important to a company. This information is needed by all companies to determine the level of production that is most efficient, in terms of production costs, on the one hand, and storage facilities, insurance costs, and the risks of forced selling, on the other. Some companies forecast only their annual total sales, and then, on the basis of this single forecast, they plan their production schedules, their inventory and price policies, and establish quotas for their salesmen. For the companies in this group which also experience large seasonal fluctuations, a good first approximation of the monthly pattern of sales can be obtained by prorating the estimated annual total over the months according to the pattern shown by the seasonal factors. The seasonal factors will be of further value in making shorter-term forecasts, that is, forecasts of month-to-month changes. The original estimates based upon the distribution of the annual forecast can be revised each month by applying the normal seasonal change to the most recent month's experience. Measures of the average magnitude of the irregular fluctuations and the pattern of their variations would provide valuable supplementary information. Knowledge of the average month-to-month 
movements of both the seasonal and the irregular factors can be used to reduce overordering, overproduction, and overstocking.

\section{Types of Economic Fluctuations}

For many years economists and statisticians have found it useful to consider each economic time series as a composite of cyclical, trend, seasonal, and irregular factors. The cycle consists of short-run cumulative and reversible movements characterized by alternating periods of expansion and contraction and lasting three to four years, on the average, from trough to trough, though the range may extend from two to ten years. The trend makes up the still longer run movements of the series and ordinarily has little effect upon month-to-month movements of economic series; for convenience in short-term forecasting it is often combined with the cyclical factor. ${ }^{1}$ The seasonal factor consists of intrayear movements and follows a more or less regular pattern. For example, each year farm income rises steadily from early spring to fall and then drops sharply again to early spring. Most economic series contain significant seasonal fluctuations, but some contain virtually none (stock prices, for example). The irregular fluctuations are those that remain after the other types are accounted for. They are occasioned by a wide variety of factors: exceptional events, such as unusual weather, strikes, unexpected political developments, or the failure of a large business concern, and statistical errors, such as sampling errors, response errors, and errors caused by defective seasonal adjustments.

Irregular, seasonal, and cyclical movements all vary a great deal in magnitude from one series to another. The irregular are very large, for example, in the liabilities of business failures but are very small in grocery sales. Similarly, the seasonal factor is quite large in the construction and retail industries but small in many lines of manufacturing. The cyclical

1 This practice is usually followed in this paper. The reader should try to bear this in mind, because sometimes the trend is important, even over short periods-for example, in series showing airline traffic since 1947. The curves used to delineate the cyclical component also show shorter movements that are not generally recognized as cyclical-for example, the rise from July to October 1932 and the decline from the spring to the fall of 1951. Furthermore, the term "cyclical" is used in other sciences, and especially in mathematics, to mean something different-a curve with a recurrent cycle that has a symmetrical pattern, a standard amplitude, and a fixed period. For these reasons, the use of the word "cyclical" to identify our curves leaves something to be desired; another word, possibly "systematic" or "oscillatory," might be preferable if we were starting afresh. But the use of the term "cyclical" to describe alternating periods of business expansion and contraction, with uneven patterns, varying amplitudes, and irregular durations, is so widespread among economists that it would probably be impossible to substitute another term now.

The method of time-series decomposition described here follows the general plan formulated by earlier analysts of economic time series, particularly Warren M. Persons (see his articles, "Indices of Business Conditions" and "An Index of General Business Conditions," Review of Economics and Statistics, January and April 1919). 


\section{CHART 17.1}

The Raw Data and the Seasonal, Cyclical, and Irregular Components, Residential Building Contracts, 1948-56

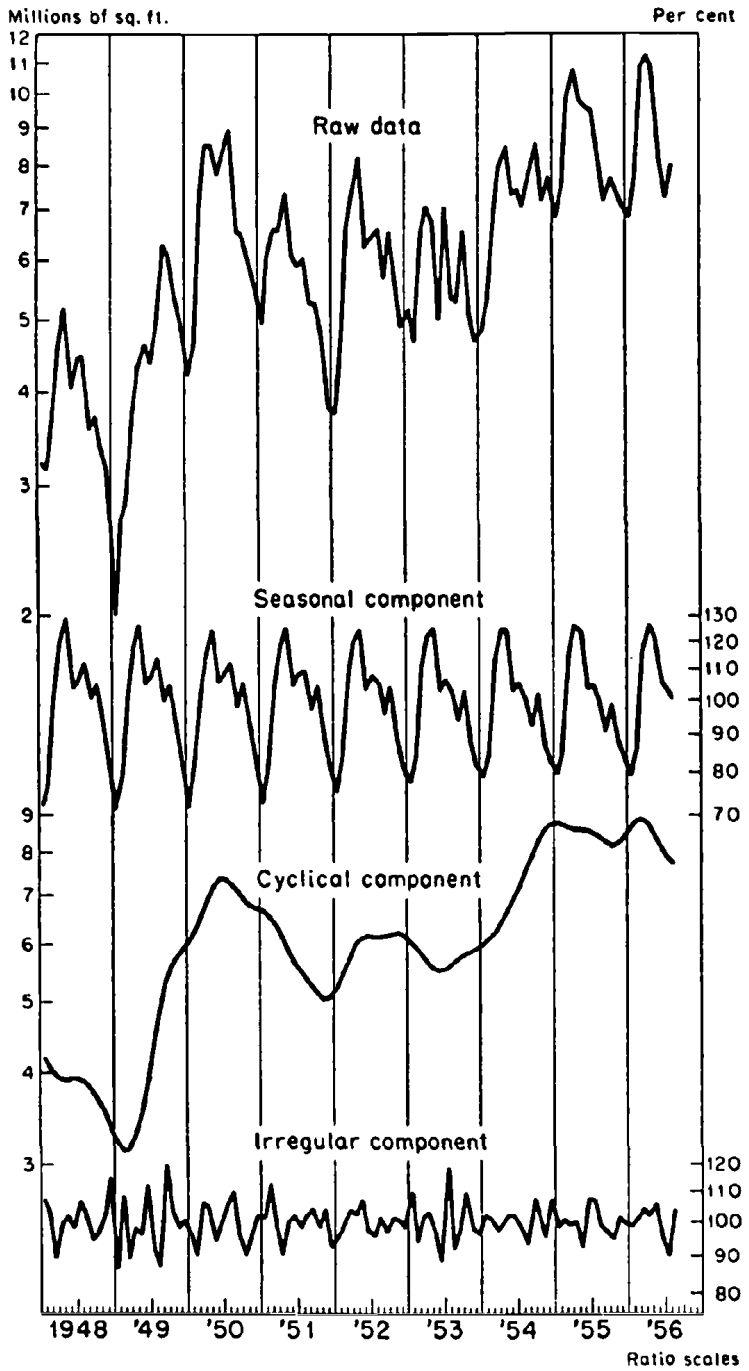




\section{CHART 17.2}

The Raw Data and the Seasonal, Cyclical, and Irregular Components, Sales of a Major Chemical Company, 1948-56

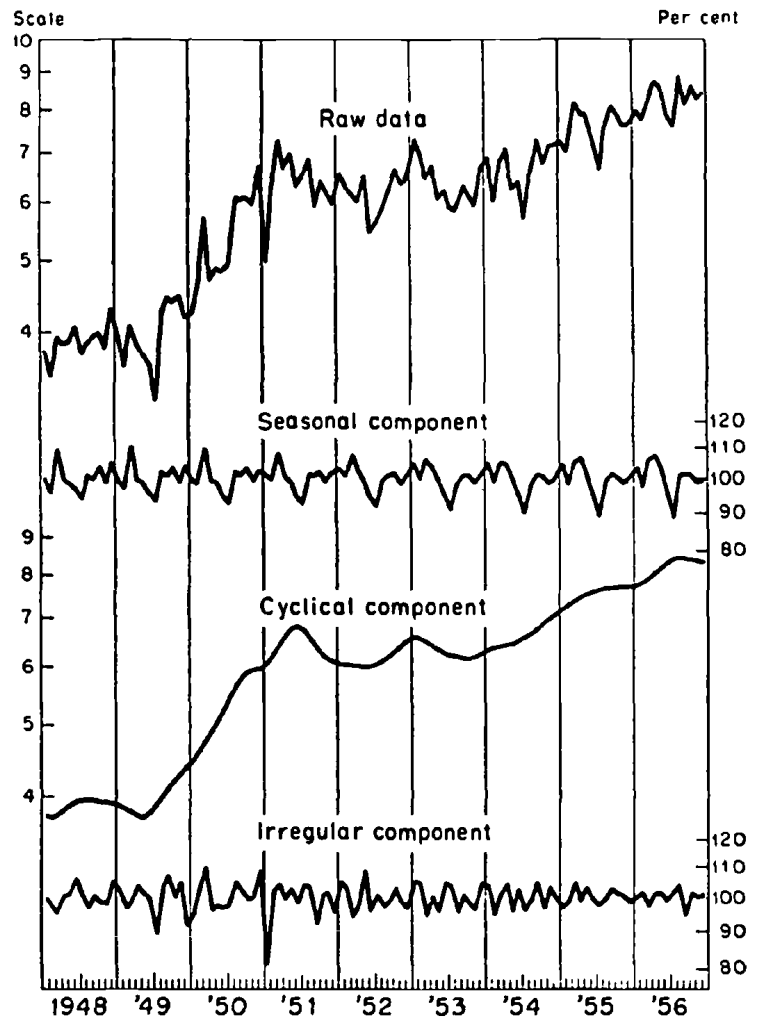

Ratio scales used throughout.

The scales on the left are arbitrary because the actual figures are confidential.

amplitude is considerably larger in new orders series than it is in employment series. The relations among these types of fluctuations for different economic series are discussed more fully later.

Chart 17.1 shows the original observations and the seasonal, cyclical, and irregular factors for a series on total residential building contracts. Chart 17.2 shows similar figures for the sales of a major chemical company. In both cases the period covered is $1948-56$.

\section{Illustrative Series-Some Economic Indicators}

Almost any economic series could be used to illustrate the technique of converting the original observations into more useful data, but we have selected some well-known economic indicators, partly because they are 
of interest for their own sake and partly because they make it easy to show how the final products facilitate economic analysis.

The Federal Reserve index of industrial production and the Bureau of Labor Statistics estimates of nonagricultural employment are shown in Chart 17.3. These series, being of broad industrial scope, represent well the business cycle movements in the economy. The period selected for this illustration is 1936-39, because the cyclical movements during this period were relatively clear. They were smaller than those of the 1929-35 period but larger than any since the end of World War II. The first curves show the data as they usually come from the primary sources; the other curves show these raw data after adjustment for seasonal variations. ${ }^{2}$ The two series show a rapid rise during 1936 and the early part of 1937. A sharp drop begins in mid-1937 and continues to June 1938. A rise starts in July 1938 and continues at a moderate pace during the remainder of 1938 and during 1939. This pattern is shown more clearly in the seasonally adjusted series (e.g. the December to January dips in employment are erased in the adjusted data), though it is also discernible in the series of original observations.

The series on nonagricultural employment and industrial production are relatively smooth; that is, the irregular and seasonal factors are relatively small. Thus the cyclical movements are discernible even in the original observations. Other series are also good economic indicators, though not in their raw form, because relatively large seasonal and irregular movements obscure the cyclical movements. The raw data and seasonally adjusted data for five such series are shown in Chart 17.4 for 1936-39 and 1953-56. Two are series which usually lead at cyclical turning points in the economy as a whole-residential building contracts and liabilities of firms failing (on an inverted basis). Two usually turn at about the same time as general business-total unemployment (on an inverted basis) and freight carloadings; and one usually lags at cyclical turning points-retail sales. All these series are much more difficult to interpret in their original form than those for factory employment and industrial production. At this point, the problem of this paper may be put in this way: How can series like business failures and retail sales be made to show their cyclical movements as clearly as those for factory employment and industrial production?

The illustrative series are plotted in various forms to show how the usefulness of raw economic data can be enhanced by various statistical adjustments. The figures for 1936-39 are plotted in Part A in Chart 17.4 and for 1953-56 in Part B. It is plain from the first panel of the charts

${ }^{2}$ All seasonal adjustments in this paper are by the electronic computer method. The corresponding 1956 official seasonal factors are given, for comparative purposes, in an appendix [not reprinted here]. 


\section{CHART 17.3}

Raw and Seasonally Adjusted Data for Two Smooth Economic Series, 1936-39

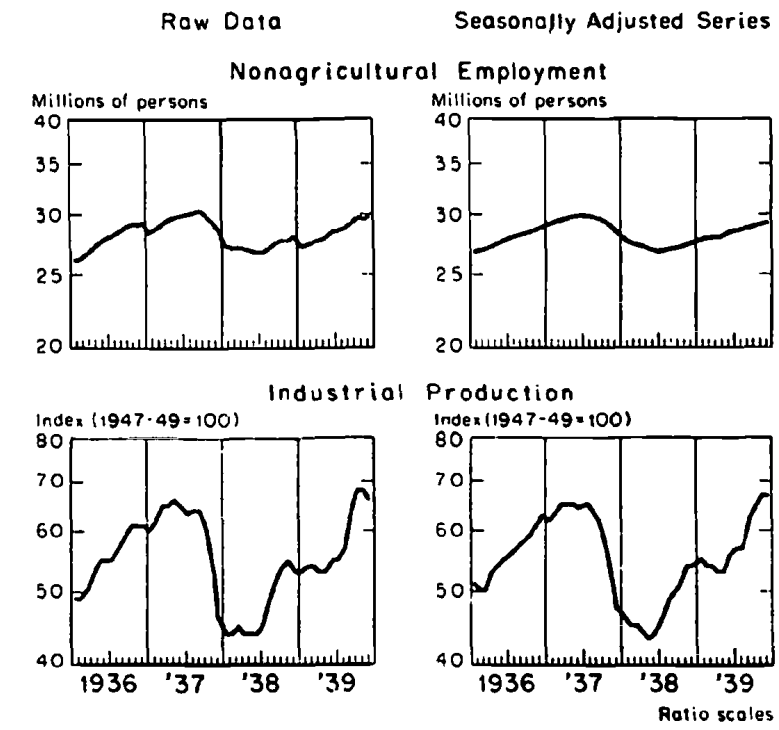

that it is difficult to trace the path of the business cycle in the raw data. Declines during 1937-38 and during 1953-54 are discernible, but the patterns of the series and the timing relations among them are obscure.

\section{Same-Month-Year-Ago Comparisons}

The simple device of same-month-year-ago comparisons is frequently used to eliminate seasonal fluctuations. Same-month-year-ago comparisons involve dividing the figure for a given month by the figure for the same month of the preceding year. This practice is widespread among financial writers and businessmen and is occasionally followed by professional economists and statisticians.

The simplicity of same-month-year-ago comparisons is, unfortunately, offset by major drawbacks. These drawbacks are sometimes critical at cyclical turning points. When a cyclical decline occurs, it usually takes a continuation of the tendency for several months before a decline below the same month of the year before becomes apparent. In using raw data for current analysis, same-month-year-ago comparisons tell broadly what has happened over the intervening twelve months, but not during that period. Such comparisons often will not indicate correctly the trend during the preceding six months, which is crucial in most current business analyses. 
CHART 17.4

Statistical Adjustments of Raw Economic Series to Improve Their Usefulness as Economic Indicators, 1936-39 and 1953-56

Part A: 1936-39
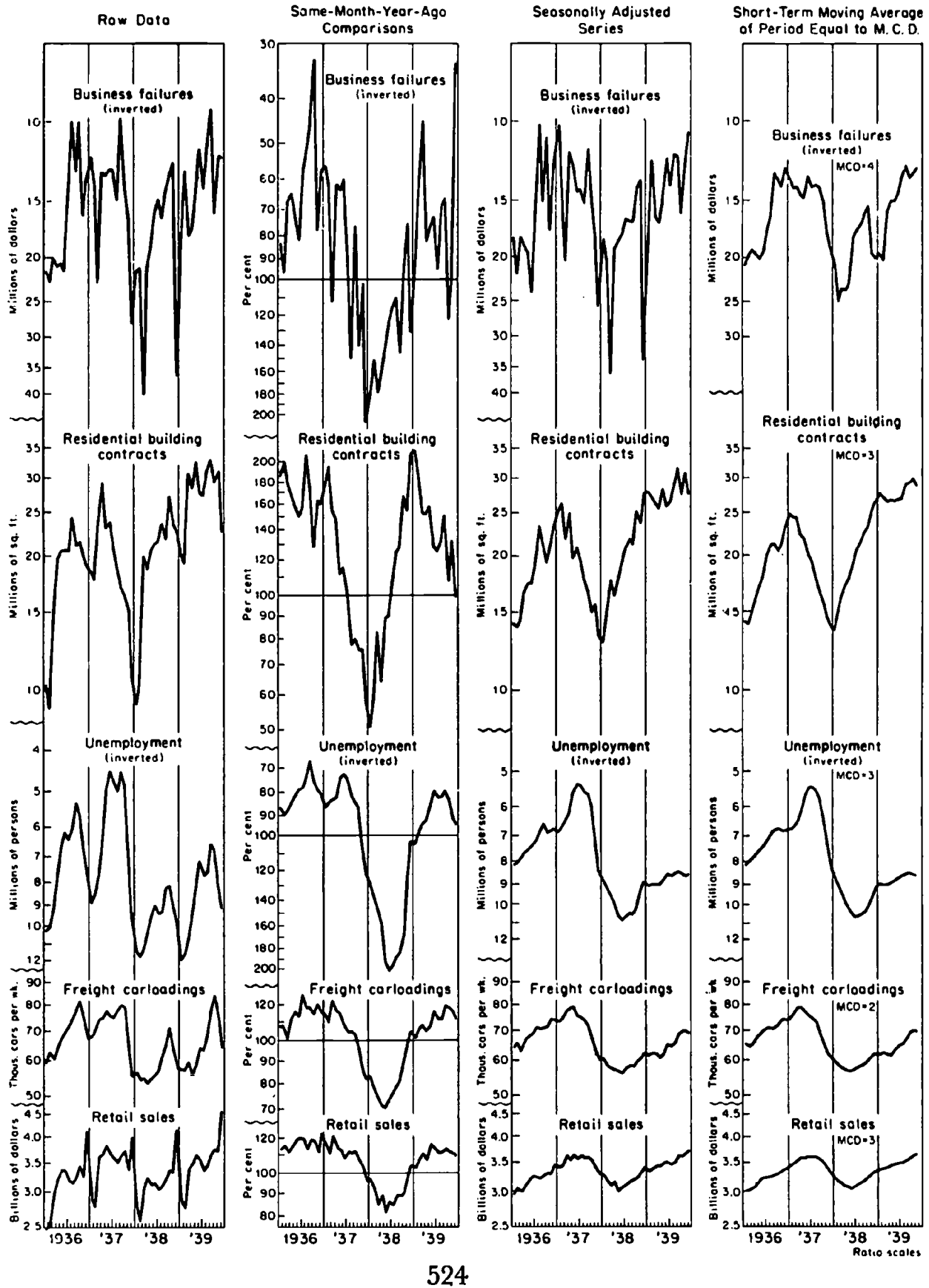
CHART 17.4 (concluded)

Part B: 1953-56
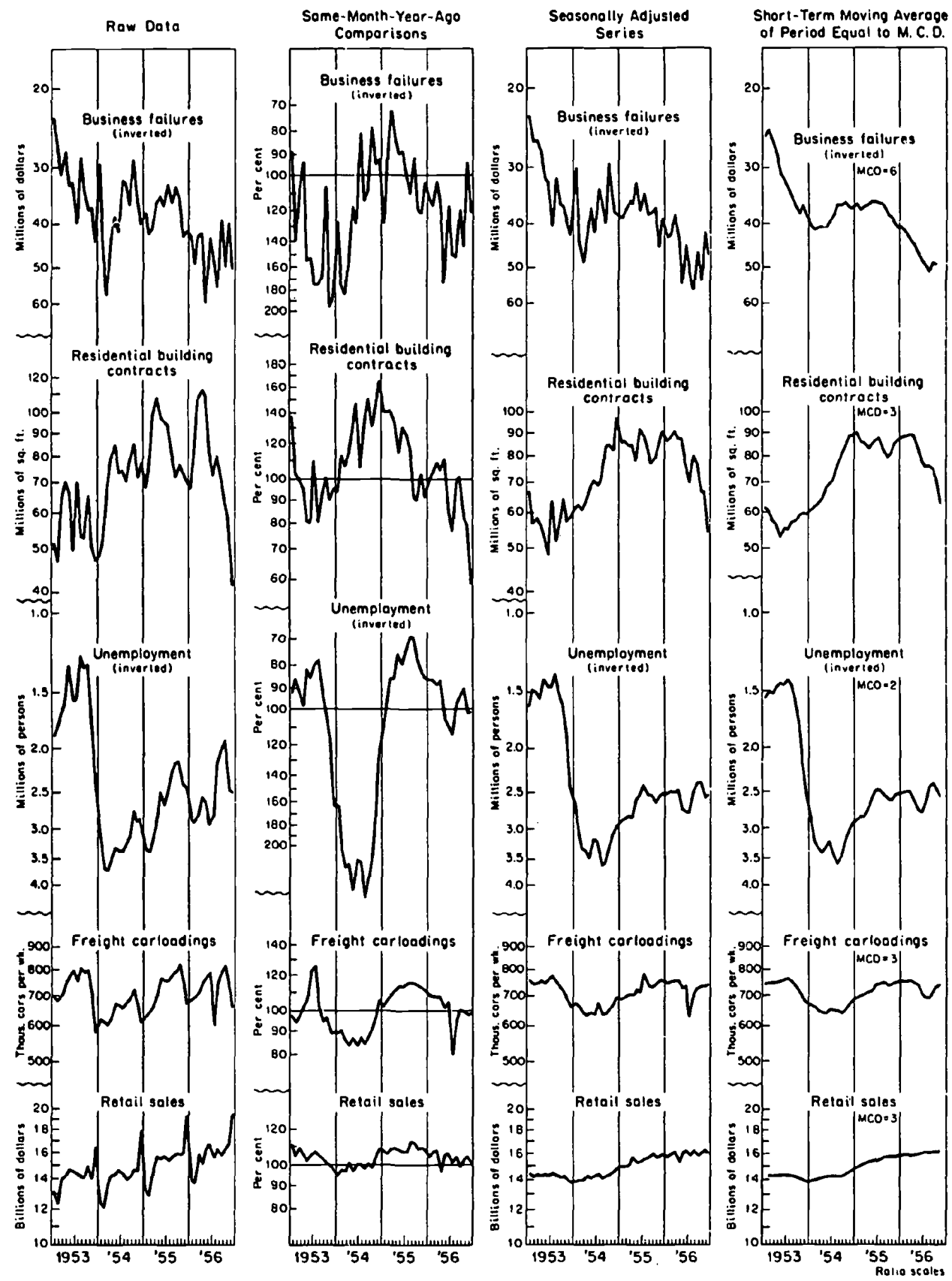
In same-month-year-ago comparisons a cycle-trend-seasonal-irregular composite for each month is divided by a similar composite for the same month one year back. In analyzing the results of such divisions, the trend factor can be disregarded on the ground that it is usually small from year to year; in any case, it affects all twelve monthly values in substantially the same way and therefore will not affect the cyclical pattern.

A constant seasonal factor will be eliminated by the division (any movement that recurs regularly every twelve months will be eliminated). If the seasonal factor changes, however, there will be a residual seasonal pattern, but on a year-to-year basis these changes are usually not very large.

The division of one set of irregular factors by another will yield still a third. Thus figures for a few months dominated by a strike may be divided by those for a few months dominated by abnormal weather, and the result could be almost anything. In general, if the irregular factors one year apart are uncorrelated with each other, as seems reasonable, their quotient can be expected to have a substantially larger relative variability than the irregular factor itself. ${ }^{3}$

The percentage change in the irregular factor is usually larger than that of the cyclical on a month-to-month basis, but not on a twelve-month basis, despite the effect just mentioned. For this reason, the heart of the matter is the effect of the division of the cyclical component of a given year by the cyclical component of another. Only when data for the first year in a same-month-year-ago comparison follow a straight horizontal line will the cyclical pattern of the second year be unaffected. If the first year's pattern is the same as the second year's, a straight horizontal line will result; if it is the reverse, the cyclical pattern of the second year will be accentuated; if the first year has a curvature and the second year is a straight line, the inverted pattern of the first year will show up in the second.

The shape of the resulting curve is similarly affected by the rates of change in the two years. Thus when a year dominated by sharp cyclical movements follows a year of slow change, the imprint of the current year's cyclical pattern will show up fairly clearly in the same-monthyear-ago curve. If the year of sharp cyclical change is then followed by a year of slow change, the same-month-year-ago curve for the third year will reflect, primarily, what happened a year ago, in inverted fashion. Thus the principal result of a same-month-year-ago comparison is the arbitrary replacement of one cyclical pattern by another.

Same-month-year-ago comparisons are often used by considering

${ }^{3}$ See Morris H. Hansen, William N. Hurwitz, and William Madow, Sample Sturvey Methods and Theory, New York, 1953, Vol. I, p. 163, eq. 18.2, with $f=0$ when the expected values of $X_{t}$ and $X_{t-12}$ are positive; also see Vol. II, Chapter iv, Secs. 11, 13, 15 , and 21 . 
only the direction of change shown by the comparison (the changes between the figures for the same months one year apart are inspected to see whether they are plus or minus). For this method of analysis the 100 per cent lines drawn in the second panel of Chart 17.4 provide a convenient comparison base. Points falling above this line indicate a rise (the figure for the second year is higher than that for the first), while points falling below the line indicate a decline. This approach will often lead to a very substantial delay in recognizing cyclical upturns or downturns. This can readily be seen from the graphs in Chart 17.4, which show same-month-year-ago comparisons for five economic indicators in the second panel and the corresponding seasonally adjusted series in the third panel. (The same-month-year-ago curves are dated at the end of the period of comparison; for example, the percentage ratio of January 1956 to January 1955 is plotted in January 1956.) Thus residential building contracts, seasonally adjusted, began to rise in February 1938, but the same-month-year-ago comparison did not show an increase (did not get above the 100 line) until five months later, in July. Similarly, unemployment began to decline in September 1954, according to the seasonally adjusted series, but the same-month-year-ago comparisons did not show a decline until February 1955.

A series will usually start to decline several months before the percentage change from the same month a year ago becomes negative. Consider, for example, the case of a smooth symmetrical cycle (such as a sine curve). Same-month-year-ago comparisons made on the ascending side of such a cycle will, of course, show increases. But increases will also be shown for the first, second, third, fourth, and fifth months after a decline starts, because the levels of the second year will be higher than those of the first year. The first decline will be indicated only in the sixth month after the contraction begins. Similarly, the first sign of a revival will be indicated only in the sixth month after the revival begins. Thus in the case of a smooth symmetrical cycle, same-month-year-ago comparisons treated on the above plan will show turning points six months late. In other, asymmetrical, types of cycles, the timing can be as much as eleven months too late. Only when a series drops off very sharply after a peak (the first month after the peak falling to a lower level than the eleventh month prior to the peak) or rises very sharply after a trough will this type of comparison show turning dates accurately.

In addition, when the same-month-year-ago comparisons are viewed as a time series, a downturn may merely reflect a retardation in the advance of a seasonally adjusted series rather than an actual decline. A retardation in the rate of advance will show up as a smaller absolute percentage change in same-month-year-ago comparisons. Since we know that retardations do not always precede contractions, such declines 


\section{PART THREE}

TABLE 17.1

Average Month-to-Month Percentage Changes (Without Regard to Sign), Seasonally Adjusted Series, and SameMonth-Year-Ago Series, 1936-39 and 1953-56

\begin{tabular}{lcc}
\hline & $\begin{array}{c}\text { Seasonally } \\
\text { Adjusted }\end{array}$ & $\begin{array}{c}\text { Same Month } \\
\text { Year Ago }\end{array}$ \\
\hline Business failures: & & \\
$\quad$ 1936-Aug., 1938 & 15.2 & 33.5 \\
$\quad$ 1953-56 & 12.7 & 22.0 \\
Residential building contracts: & & \\
$\quad$ 1936-39 & 9.1 & 15.0 \\
$\quad$ 1953-56 & 7.7 & 12.0 \\
Retail sales: & & \\
1936-39 & 2.1 & 3.8 \\
1953-56 & 1.6 & 2.9 \\
Freight carloadings: & & \\
1936-39 & 2.2 & 4.5 \\
$\quad$ 1953-56 & 2.8 & 4.5 \\
Unemployment: & & \\
1936-39 & 3.5 & 6.3 \\
1953-56 & 5.5 & 9.6 \\
\hline
\end{tabular}

a The data in this table are not strictly comparable because the same-month-year-ago comparisons implicitly involve an additional year-that prior to the period specified. Thus the 1953-56 same-month-year-ago figures involve 1952, a year in which there were major changes in series affected by the steel strike.

indicated by same-month-year-ago comparisons may be misleading. For example, the sharp decline during 1939 in the same-month-yearago comparisons for residential building contracts (Chart 17.4, Part A) were quite as dramatic as the decline during the first half of 1937; but in 1939 this reflected only a retardation in growth, whereas in 1937 the same pattern reflected a sharp decline in the level of activity. The difference is evident in the seasonally adjusted data.

Further troubles arising from same-month-year-ago comparisons are also illustrated in Chart 17.4. Note that the sharp decline in late 1937 and early 1938 is preserved in the same-month-year-ago comparisons, but the earlier cyclical patterns are sometimes distorted (e.g. residential building contracts) and the subsequent cyclical expansion almost always misrepresented. Similarly, the high level of the unemployment ratios in 1955 is misleading, as is the sharp decline in the residential building contracts ratios during 1955. Perhaps the most striking illustration, however, is provided by the 1953 figures for freight carloadings. They show a short pronounced rise, followed by a similar decline; these movements reflect in reverse those produced by the steel strike in 1952. They are entirely absent in the seasonally adjusted series in 1953.

These charts also point up the fact that month-to-month irregular movements in the same-month-year-ago series are substantially larger 
than in the seasonally adjusted series and thus further obscure the underlying cyclical movements. This observation is supported by the statistics shown in Table 17.1, where the average month-to-month percentage changes (without regard to sign) in the seasonally adjusted and the same-month-year-ago series are compared for the five series plotted in Chart 17.4 and for both periods (1936-39 and 1953-56). In every case the average month-to-month percentage change in the same-month-year-ago series is much larger. An increase in the variability of the irregular factor must have been the cause of this increase, since it is so much larger than the cyclical. Special computations for business failures, 1953-56, provide empirical support for this conclusion. The average percentage changes for the seasonally adjusted and same-monthyear-ago series are, respectively: irregular, 12.2 and 20.4; cyclical, 2.7 and 3.8. The irregular movements are 4.5 times as large as the cyclical in the seasonally adjusted data; they are 5.4 times as large as the cyclical in the same-month-year-ago comparisons.

This leads to the conclusion that same-month-year-ago comparisons of raw data do not provide a satisfactory short cut to seasonal adjustments. We must look for other ways of improving raw economic series for the analysis of current economic conditions. ${ }^{4}$

\section{The Electronic Computer Program}

An electronic computer program for adjusting seasonal and irregular time series to a form that shows primarily the cyclical movements has been developed and tested. This program also reveals the seasonal pattern of the series, describes the course of its irregular fluctuations, and computes many summary measures. It can be applied to any kind of time series-for important economic indicators, for employment in a geographic area, for the sales of a company-whatever the degree of irregularity and seasonality. The program is designed for monthly data but can readily be applied to quarterly data.

\footnotetext{
4 Economists have long been critical of same-month-year-ago comparisons. Thus in 1931 Frederick R. Macaulay wrote: "There is a simple and enlightening way to describe the operation of subtracting the quotation for the same month last year from the quotation for the present month and using the resulting figure instead of the raw data. It amounts to taking a 12-months moving total of the data and using the first differences of this moving total instead of the raw data. The procedure which consists of dividing the quotation for the present month by the quotation for the same month last year amounts to using the antilogarithms of the first diffcrences of a 12-months moving total of the logarithms of the data-instead of the raw data.

"In either case the results are based upon month to month changes (first differences) of a crude graduation, namely, a 12-months moving average.... Moreover, as the 12-months moving average does not extend to the end of the data, its first differences do not tell whether, at the present time, the underlying curve of the data is high or low or whether it is rising or falling, but simply whether it was rising or falling six months ago" (see Frederick R. Macaulay, The Smoothing of Time Series, New York, NBER, 1931, pp. 134-35).
} 
The program first corrects the original observations for differences in the number of working or trading days in each month. It next adjusts the series for seasonal variations by an improved version of a familiar method. Then it irons out the irregular movements so that all series are equally smooth and so that their month-to-month movements are primarily cyclical. In the process, some familiar and some new measures of economic fluctuations are computed.

This program has been used by many government agencies during the past few years-for about three thousand economic series altogether. It has been thoroughly tested experimentally and in practice. ${ }^{5}$ Improvements can be and are continually being introduced as methods of making them become clear. A full run of this program, for a ten-year monthly series, requires less than five minutes on a large-scale computer of the Univac class. A detailed listing of all the computational steps in this program and a sample print-out of the final tables are given in the appendix. In what follows we shall describe the program in general terms and show how it helps in analyzing selected business indicators.

\section{ELIMINATING SEASONAL VARIATIONS}

Cyclical movements are shown more accurately and stand out more clearly in data that are seasonally adjusted. As we have seen, seasonally adjusted data not only avoid some of the biases to which same-monthyear-ago comparisons are subject but also often reveal cyclical changes several months earlier. Seasonal adjustments, therefore, help the business statistician to make more accurate and more prompt diagnoses of the current economic situation. A businessman who uses seasonally adjusted series in lieu of same-month-year-ago comparisons will be in a position to note changing trends in his industry months before his less statistically sophisticated competitor will. As a general purpose aid, both in historical studies of the business cycle and in studies of current economic trends, seasonal adjustments rank second only to the provision of the raw observations themselves.

The third panel of Chart 17.4 shows the five economic indicators in seasonally adjusted form. Although the fluctuations are still marked by irregular movements and the curves do not follow patterns that can be neatly described by mathematical equations, the cyclical movements are relatively clear. The series all rose more or less steadily throughout 1936, they reached peaks late in 1936 or in 1937, they then declined for about a

${ }^{5}$ These tests are described in two more technical reports: Julius Shiskin and Harry Eisenpress, "Seasonal Adjustments by Electronic Computer Methods," Journal of the American Statistical Association, December 1957, and National Bureau Technical Paper 12; and Shiskin, "Problems in the Seasonal Adjustment of Economic Indicators-A Progress Report," Proceedings of the Business and Economic Statistics Section, American Statistical Association, 1957. Other tests are also under way; these will be clescribed in later reports. 


\section{AIDS TO THE CURRENT USE OF INDICATORS}

year and then rose throughout 1939. Furthermore, the timing relations among these series are fairly clear; the turning points in residential building contracts and business failures precede those in unemployment and freight carloadings, and these in turn led retail sales at the peak, though not at the trough. Similar observations can be made about their movements during the milder 1953-54 contraction. Irregular fluctuations still becloud the course of the business cycle, but much of the mist has been swept away. ${ }^{6}$

There are many different methods of adjusting time series for seasonal variations. All are, however, based on the fundamental idea that seasonal fluctuations can be measured and separated from the trend, cyclical, and irregular fluctuations. The task is to estimate the seasonal factor and to eliminate it from the original observations by either subtraction or division or some combination of the two.

All common methods of seasonal adjustment follow this simple logic, including such familiar methods as the monthly-means, the link-relative, and the ratio-to-moving-average methods. The monthly-means and the link-relative methods were among the first developed; they are simple to compute, but they give crude results. The ratio-to-moving-average method has the advantages of more precise measurement of the components and greater flexibility. In addition, it permits analysis of each of the successive stages in the seasonal adjustment process. For these reasons it has been adopted by almost all groups engaged in large-scale seasonal adjustment work, despite the fact that it is relatively laborious.

The ratio-to-moving-average method first obtains an estimate of the trend and cyclical factors by the use of a simple moving average which combines twelve successive monthly figures, thereby eliminating the seasonal fluctuations. Such a moving average is known as a "trend-cycle curve," since it contains virtually all the trend and cycle and little or none of the seasonal and irregular movements in the data. Division of the raw data by the moving average yields a series of seasonal-irregular ratios. An estimate of the seasonal adjustment factors is then secured by averaging the seasonal-irregular ratios, month by month, and assuming that the irregular factor will be canceled out in the averaging process. Finally, the original observations are seasonally adjusted by dividing them by the seasonal adjustment factors.

Important improvements introduced in the ratio-to-moving average method have included moving seasonal adjustment factors and smoother and more flexible trend-cycle curves. Moving seasonal adjustment factors have generally been approximated by smooth curves fitted freehand to

\footnotetext{
' For other illustrations of how seasonal adjustments are helpful in studying cyclical movements and for an instructive discussion of this problem, see Burns and Mitchell, Measuring Business Cycles, pp. 43-55.
} 
the seasonal-irregular ratios for each month. Improved trend-cycle curves have been obtained by fitting smoother curves, also freehand, to preliminary seasonally adjusted series, using their twelve-month moving averages as guides.

A new and improved version of the ratio-to-moving-average method of seasonal adjustment has been included as part of the electronic computer program. The new method, Census Method II, takes advantage of the electronic computer's high-speed, low-cost computations; it utilizes more powerful and refined techniques than widely used clerical methods do and produces more information about each series. The principal features are summarized below, not with the expectation that the reader will follow them in detail, but to indicate the power and generality of the new method, as well as its limitations.

The new method computes a preliminary seasonally adjusted series following primarily the conventional ratio-to-moving-average technique. It starts in the usual way: ratios are computed by dividing the original observations by a twelve-month moving average; moving seasonal adjustment factors are computed from these ratios; and a preliminary seasonally adjusted series is obtained by dividing these preliminary seasonal adjustment factors into the original observations.

Method II then goes on to refine these results. It utilizes a complex graduation formula-a weighted fifteen-month moving average-as the estimate of the trend-cycle curve used to obtain the final seasonally adjusted series. For most series this formula yields a curve that is flexible, follows the data closely, and gives a. smooth representation of the trendcycle components. The method then utilizes a control-chart procedure to identify extreme items among the seasonal-irregular ratios and systematically reduces their weight for the subsequent computations. For each month, control limits of two standard errors are determined above and below a five-term moving average fitted to the seasonal-irregular ratios. Any ratio falling outside the limits is designated as "extreme" and is replaced by the average of the "extreme" ratio and the ratios immediately preceding and following. The new method employs weighted moving averages of the seasonal-irregular ratios for each month to obtain the seasonal adjustment factors-for example, a three-term moving average of a three-term moving average, which is equivalent to a five-term moving average with the weights $1,2,3,2,1$.

Census Method II utilizes a measure of the irregular component of each series to determine the type of moving average to fit to the seasonalirregular ratios. The larger the irregular component, the larger the amount of smoothing that is required. Alternative graduation formulas, appropriate for the different magnitudes of the irregular component in various series, are placed in the computer "memory" and automatically 
selected according to the average monthly amplitude of the irregular fluctuations.

The new method takes into account changing trends in calculating seasonal adjustment factors for the first and last few years of each series. Instead of following the usual procedure of extrapolating the seasonal adjustment factor curve to the end of the series, this method takes an average of the last two seasonal-irregular ratios for a given month as the estimated value of each of the following two or three ratios. These estimates are then used in computing the two seasonal factors that would otherwise be missing at the end of the series. A similar procedure is used to obtain missing values for computing the ends of the trend-cycle curve. ${ }^{7}$ This program also computes seasonal factors for each of the twelve months ahead. Suppose the program is run for a series ending in December 1957. Then seasonal factors for each of the twelve months of 1958 would also be shown (see Table 12 in the appendix). These factors are computed by adding to the factors for the last year one-half the trend between the previous year and that year. ${ }^{8}$ Tests indicate that this method is better than the use of the seasonal factors for the last year without a trend allowance. ${ }^{9}$ Such factors may be helpful in keeping seasonally adjusted series up to date as new raw data become available each month; periodically, however, the seasonal factors should be revised on the basis of the new data.

The seasonal adjustments shown in the third panel of Chart 17.4 were all made on an electronic computer by this method.

\section{WORKING- AND TRADING-DAY ADJUSTMENTS}

Variations in levels of activity between the same months of different years take place in part because of differences in the number of working or trading days in the same months. For example, there were five Saturdays and five Sundays in September 1956 and only four each in September 1955. Many types of economic activity are affected by such variations, particularly those in which there is a disproportionately large volume of activity on Saturdays, such as retail trade and personal services.

The effect of such calendrical variations is illustrated in Chart 17.5, which shows bank debits and sales of grocery stores in various forms: (1) same-month-year-ago comparisons of the original observations, (2) seasonally adjusted data, and (3) seasonally adjusted data with a simple

' For a detailed description of the seasonal methods referred to here see Julius Shiskin, "Seasonal Computations on Univac," American Statistician, February 1955, pp. 19-23, and Shiskin and Eisenpress, op. cit. The summary given here is adapted from these papers.

${ }^{8}$ Here we follow a suggestion by W. A. Beckett, of the Department of Trade and Commerce of Canada.

${ }^{\ominus}$ For a description of these tests see Shiskin, "Problems in the Seasonal Adjustment of Economic Indicators-A Progress Report." 


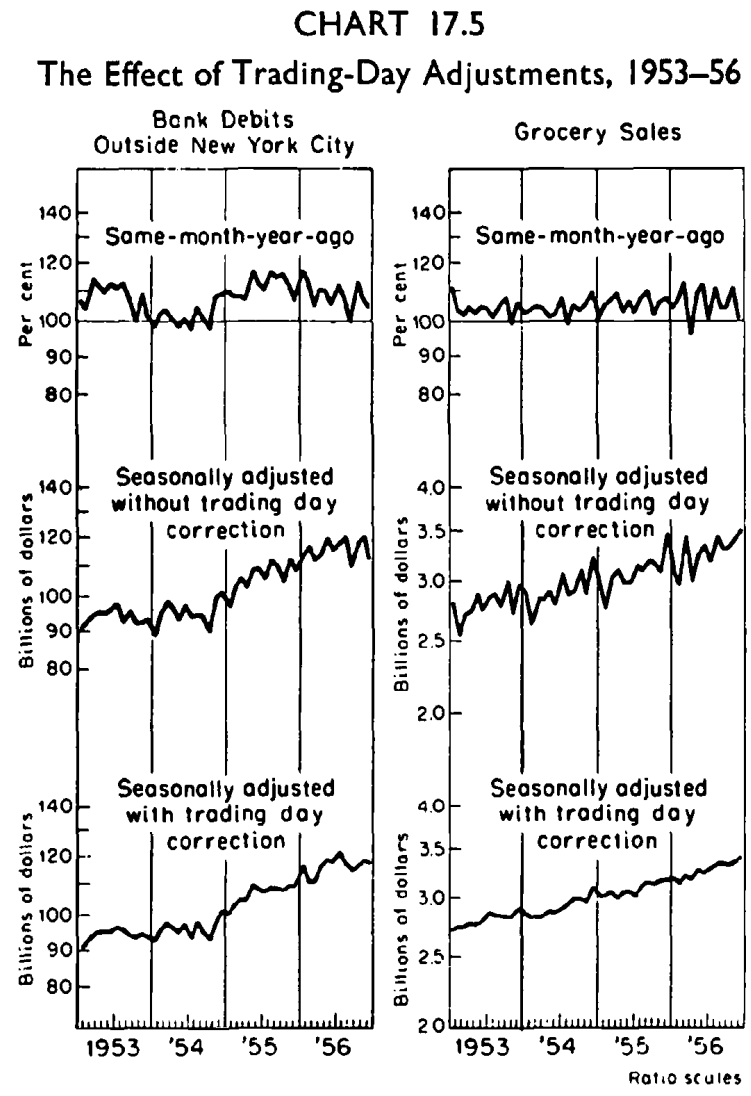

adjustment for the number of trading days. The trading-day adjustment is made by dividing the original series by the number of trading days, month by month. ${ }^{10}$ Note that the same-month-year-ago comparisons of the original observations for bank debits in September 1956 indicate a decline from the preceding year, the first such decline since 1954. The seasonally adjusted data also show a moderate decline, sufficient to bring the September figure down to the level of the preceding September. But when adjustment is made both for seasonal variations and for the extra Saturday and Sunday in September 1956, the figure turns out to be substantially higher than in the preceding year and much more nearly in line with preceding and following months.

10 Where the volume of activity cannot be assumed to be directly proportional to the number of working days (e.g. retail sales), a special adjustment technique must be used. Similar adjustments can be made for holidays which occur on different days of the week (e.g. Independence Day) or different periods of the month (e.g. Easter) (see Harry Eisenpress, "Regression Techniques Applied to Seasonal Corrections and Adjustments for Calendar Shifts," Journal of the American Statistical Association, December 1956, pp. 615-620). 
The effects of a trading-day adjustment are even more strikingly illustrated by the series on sales of grocery stores from 1953 to 1956. The seasonally adjusted series makes up a very choppy line with an underlying upward trend. The choppiness is almost entirely eliminated by the trading-day adjustment, which yields a fairly smooth curve. It becomes clear that the purchase of groceries has been rising steadily, with most of the apparent variation due to differences in the number of days the stores were open each month and in the consumers' preferences for buying more during certain days of the week.

The electronic computer program provides for working- or trading-day corrections where they are needed. These correction factors must be made available, however, along with the raw data; there is no technique built into the electronic computer program for estimating such factors.

IRONING OUT IRREGULAR FLUGTUATIONS

Now what kind of allowance can we make, implicit or explicit, for the irregular factor? Since it is irregular, a technique similar to that adopted for seasonal fluctuations cannot be followed.

Eventually, the irregular fluctuations in economic data may be less troublesome than at present. First, there will probably be a gradual reduction in the errors of measurement. Second, we may be able to measure and make statistical adjustments for some of the factors that create irregular movements-for example, unusual variations in the weather. While present methods for treating the irregular factor are less satisfactory than for the seasonal factor, some useful things can be done. We can compute measures of the average month-to-month amplitude of the irregular component and the ratio of this amplitude to the corresponding amplitude of the cyclical component, and we can determine the number of months that must go by before the cyclical factor, which is cumulative in the short run, dominates the irregular factor, which is not cumulative. These measures provide a notion of the extent to which month-to-month movements in seasonally adjusted series can be taken to reflect cyclical movements and about when it is safe to say that a change is cyclical.

We have already described how the seasonal factor is isolated and how the raw data are adjusted for this factor. The smooth curve used to obtain the estimate of the cyclical factor in the seasonal adjustment technique (a weighted fifteen-term graduation formula) is also fitted to the final seasonally adjusted series. This curve smooths out the irregular fluctuations and is taken as the estimate of the cyclical factor. When it is divided into the seasonally adjusted series, the resulting series represents the irregular factor alone.

1. Summary measures. A group of summary measures of the irregular, 
PART THREE

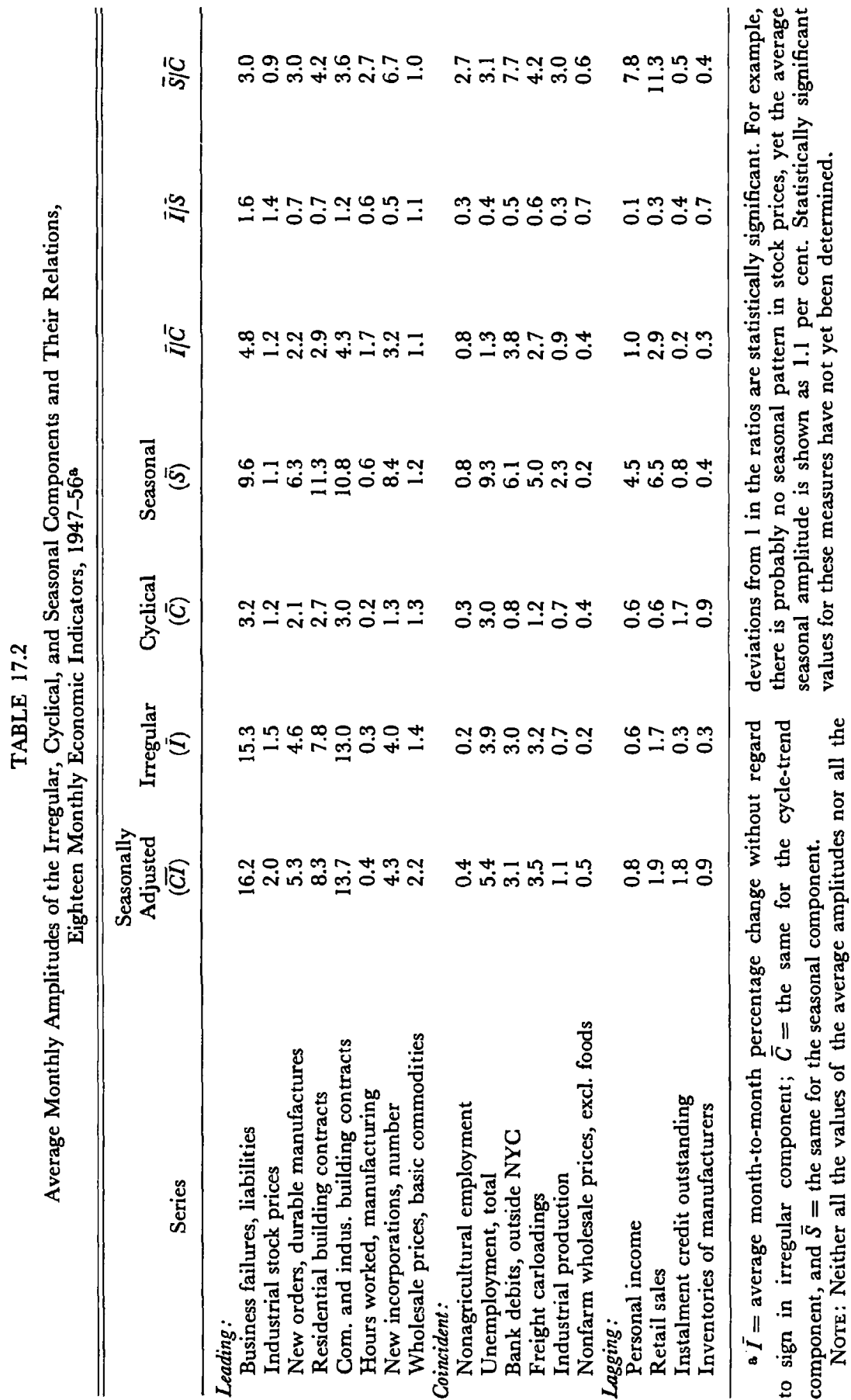


seasonal, and cyclical components and the relations among them is then computed. The first measure is the average month-to-month amplitude in the irregular factor, $I$. It is computed by averaging the monthly percentage changes in the irregular factor without regard to sign. Similarly, the average monthly amplitude of the cyclical factor, $\bar{C}$, is obtained by averaging the month-to-month percentage change in the cyclical factor without regard to sign. And the average monthly amplitude of the seasonal factor, $\bar{S}$, is obtained by averaging the month-tomonth percentage changes without regard to sign in the seasonal factor curve. These measures and the relations among them are shown for eighteen important monthly economic indicators in Table 17.2.11

Ratios of the average amplitudes of the irregular to the cyclical factors are computed for one-, two-, three-month, and longer spans. For the one-month span the computation is based on the percentage changes January to February, February to March, etc.; for the two-month span the percentage changes are computed for January to March, February to April, etc.; for the three-month span, the percentage changes are computed for January to April, February to May, etc.; and so on. Tests show that the magnitude of the irregular amplitude remains about the same regardless of the span, while the cyclical amplitude cumulates uninterruptedly as the span increases. ${ }^{12}$ The number of months necessary

11 The raw data, the seasonally adjusted data, the $M C D$ span moving averages, and the Univac seasonal adjustment factors for these 18 series are given in an appendix for 1956 [not reprinted here]. The official seasonal factors, estimated seasonal factors one year ahead, and the sources of the raw data are also given. These series are 18 of 21 selected by Geoffrey $\mathrm{H}$. Moore as consistent indicators of cyclical revivals and recessions. Three series (corporate profits, gross national product, and bank interest rates) are omitted because they are quarterly [see Table 7.11 in Chapter 7 above].

12 If this were precisely true, one would expect the two-month span computation to yield an $\bar{I} / \bar{C}$ ratio half as large as that for the one-month span; the three-month span to yield a ratio one-third as large; etc. Inspection of Table 17.3 shows that this holds true approximately. The average $\bar{I} / \bar{C}$ ratios for all eighteen indicators and the expected ratios estimated from the average for the one-month span are as follows:

$\begin{array}{lcc} & \text { Actual } & \text { Expected } \\ \text { One-month span } & 1.98 & \\ \text { Two-month span } & 1.04 & 0.99 \\ \text { Three-month span } & 0.61 & .63 \\ \text { Four-month span } & 0.52 & .49 \\ \text { Five-month span } & 0.39 & .39 \\ \text { Six-month span } & 0.31 & .33 \\ \text { Nine-month span } & 0.22 & .22 \\ \text { Twelve-month span } & 0.21 & 0.16\end{array}$

Hence one can estimate fairly closely the span required to reduce the $i / \bar{C}$ ratio to any desired level from the value of the ratio for any given span. Moreover, since the electronic computer program does not calculate $\bar{I} / \bar{C}$ ratios for spans greater than five months, this relationship may be used to estimate average $\bar{I} / \bar{C}$ values beyond this range and hence to determine $M C D$ spans for highly irregular series. 
PART THREE

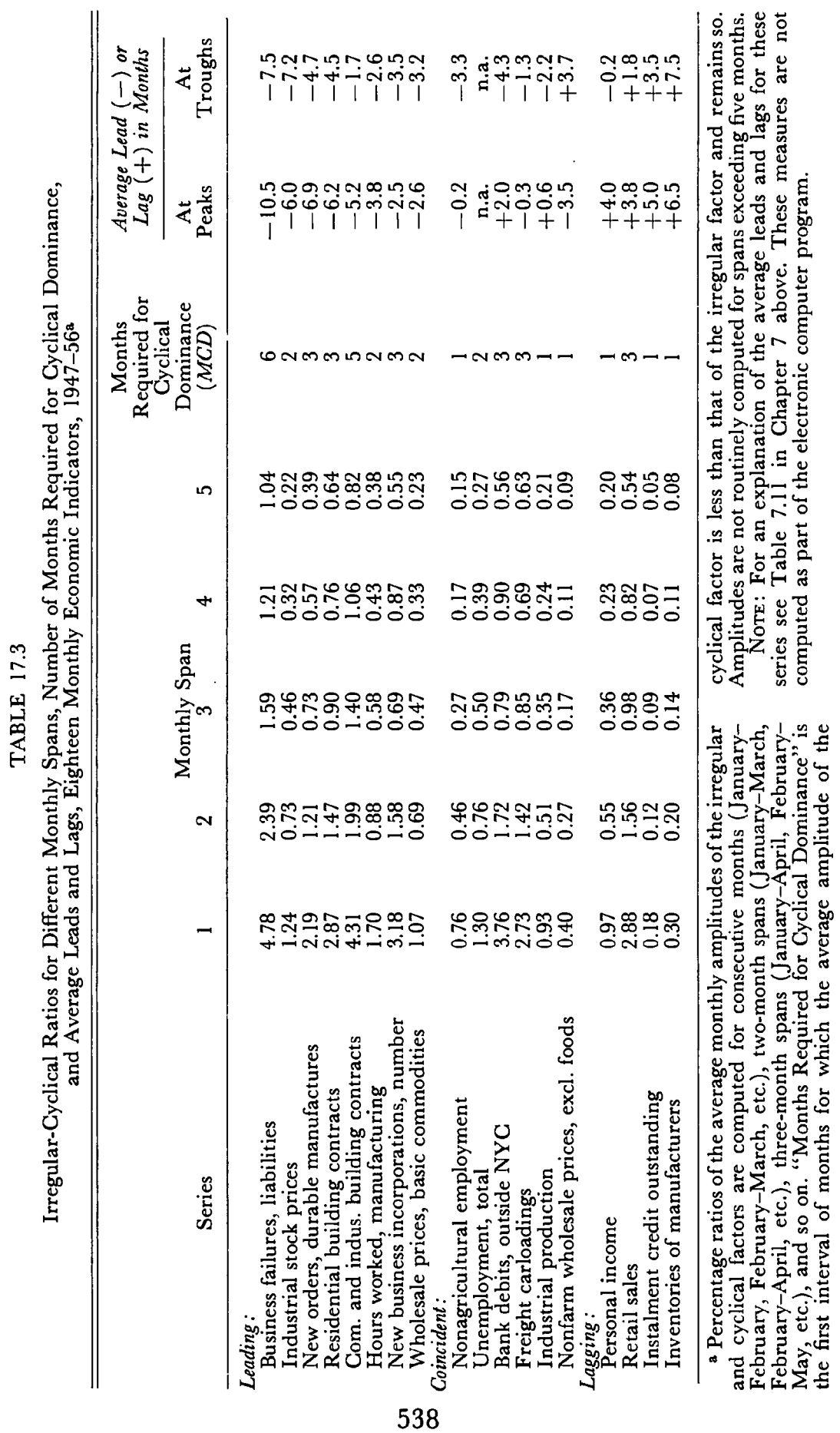


for this ratio to fall below 1 may, therefore, be taken as an index of the months required for cyclical dominance, on the average. This index is identified by the symbol $M C D$ (Months for Cyclical Dominance); thus $M C D$ is 3 for the manufacturers' new orders series and 1 for the index of industrial production. These measures are shown for the eighteen monthly indicators in Table 17.3.

These measures show that cyclical movements are typically smaller on a month-to-month basis than seasonal and irregular movements. Table 17.2 indicates clearly that on this basis the seasonal factor has been dominant in many important series during the postwar period, and similar data show its dominance during earlier periods. In thirteen of the eighteen economic indicators, the average monthly change of the seasonal factor is larger than that of the cyclical factor. Only in the price indexes does the cyclical factor generally dominate the seasonal. Next in magnitude is the irregular factor, which is larger than the cyclical factor in twelve of the eighteen series. The measures shown in Table 17.3 suggest that it often takes three or more months for the cyclical factor to cumulate to a magnitude greater than the irregular; this is true in eight of the eighteen series. Furthermore, the average changes of these three factors are highly correlated; that is, in series for which the cycle is large, the seasonal and irregular factors are also large. Thus, in making judgments about the business cycle on a month-to-month basis, we are very often most interested in the behavior of the smallest in a composite of three variables. For this reason, especially great care is required to isolate the cyclical movements.

Let us consider these measures for two key economic indicators. The average month-to-month irregular amplitude in manufacturers' new orders of durable goods is 4.6 per cent, the average cyclical amplitude is 2.1 , and their ratio is 2.2 (Table 17.2). The corresponding ratio for a two-month comparison is 1.2 and for a three-month comparison 0.7 (Table 17.3). Thus comparisons in seasonally adjusted data over a threemonth period are required for the cyclical component to dominate the irregular, and in this interval the cyclical changes exceed the irregular by almost 40 per cent, on the average. This information suggests that we should not give much weight to the month-to-month percentage changes for this series but that comparisons made over three-month periods are substantially more reliable for current business cycle studies. On the other hand, the corresponding figures for the Federal Reserve index of industrial production (irregular, 0.69 ; cyclical, 0.74 ; percentage ratio of irregular to cyclical, 0.93 ; and $M C D, 1)$ suggest that in this series even month-to-month movements are dominated by the cyclical factor, on the average.

2. $M C D$ span moving averages. Comparisons of the differences between figures a specified number of months apart are also shown by 
simple moving averages. For example, an unweighted three-month moving average is calculated by summing the figures for the first three months, then adding the fourth month and dropping the first, adding the fifth month and dropping the second, and so on (in each case the sum is, of course, divided by 3 ). Therefore, a three-month moving average will change according to the differences between the figures separated by three months (counting from midmonth to midmonth), e.g. JanuaryApril, February-May, etc. Similarly, a four-month moving average will change with the differences between the figures separated by four months, a five-month moving average by figures separated by five months, and so on. Thus changes in simple moving averages are equivalent to differences between figures for months separated by an interval equal to the period of the moving average. These relations suggest that a moving average of a seasonally adjusted series calculated for the period equal to $M C D$ would show primarily changes in the cyclical factor.

The month-to-month movements of many economic indicators in their seasonally adjusted form contain a fairly large irregular factor, as pointed out earlier. Our measure, $I / \bar{C}$, the irregular. factor divided by the cyclical factor, shows that the irregular factor is usually larger than the cyclical factor on a month-to-month basis. In the eight leading series, those that are particularly useful as early indicators of cyclical revivals and recessions, the irregular factor is relatively largest; in every series it is larger than the cyclical factor, and it is usually more than twice as large. The dominance of the irregular factor makes it difficult to trace the cyclical movements in the seasonally adjusted series and especially to date turning points.

The relative magnitudes of the irregular factor and the cyclical factor are reversed in the short-term moving averages automatically selected and computed by the electronic computer program. These short-term moving averages are of varying periods; in each the period is equal to the number of months required for the cyclical factor to dominate the irregular factor, and the $I / \bar{C}$ ratios for the spans measured by these moving averages show this to be true: they are all less than 1 (Table 17.4, last col.). Thus the month-to-month movements in these moving averages are primarily cyclical, in contrast to the primarily irregular monthto-month movements of the seasonally adjusted series. When the general sweep of these moving average series is considered, then the dominance of the cyclical movements is overwhelming, and the cycles stand out clearly, as can be seen in Chart 17.6.

Longer-period moving averages might show the cyclical factor even more clearly, and from this point of view the weighted fifteen-term moving average used earlier in the electronic computer program as the estimate of the cyclical factor would usually be satisfactory. But all 
AIDS TO THE CURRENT USE OF INDICATORS

CHART 17.6

Short-Term Moving Averages of Eighteen Business Indicators, 1948-57

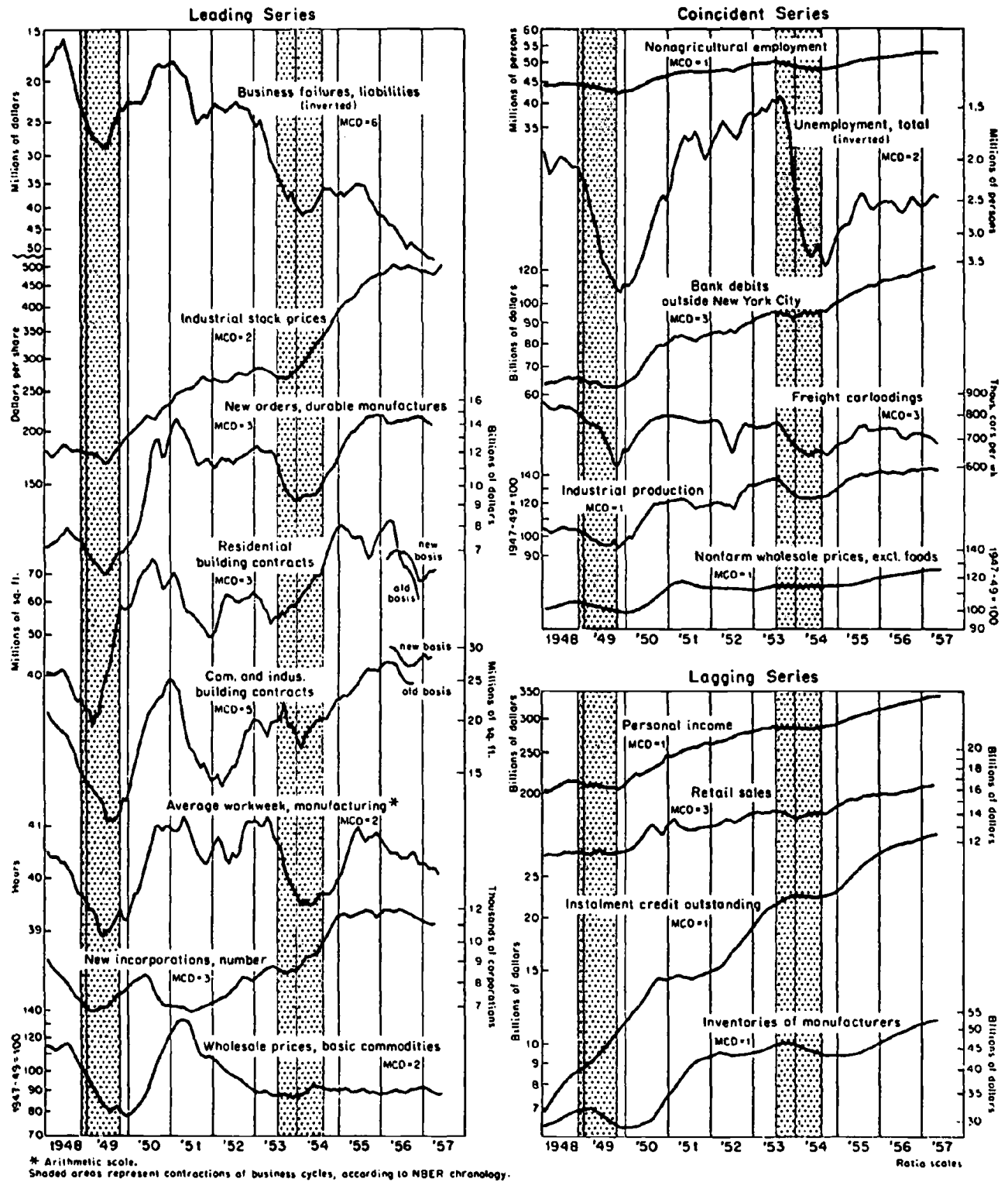

Ratio scales used throughout, except for series marked by *.

Shaded areas represent business contractions; unshaded areas, expansions. 
PART THREE

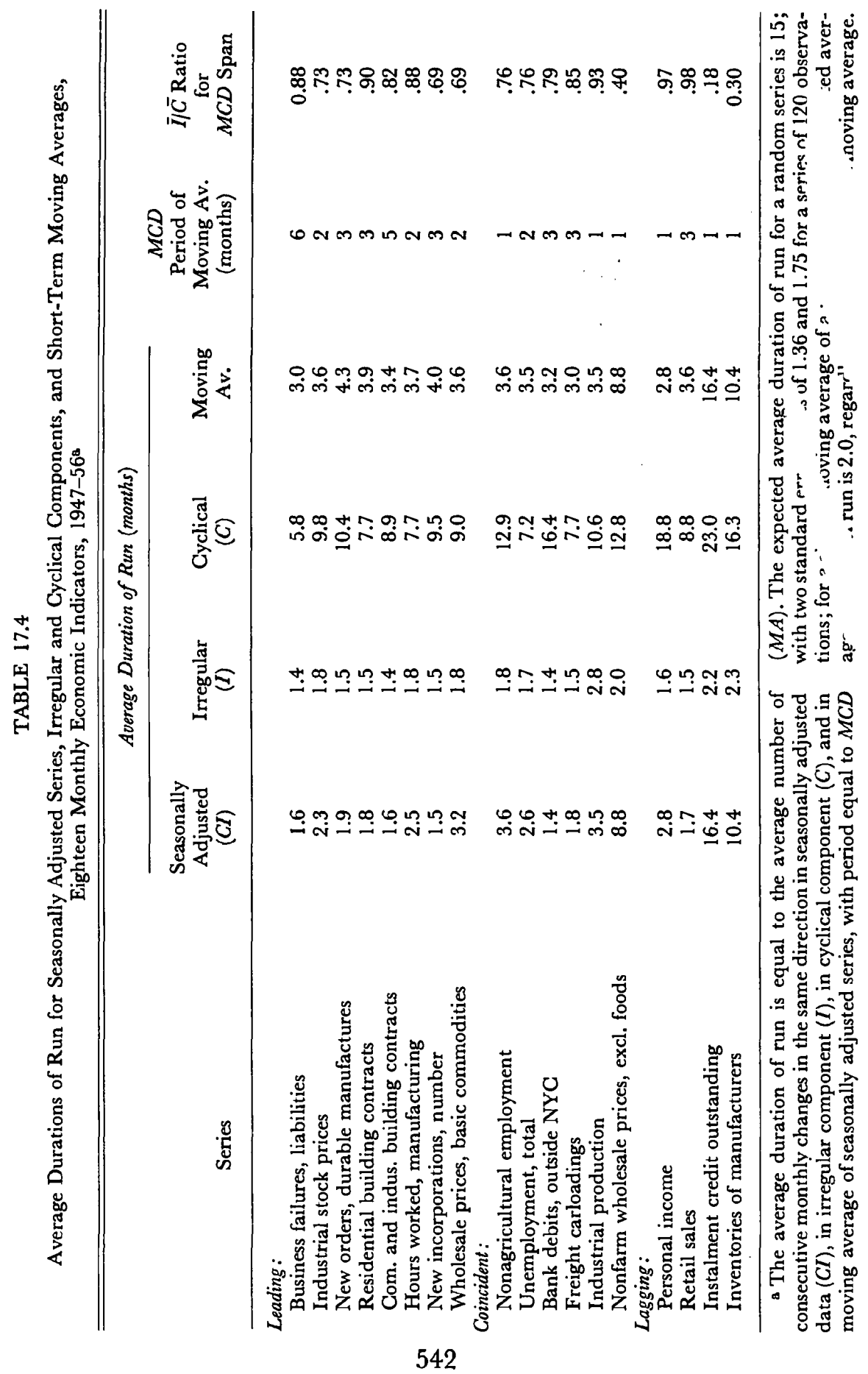




\section{AIDS TO THE CURRENT USE OF INDICATORS}

moving averages suffer from the handicap that they do not reach to the current month. Since they are centered at the middle month of the interval covered by the average, there are no values for the last month(s). Longterm moving averages lose so many months that their usefulness in current economic analysis is greatly diminished, as we observed in connection with the same-month-year-ago comparisons, which are equivalent to changes in twelve-month moving averages. Thus our weighted fifteen-term moving average is always seven months behind the current date. Furthermore, changes over a span of months may skip over a cyclical turn in the series and hence show a rise when the series is currently declining, or vice versa. The longer the span, the more likely is this possible error in identifying the current trend. On the other hand, short spans may lead to errors of another type, as when an irregular turn is identified as cyclical and is shortly reversed. Use of a span equal to $M C D$ appears to be a reasonable compromise that avoids many errors of either type. ${ }^{13}$

This point may be stated somewhat more precisely. $M C D$ is taken for the first comparison for which the $I / C$ ratio is less than 1 and remains so. This is, to some extent, arbitrary. To begin with, when this ratio falls below 1 , it will not always be significantly below 1 in the statistical sense. An advance will have been made when levels of significance have been determined for $\bar{I}, \bar{C}, \bar{S}$, and their ratios. But, in addition, it might be better to use a lower critical value for the $I / C$ ratio, say 0.75 or 0.50 instead of 1.00. These lower values would certainly imply longer moving averages and hence smoother curves; indeed, almost any degree of smoothness can be obtained by appropriate selection of the critical value for $\bar{I} / \bar{C}$. Lower critical values, however, would entail comparisons over longer periods and the loss of more moving average values for the current period. The present choice of a critical value for the $\bar{I} / \bar{C}$ ratio is based upon the idea that it yields a series dominated, on the average, by the cyclical rather than the irregular factor, with the smallest loss of current figures. Future experience with this problem, however, may lead us to change this critical value.

While the loss of data for a few current months entailed by the use of moving averages of period equal to the $M C D$ span is regrettable, it is not crucial, so far as the use of leading indicators is concerned. This can be seen by comparing the period of the moving average equal to $M C D$ and the average lead or lag for each of the eighteen monthly economic indicators. Such comparisons, shown in Table 17.3, indicate that in only two of the lead series are more than one month's data lost (business failures and commercial and industrial building contracts), and in these

13 The fact that two different cyclical curves are computed for each series stresses the point that the cyclical curves (as well as the seasonal and irregular curves) are only estimates of the phenomenon we are trying to measure and cannot be depended on in any absolute or certain sense. 
the average lead is substantially longer than the loss due to centering the moving average (except for commercial building at troughs). In the case of the series with short leads, the loss of data is only one month or less, as is also the case for the coincident and lagging series.

Simple moving averages of period equal to $M C D$ would appear to trace out the cyclical pattern better than the seasonally adjusted series, but they are not quite up to date. They therefore appear to be useful supplements to, but not replacements for, seasonally adjusted series in current economic analysis. ${ }^{14}$ To maintain the currency and flexibility of the moving average, the maximum period is limited to six months when $M C D$ is 6 or more. Such moving averages are plotted for five series in the fourth panel of Chart 17.4 and for all eighteen indicators in Chart 17.6. Here we see that a substantial degree of similarity in smoothness has been achieved among series that differ widely in this respect in the raw and seasonally adjusted data.

These relations among the different forms of monthly series and other significant relations are also shown by a simple measure, the average duration of $\operatorname{run}^{15}$ (see Table 17.4). This measure equals the average number of consecutive monthly changes in the same direction; it takes into account only the signs of the changes and not their amplitudes. For a random series, short runs occur much more frequently than long runs, and the expected average duration of run is only 1.5 (months, quarters, or whatever the time unit in which the series is expressed). For random series with 120 observations (i.e. ten years of monthly data), the average duration of run falls within the range 1.36 and 1.75 about 95 per cent of the time. This measure provides a basis for determining whether the month-to-month movements of an economic series depart significantly from randomness. Thus it shows that the month-to-month movement of the irregular component extracted by our method for most of the eighteen economic indicators is essentially random. This is true for all for which $M C D$ is greater than 1 . This measure also makes it possible to test quantitatively our procedure for reducing all series to the same degree of smoothness.

Table 17.5 separates from the greater detail shown in the preceding tables the average durations of run, $M C D$, and the $I / C$ ratio for the span at which $M C D$ falls below 1 for our five illustrative series. The average durations of run for the seasonally adjusted series in four of the five cases

${ }^{14}$ A similar use of short-term moving averages is made by Geoffrey $\mathrm{H}$. Moore in the construction of diffusion indexes (see Chapter 20 below). The moving average periods used by Moore average about one and one-half months longer than the $M C D$ spans.

${ }^{15}$ For an explanation of the average duration of run, its significance and uses, see W. Allen Wallis and Geoffrey H. Moore, A Significance Test for Time Series (National Bureau of Economic Research Technical Paper 1, New York, 1941); see also Wesley C. Mitchell and Arthur F. Burns, Statistical Indicators of Cyclical Revivals [reprinted here, Chapter 6], Table 6.1, col. 14. 
AIDS TO THE CURRENT USE OF INDICATORS

TABLE 17.5

Average Durations of Run and Related Measures for

Five Illustrative Series, 1947-56

\begin{tabular}{|c|c|c|c|c|c|}
\hline \multirow[b]{2}{*}{ Series } & \multicolumn{3}{|c|}{ Average Duration of Run (months) } & \multirow[b]{2}{*}{$\begin{array}{l}\text { Months } \\
\text { for } \\
\text { Cyclical } \\
\text { Dominance } \\
(M C D)\end{array}$} & \multirow[b]{2}{*}{$\begin{array}{c}\bar{I} / \bar{C} \\
\text { for Span } \\
\text { Equal to } \\
M C D\end{array}$} \\
\hline & $\begin{array}{l}\text { Irregular } \\
\text { Component }\end{array}$ & $\begin{array}{l}\text { Seasonally } \\
\text { Adjusted } \\
\text { Series }\end{array}$ & $\begin{array}{c}\text { Moving } \\
\text { Av. with } \\
\text { Period } \\
\text { Equal to } \\
M C D\end{array}$ & & \\
\hline Business failures, liabilities & 1.4 & 1.6 & 3.0 & 6 & 0.88 \\
\hline Residential building contracts & 1.5 & 1.8 & 3.9 & 3 & .90 \\
\hline Freight carloadings & 1.5 & 1.8 & 3.0 & 3 & .85 \\
\hline Unemployment, total & 1.7 & 2.6 & 3.5 & 2 & .76 \\
\hline Retail sales & 1.5 & 1.7 & 3.6 & 3 & 0.98 \\
\hline
\end{tabular}

are only slightly higher than for the irregular component and close to the figure for a random series. This does not mean that the seasonally adjusted series are random but rather that the irregular factor is so large in the seasonally adjusted series that it dominates the month-to-month movements. When the irregular factor is reduced by smoothing the data with short-term moving averages, the cyclical (nonrandom) character of the series emerges. The moving average of a random series has an expected average duration of run of 2.0, regardless of the period of the moving average. The average durations of run for the moving averages of period equal to $M C D$ are all between 3.0 and 4.0. They thus exceed beyond reasonable limits the figure expected for a random series and therefore represent the cyclical (nonrandom) movements of the series. ${ }^{16}$

The average durations of run for the moving averages of these five series are not only close to one another but are also close to those for the seasonally adjusted form of the two smooth series-nonagricultural employment and industrial production-selected earlier in this paper to introduce the problem. The average durations of run for these series are 3.6 and 3.5 , respectively. The $\bar{I} / \bar{C}$ measures for the spans equal to $M C D$ are also all about the same and less than 1 ; they fall between 0.76 and 0.98 . Series with relatively large and varying seasonal and irregular factors have been reduced to a form that is primarily cyclical and of a comparable degree of smoothness. This method appears to offer a workable solution to a problem posed at the beginning of this paper: How

${ }^{16}$ Using moving averages of somewhat longer periods, Geoffrey H. Moore has applied this test to a large number of economic series. He concluded: "Although a few of the series might, in terms of the average duration of run in the seasonally adjusted data, be deemed to behave like random series, this hypothesis is not consistent with the behavior of the moving averages. All the smoothed series exhibit average durations of run far in excess of the value (2.0) expected on the random series hypothesis" (unpublished manuscript, "A Note on Serial Correlation in Economic Data"). 
can series like business failures and retail sales be made to show their cyclical movements as clearly as those for factory employment and industrial production?

The sequence of adjustments is further illustrated in Charts 17.7 and 17.8 , in which different forms of data for a single series are plotted one below the other. The series are for residential building contracts during two periods, 1936-39 and 1953-56, and for the sales of a major chemical company, 1948-56.

\section{Present and Prospective Applications}

The importance of seasonal and other adjustments of raw economic series for current business analysis has long been recognized. However, all satisfactory methods are laborious to compute, and, in general, the better the method, the greater the computing burden. Consider, for instance, the well-established method, used in the Federal Reserve System in 1954; for a ten-year monthly series (for example, the number of shoes produced each month from January 1946 to December 1955) about 2,500 computations would be required to compute moving seasonal adjustment factors and to adjust the series. If the checking were counted, about 5,000 computations would be required. It would take a clerk about a week to make and check these calculations and to record the results. The labor cost alone would be about $\$ 75$, and, in addition, there would be the supervisory costs associated with a complicated assignment of this kind.

Experience has shown that many series are needed for a reliable, comprehensive view of current business conditions, and there are many special industry and regional interests. Thousands of series need seasonal adjustment. Economic Indicators, prepared for the Congressional Joint Committee on the Economic Report by the Council of Economic Advisers, shows only the most important national series; yet it includes more than 125 monthly series. The Survey of Current Business, issued by the Department of Commerce, carries several thousand monthly economic series. And this is to say nothing of the numberless series compiled by individual business firms, banks, government agencies, etc. Nearly all these series require seasonal adjustment for effective use in current analysis. Furthermore, it is desirable to bring the seasonal adjustments up to date each year.

In the summer of 1954 a congressional committee held hearings on the adequacy of the economic statistics compiled by the federal government. Principal users of current economic series-for example, the chairman of the Council of Economic Advisers and the chief economist of the National Industrial Conference Board-complained that many of the monthly series published by the government were not adjusted for seasonal variations at all; that many others were adjusted by crude methods; and 
AIDS TO THE GURRENT USE OF INDICATORS

CHART 17.7

Different Forms of the Series on Residential Building Contracts,

1936-39 and 1953-56
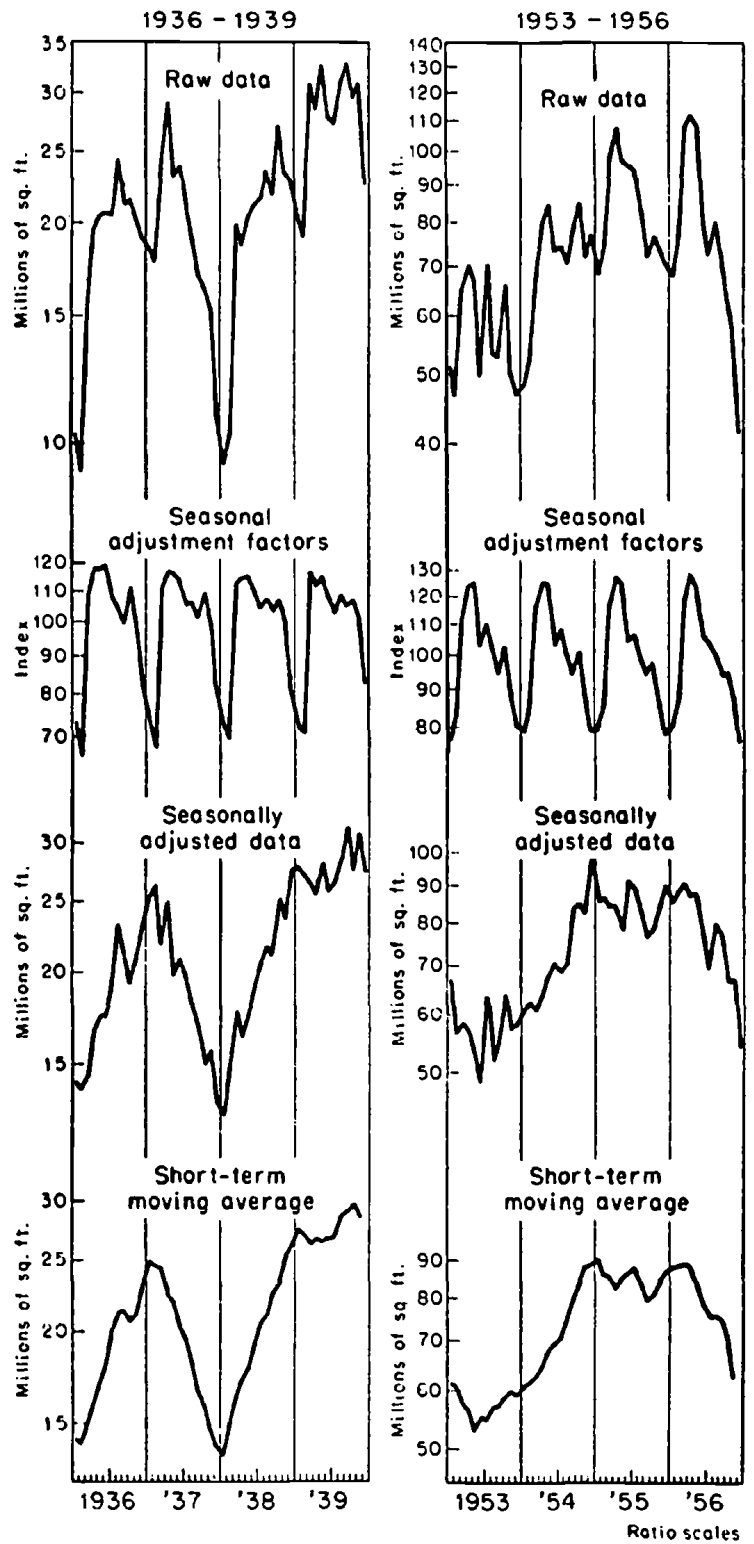


\section{PART THREE}

\section{CHART 17.8}

Different Forms of the Series for the Sales of a Major

Chemical Company, 1948-56

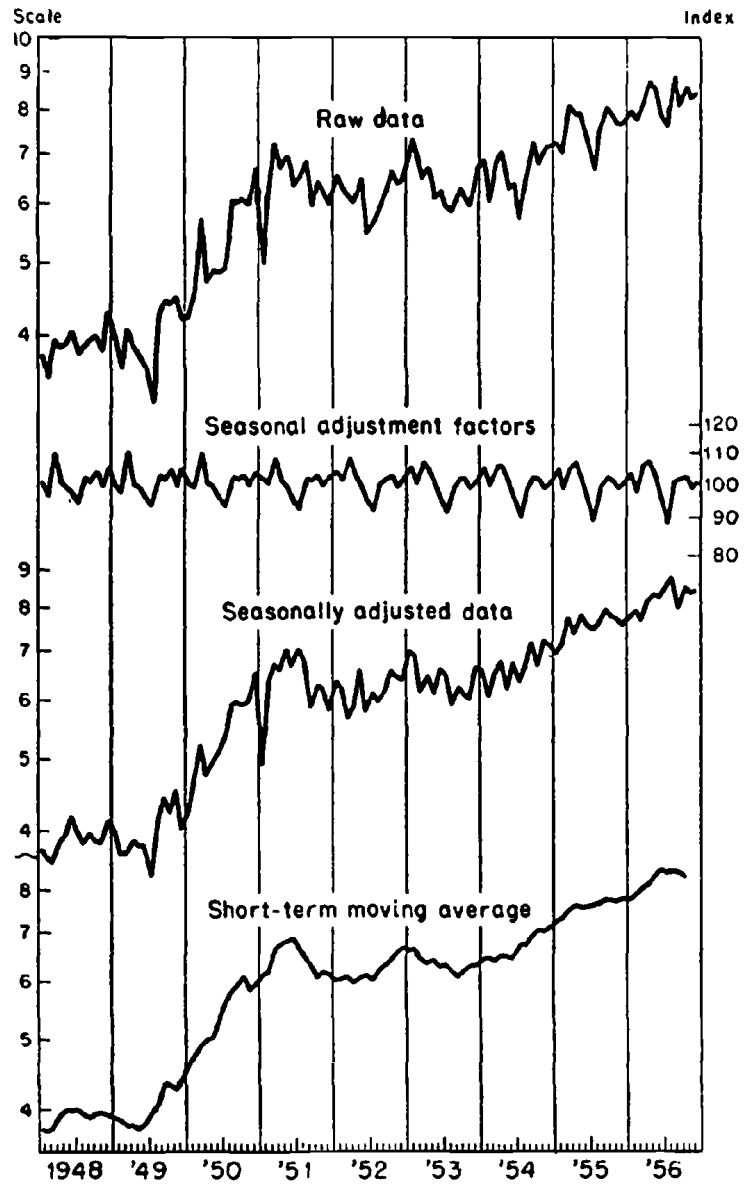

Ratio scales used throughout.

The scales on the left are arbitrary because the actual figures are confidential.

that for still others the seasonal adjustments did not reflect the most recent experience. As a result, they pointed out, it is difficult to make judgments on the state of current business. This situation is not due to the unwillingness or inability of the government statisticians to make such adjustments; it is attributable primarily to the huge amount of computation required and to the large costs involved. The use by business concerns of the crude same-month-year-ago comparison is due to similar factors. 


\section{AIDS TO THE CURRENT USE OF INDICATORS}

The isolation of the irregular factor by the technique described above also requires a large amount of computation and can be considered only after a seasonally adjusted series is available. Furthermore, the trendcycle curve that is divided into the seasonally adjusted series to yield the estimate of the irregular component must be smooth and fit the data closely. A simple unweighted moving average will not do, because imperfections in the measurement of the cycle will give rise to larger irregular fluctuations, on the average. Consequently, complex graduation formulas must be used. Such laborious computations were in the past made only for a limited number of series on an experimental basis. Summary measures, such as those described here, were not computed at all.

The large-scale digital electronic computer has brought an end to this situation. These machines record, store, transfer, calculate, and compare numbers and letters. They compute on the binary scale and convert automatically from and to the decimal scale. Such computers perform arithmetic computations at a very high speed; their checking circuits prevent the propagation of errors; and their operations are almost completely automatic. They can be programmed to select the appropriate one of several series of computations according to the results of earlier computations.

Computers of this class are at their best in performing operations involving long series of sequential or iterative computations on relatively small numbers of original observations. They are particularly useful in the computation of seasonally adjusted series and moving averages, requiring only a small amount of input (e.g. card-punching and card-totape conversion). Although the output of data in our electronic computer program is large relative to the input (the ratio of output to input is about 30 to 1 ), it is easily handled by a high-speed printer. A high-speed printer not only can print the results but also can make charts adequate to serve as visual aids in interpreting them, all at the speed of the electronic computations.

This present program is essentially a modification of conventional methods, which combine laborious hand computations and professional judgments, to meet the requirements of electronic programming. The approach is intuitive and not aided by rigorous mathematical analysis; it does not even take advantage of existing mathematical techniques, such as regression and correlegram analysis, which might be adapted to economic time-series analysis. Fairly obvious measures, such as confidence limits, which are useful in judging the significance of month-to-month changes in the seasonally adjusted series are left out. Furthermore, defects in some of the measures in the program have already been observed in tests of the results and the experience of users. Thus the method of estimating the trend-cycle curve is not satisfactory in very smooth or highly 
irregular series; a more variable type of graduation formula should be substituted in the very smooth series and a less variable formula in the highly irregular series. The technique for obtaining seasonal factors for the initial and terminal years of each series must be improved. Troublesome questions arise regarding the relations of the $M C D$ approach and the confidence-limits approach in judging the cyclical significance of month-to-month movements of seasonally adjusted series. Tests of significance have not yet been developed for the measures of the average monthly amplitude of the irregular, cyclical, and seasonal movements and the relations among them. Similarly, we pay a price for our measures of the cyclical factor-the loss of a few months' data at the ends. This is to list but a few of the limitations of this program that we know about already: no doubt more will be uncovered as further experience is gained with the results.

For these reasons the present program provides only a glimpse of what can be accomplished, if electronic computers are fully exploited for business and economic analysis. It is to be hoped that the application of fresh young minds, not shackled to the methods of the past, will bring a modification of this program beyond recognition and, perhaps more important, the development of completely new and more fruitful approaches to the analysis of economic problems. Nevertheless, the present program appears to represent a real improvement over widely used clerical methods in terms of the speed, the cost, and the results. And, since it is based upon methods that have, for the most part, met the test of experience and usefulness, it would appear desirable to use this program until the day comes that newer and better approaches have been developed and have passed similar tests. In the meantime, improvements will continue to be introduced into this program as the need for them becomes clear and techniques for making them are developed.

Almost all federal statistical agencies are now using the government's electronic computers and the program described in this article. About three thousand government series have been processed on the Census Bureau's Univacs by the present and earlier versions of this method. The method is being used for many of the Census Bureau's own series and by the Bureau of the Budget, the Bureau of Labor Statistics, the Council of Economic Advisers, the Federal Reserve System, the Department of Agriculture, the National Office of Vital Statistics, and the Office of Business Economics. Other users include private research groups, such as the National Bureau of Economic Research and the National Industrial Conference Board. In addition, groups in Canada, Australia, and Norway have sent their series to the United States Bureau of the Census for such processing.

Several of the large commercial computer centers also have this 
program available for the general public, and business organizations have started to use it. The cost is far less than that of cruder adjustments by clerical methods, and trivial compared to the cost of compiling the raw data. ${ }^{17}$ Students of business conditions can therefore expect to have currently all important economic indicators in seasonally adjusted and smoothed form and to have measures of the cyclical behavior of these series. Business concerns can shift away from the crudesame-month-year-ago comparisons to more useful measures of the fluctuations in their own activities.

In the light of the recent advances made in our understanding of the processes of economic change and the availability of electronic computers to prepare measures of these changes promptly and cheaply, it seems reasonable to expect better diagnoses of the current state of the business cycle and improvement in businessmen's forecasts of their own companies' activities. $^{18}$

\section{Appendix: Electronic Computer Time Series"Analysis and Adjustment Program}

\section{COMPUTATION OF PRELIMINARY SEASONALLY ADJUSTED SERIES}

1. Original-observations. Where an adjustment for the number of working or trading days is made, these figures are shown after adjustment and all subsequent computations are based on these adjusted figures (Table 1 of sample "print-out" shown below).

17 Note, however, that substantial costs, human as well as financial, went into this program before it became a reality. These included costs of developing explicit criteria to enable the machine to make appropriate choices among alternatives in a long series of computations; of writing the computer instructions and "proving in" the program; and of training personnel in new skills. These are no longer factors for the present program; it can now be used at little more than the cost of operating the computer. But such costs must be taken into account in planning new programs.

${ }^{18}$ Other electronic computer programs for analyzing economic series have also been completed or are approaching completion as part of the National Bureau project on the use of electronic computers in economic analysis. One program, already completed for the Univac, embodies and expands the National Bureau's techniques for measuring the behavior of components in relation to aggregates. It supplies measures of the dispersion of changes between any two periods for components of aggregates or for members of a family of time series. Among the measures included are (1) frequency distributions of percentage rates of change, both absolute and relative; (2) arithmetic means of all rates of change, the rises alone and the falls alone; (3) deciles of the rates of change; and (4) diffusion indexes, both total and net percentage rising. Another program--the standard National Bureau business cycle measures of amplitude, duration, pattern, and conformity, as well as the accompanying measures of secular trend, for any monthly, quarterly, or annual time series, such as steel production for the industry or any of the steel companies-is now being programmed for the IBM 704.

These programs will be described more fully in later National Bureau publications. Summaries appear in the Thirly-seventh Annual Report of the National Bureau of Economic Research, May 1957, pp. 65-72. See also Chapter 18 below. 
2. Ratios of the original observations for each month to the average of the original observations for the preceding and following months are computed. Arithmetic means of these ratios for each month are given at the bottom of the table (Table 2).

3. A twelve-month moving average of the original series is computed. This curve provides a measure of the trend-cycle component of the series. It also provides annual averages of the original series (Table 3 ).

4. The twelve-month moving average is centered-that is, a two-month moving average of the twelve-month moving average is computed. This operation places the moving average values at midmonths. The first value of the centered moving average is placed at the seventh month of the original series. Thus six moving average values will be missing at the beginning and at the end of the series (Table 4).

5. Ratios of the original observations to the centered twelve-month moving average are computed. This computation results in a series which shows primarily the seasonal and irregular components of the original series (Table 5).

6. This step will provide a method for identifying extreme items among the ratios computed by step 5 , substituting more representative ratios for these extreme ratios and fitting smooth curves to all ratios for each month.

$a$. Fit a five-term moving average to the ratios for each month. This results in the loss of moving average values for the first two and the last two years for which ratios are available. To obtain moving averages for the first two years, use the average of the first two ratios as the estimated value of the ratio for each of the two years preceding the first year available. This is equivalent to weighting the first three years' ratios by $\frac{2}{5}, \frac{2}{5}$, and $\frac{1}{5}$, respectively, to obtain the first year's moving average value, and to weighting the first four years' ratios by $\frac{3}{10}, \frac{3}{10}, \frac{2}{10}$, and $\frac{2}{10}$, respectively, to obtain the second year's moving average value. Moving average values for the last two years are obtained in a similar manner.

$b$. For each month, compute two-sigma control limits about the five-term moving average line. All ratios falling outside these limits are designated as extreme.

c. Replace extreme ratios as follows: For an extreme ratio falling at the first point in the series, substitute the average of the first three ratios of the series; for an extreme ratio falling in the middle of the series, substitute the average of the extreme ratio and the preceding and following ratios; for an extreme ratio falling at the end of the series, substitute the average of the extreme ratio and the two preceding ratios.

$d$. The six missing ratios at the beginning of the series are supplied by 


\section{AIDS TO THE CURRENT USE OF INDICATORS}

extending the first available ratios for the corresponding months back to the initial month of the series. The six missing ratios at the end are supplied similarly.

$e$. For each year, center the twelve ratios (i.e. adjust the twelve ratios so that their sum will be 1,200 ) by division of the twelve items by their arithmetic mean. If the initial year is incomplete, use as the ratio for any missing month the value of the average ratio for the same month in the next two years in centering the initial year's ratios. Treat the terminal year's ratios in a similar manner.

$f$. For each month, compute a three-term moving average of a threeterm moving average of the centered ratios yielded by step $6 e$, above. This will result in the loss of two moving average values at the beginning and two at the end. To obtain the values missing at the beginning, use the average of the first two centered ratios as the estimated value of the centered ratio for each of the two years preceding the first year available. This is equivalent to weighting the first three years' centered ratios by $\frac{9}{18}, \frac{7}{18}$, and $\frac{2}{18}$, respectively, to obtain the first year's moving average value, and to weighting the first four years' centered ratios by $\frac{-5}{18}, \frac{7}{18}, \frac{4}{18}$, and $\frac{2}{18}$, respectively, to obtain the second year's moving average value. The missing values at the end are obtained in a similar way. The values of these twelve curves constitute the preliminary seasonal adjustment factors (Table 6).

7. These seasonal factors are divided into the corresponding figures of the original series, month by month; i.e. the seasonal factor for January 1947 is divided into the original observation for January 1947; the factor for January 1948 is divided into the original observation for January 1948. Similarly, the factor for February 1947 is divided into the original observation for February 1947; the factor for February 1948 into the original observation for February 1948; and so on. This yields the preliminary seasonally adjusted series (Table 7).

\section{COMPUTATION OF FINAL SEASONALLY ADJUSTED SERIES}

8. Compute a weighted fifteen-month moving average (Spencer's fifteen-term formula) of the preliminary seasonally adjusted series. The weights are as follows: $-3 / 320,-6 / 320,-5 / 320,3 / 320$, $21 / 320,46 / 320,67 / 320,74 / 320,67 / 320,46 / 320,21 / 320,3 / 320$, $-5 / 320,-6 / 320,-3 / 320$. This is equivalent to a weighted fivemonth moving average (weights are $-\frac{3}{4}, \frac{3}{4}, 1, \frac{3}{4},-\frac{3}{4}$ ) of a five-month moving average, of a four-month moving average, of a four-month moving average of the data.

To obtain values for the beginning points of this curve, use the average of the first four values of the preliminary seasonally adjusted series 
as the estimated value of this series for each of the seven months preceding the first month available. The values for the end are supplied similarly.

The preliminary seasonally adjusted series contains the cyclical, trend, and irregular components of the series with only a trace of the seasonal component. The weighted fifteen-month moving average can be used in place of a twelve-month moving average because there is no significant seasonal factor to suppress. The weighted fifteen-month moving average is much more flexible than a twelvemonth moving average and will therefore provide a better measure of the trend-cycle component; it is also much smoother than a simple five-month moving average, and it fits the data about as closely as does the five-month moving average (Table 8 ).

9. Ratios of the original observations to the weighted fifteen-month moving average are computed (Table 9).

10. Compute the ratios of the preliminary seasonally adjusted series (step 7) to its weighted fifteen-month moving average (step 8). Month-to-month changes in these ratios are computed and averaged without regard to sign. This yields a preliminary measure of the average amplitude of the irregular component.

11. This step will provide a method for identifying extreme items among the ratios computed by step 9 , substituting more representative ratios for these extreme ratios, and fitting smooth curves to all ratios for each month.

$a$. Fit a five-term moving average to the ratios for each month. This results in the loss of moving average values for the first two and the last two years. To obtain moving averages for the first two years, use the average of the first two ratios as the estimated value of the ratio for each of the two years preceding the first year available. This is equivalent to weighting the first three years' ratios by $\frac{2}{5}, \frac{2}{5}$, and $\frac{1}{5}$, respectively, to obtain the first year's moving average value, and to weighting the first four years' ratios by $\frac{3}{10}, \frac{3}{10}, \frac{2}{10}$, and $\frac{2}{10}$, respectively, to obtain the second year's moving average value. The moving average values for the last two years are obtained in a similar manner.

$b$. For each month, compute two-sigma control limits about the fiveterm moving average line. All ratios falling outside these limits are designated as "extreme."

c. Replace extreme ratios as follows: For an extreme ratio falling at the first point in the series, substitute the average of the first three ratios of the series; for an extreme ratio falling in the middle of the series, substitute the average of the extreme ratio and the preceding and following ratios; for an extreme ratio falling at the end 


\section{AIDS TO THE CURRENT USE OF INDICATORS}

of the series, substitute the average of the extreme ratio and the two preceding ratios (Table 10 ).

d. For each year center the twelve ratios (i.e. adjust the twelve ratios so that their sum will be 1,200 ) by division of the twelve items by their arithmetic mean. If the initial year is incomplete, use as the ratio for any missing month the value of the average ratio for the same month in the next two years in centering the initial year's ratios. Treat the terminal year's ratios in a similar manner (Table 11).

e. If the average irregular amplitude, computed in step 10 above, is under 2, use step $11 \mathrm{f}$; if it is 2 or more, use step $11 \mathrm{~g}$.

$f$. For each month compute a three-term moving average of a threeterm moving average of the centered ratios yielded by step $11 d$, above. This will result in the loss of two moving average values at the beginning and two at the end. To obtain the values missing at the beginning, use the average of the first two centered ratios at the estimated value of the centered ratio for each of the two years preceding the first year available. This is equivalent to weighting the first three years' centered ratios by $\frac{9}{18}, \frac{7}{18}$, and $\frac{2}{18}$, respectively, to obtain the first year's moving average value, and to weighting the first four years' centered ratios by $\frac{5}{18}, \frac{7}{18}, \frac{4}{18}$, and $\frac{2}{18}$, respectively, to obtain the second year's moving average value. The missing values at the end are obtained in a similar way. These smoothed ratios constitute the final seasonal adjustment factors. This series is identified later by the symbol $S$ (Table 12).

$g$. For each month compute a three-term moving average of a fiveterm moving average of the centered ratios yielded by step $11 d$, above. This will result in the loss of three moving average values at the beginning and three at the end. To obtain the values missing at the beginning, use the average of the first two centered ratios as the estimated value of the centered ratio for each of the three years preceding the first year available. This is equivalent to weighting the first four years' centered ratios by $\frac{6}{15}, \frac{6}{15}, \frac{2}{15}$, and $\frac{1}{15}$, respectively, to obtain the first year's moving average value; to weighting the first five years' centered ratios by $\frac{9}{30}, \frac{9}{30}, \frac{6}{30}, \frac{4}{30}$, and $\frac{2}{30}$, respectively, to obtain the second year's moving average value; and to weighting the first six years' centered ratios by $\frac{5}{30}, \frac{7}{30}, \frac{6}{30}, \frac{8}{30}, \frac{4}{30}$, and $\frac{2}{30}$, respectively, to obtain the third year's moving average value. The missing values at the end are obtained in a similar way. These smoothed ratios constitute the final seasonal adjustment factors. This series is later identified by the symbol $S$ (Table 12).

$h$. Estimates of the seasonal factors one year ahead are given at the 


\section{PART THREE}

bottom of Table 12. These estimates are made by adding to the seasonal factor for the end year, one-half the trend between the factor for that year and the preceding year. If $X=$ seasonal adjustment factor for year $N$, then $X_{N+1}$ is estimated by the equation

$$
X_{N+1}=\frac{3 X_{N}-X_{N-1}}{2} .
$$

12. These seasonal factors are divided into the corresponding figures of the original series, month by month; i.e. the seasonal factor for January 1947 is divided into the original observation for January 1947; the factor for January 1948 is divided into the original observation for January 1948. Similarly, the factor for February 1947 is divided into the original observation for February 1947; the factor for February 1948, into the original observation for February 1948; and so on. This yields the final seasonally adjusted series. This series is later identified by the symbol $C I$ (Table 13).

13. The ratios of the final seasonally adjusted series to the averages of the final seasonally adjusted series for the preceding and the following months are computed. This is a rough test for residual seasonality. similar to that made on the original observations described in step 2, above. Arithmetic means of these ratios for each month are given at the bottom of the table (Table 14).

14. Compute an uncentered twelve-month moving average of the final seasonally adjusted series. This step is required to carry out the test described in step 15. It also provides annual averages of the seasonally adjusted series (Table 15).

15. Compute ratios of the uncentered twelve-month moving average of the standard seasonally adjusted series to the uncentered twelvemonth moving average of the original series. This is a test of the effect of the seasonal adjustment on the level of the series, showing whether the adjustment has resulted in significant differences between the level of the adjusted and the unadjusted series for any twelvemonth period (Table 16).

16. Using the final seasonally adjusted series, compute the ratio of the value of each month, from February through the following January, to that of the preceding January. Such a table of ratios will disclose repetitive patterns in successive years of more than one month's duration (Table 17).

III. MEASURES OF THE IRREGULAR, CYGLICAL, AND SEASONAL COMPONENTS

17. Compute a weighted fifteen-month moving average (Spencer's fifteen-term formula) of the final seasonally adjusted series. The weights are as follows: $-3 / 320,-6 / 320,-5 / 320,3 / 320,21 / 320$, 
$46 / 320,67 / 320,74 / 320,67 / 320,46 / 320,21 / 320,3 / 320,-5 / 320$, $-6 / 320,-3 / 320$. This is equivalent to a weighted five-month moving average (weights are $-\frac{3}{4}, \frac{3}{4}, 1, \frac{3}{4},-\frac{3}{4}$ ), of a five-month moving average, of a four-month moving average, of a four-month moving average of the data.

To obtain values for the beginning points of this curve, use the average of the first four values of the final seasonally adjusted series as the estimated value of this series for each of the seven months preceding the first month available. The values for the end are supplied similarly.

The final seasonally adjusted series contains the cyclical, trend, and irregular components of the series. The weighted fifteen-month moving average can be used in place of a twelve-month moving average because there is no seasonal factor to suppress. The weighted fifteen-month moving average is much more flexible than a twelvemonth moving average and will therefore provide a better measure of the trend-cycle component; it is also much smoother than a simple five-month moving average, and it fits the data about as closely as does the five-month moving average. This series is identified by the symbol $C$ (Table 18$)$.

18. Compute the month-to-month percentage changes in the original series (Table 19).

19. Compute the month-to-month percentage changes in the final seasonal adjustment factors (Table 20).

20. Compute the month-to-month percentage changes in the final seasonally adjusted series (Table 21 ).

21. Compute the month-to-month percentage changes in the ratios (step 9) of the original observations to the weighted fifteen-month moving average (Table 22).

22. Compute the ratios of the final seasonally adjusted series (step 12) to its weighted fifteen-month moving average (step 17). This provides a measure of the irregular component of the series. This series is identified by the symbol $I$ (Table 23).

23. Compute the month-to-month percentage changes in the irregular component (Table 24).

24. Compute the month-to-month percentage changes in the weighted fifteen-month moving average of the final seasonally adjusted series (Table 25).

25. Compute the average, without regard to sign, of the percentage changes in steps $18,19,20,23$, and 24 . This operation yields measures of the average monthly amplitude of the original series, the seasonal component, the seasonally adjusted series, the irregular component, 
and the cyclical component, respectively. The symbols used to represent these averages are original, $\bar{O}$; irregular, $\bar{I}$; cyclical, $\bar{C}$; seasonal, $\bar{S}$; and seasonally adjusted, $\overline{C I}$ (Table 27 ).

26. Compute the following ratios of the average monthly amplitudes of step 25:
a. Irregular component to cyclical component $(\bar{I} / \bar{C})$
b. Irregular component to seasonal component $(\bar{I} / \bar{S})$
c. Seasonal component to cyclical component $(\bar{S} / \bar{C})$
$d$. Irregular component to original series $(I / \bar{O})$
e. Cyclical component to original series $(\bar{C} / \bar{O})$
$f$. Seasonal component to original series $(\bar{S} / \bar{O})$
See Table 27.

27. Compute the ratio of the average monthly amplitude of the irregular to the cyclical components when percentage changes are taken between entries two, three, four, and five months apart (Table 27).

The interval corresponding to the last $\bar{I} / \bar{C}$ ratio that is less than 1.00 is designated as "Number of Months for Cyclical Dominance," and a moving average of the seasonally adjusted data is computed, using this interval as its period (Table 26).

28. The average duration of run, that is, the average number of months the series moves before changing direction, is computed for the following:

a. Seasonally adjusted series

$b$. Irregular component

c. Cyclical component

$d$. Seasonally adjusted series smoothed by moving average with period as given by number of months for cyclical dominance See Table 27.

29. Compute the ratios of $(a)$ the twelve-month moving average of the month-to-month percentage changes in the irregular component (step 23) to $(b)$ the twelve-month moving average of the month-tomonth percentage changes in the cyclical component (step 24). In the computation of these moving averages the signs of the percentage changes are disregarded (Table 28).

IV. NOTES

30. Where the average monthly amplitude of the irregular component is 4.0 or larger (on the basis of the preliminary seasonally adjusted series) and for special purposes, two additional tables are computed and inserted between Tables 10 and 11. In the first one, the stable adjustment factors are computed by averaging the modified ratios 
of step $11 c$ for each month and then centering the average so that their sum will be 1,200 . In the second table, these stable factors are divided into the corresponding values of the original data, yielding a seasonally adjusted series based on a constant seasonal pattern. These two additional tables (identified as Tables 10A and 10B in the sample given) do not affect the computations in any other tables.

31. After the tables, four Univac point charts are printed: (1) original and seasonally adjusted series, (2) seasonally adjusted and smoothed series, (3) seasonal-irregular ratios and seasonal adjustment factors, in chronological order, and (4) seasonal-irregular ratios and seasonal adjustment factors, month-by-month.

The following points will be helpful in interpreting such charts:

$a$. The scales for the first two charts are identical and are limited to one of five standard scales: $1^{\prime \prime}=10,100,1,000,10,000,100,000$, depending upon the amplitude of the series.

$b$. The scale for the third chart ranges from 60 to 170 per cent. Ratios or factors that do not fall in this range are not charted but are shown numerically in the margin next to the time scale.

c. The last chart is printed in twelve sections, one for each month. The scale is limited to one of four standard scales: $1^{\prime \prime}=1$ per cent, 2 per cent, 4 per cent, or 8 per cent. The scale used is printed below the title of each section of the chart, that is, scale $1,2,4$, or 8 . If scale 8 is too small for the amplitude of the data, this chart is not printed.

$d$. Throughout all the charts, only one symbol, $X$, is printed whenever both points for one month are identical.

For the method of preparing such charts, which are shown in Part V of this appendix, see Harry Eisenpress, James L. McPherson, and Julius Shiskin, "Charting on Automatic Data Processing Systems," Computers and Automation, August 1955.

32. It is not necessary to make the full run. The following alternative sets of tables can be prepared, when specified:

a. Complete run (approximately 6 minutes per ten-year series)

$b$. Seasonal adjustment only (Tables 1-17; approximately 2.3 minutes per ten-year series)

c. Seasonal adjustment and auxiliary measures (all tables, 1-28; approximately 4 minutes per ten-year series)

$d$. Seasonal adjustment, auxiliary measures, and first two charts (approximately 4.8 minutes per ten-year series)

The stable seasonal adjustment factors and seasonally adjusted series can also be obtained with each run, without appreciably affecting the time required. 


\section{A SAMPLE RUN}

The sample "print-out" shown below is from a more recent version of the program than that shown in the original printing of this paper. In the revised program three new sets of tables are computed and there are two differences in technique.

The first new set of tables shows the seasonal factors converted to percentages of 100. Each of the monthly seasonal factors is divided by twelve to make up Table 12A (Monthly Seasonal Factors as Percent of Year), and appropriate values from Table 12A are added to obtain Table 12B (Quarterly Seasonal Factors as Percent of Year), e.g. first quarter values in Table 12B are sums of January, February, and March values of Table 12A, etc. The sum of the percentages in each row (year) approximately equals 100 .

These tables indicate the percentage of the year's activity that may be "expected" each month or each quarter of the year as a result of the seasonal factor alone. They may be helpful in distributing an annual forecast by months; for this purpose, an allowance should be made for the cycle and trend movements within the year. These tables may also be useful in distributing annual budgets seasonally and in supervising monthly expenditures of annual appropriations.

The second set of tables shows by stage how the $M C D$ curve (Table 26 ) is adjusted for amplitude. The series shown in the final table (26C) of this set is adjusted for seasonality, irregularity, and amplitude. Such series add another level to the adjustment process and facilitate comparisons of the cyclical timing and pattern of different series.

Tables 26A, 26B, and 26C are entitled Symmetrical Percent Change from Preceding Month in Short-Term Moving Average, Standardized Symmetrical Percentage Change from Preceding Month in Short-Term Moving Average, and Standardized Short-Term Moving Average Index, respectively. Table $26 \mathrm{~A}$ shows percentage changes over one-month intervals in the $M C D$-term moving average of the final seasonally adjusted series. The percentage change is computed from Table 26 by the formula $200(B-A) /(B+A)$, where $B$ is the moving average value for the given month and $A$ is the moving average value for the preceding month. Table 26B is obtained by dividing each value in Table $26 \mathrm{~A}$ by the average (without regard to sign) of all the values in Table 26A. This average value is shown after the title of Table $26 \mathrm{~B}$. Table $26 \mathrm{C}$ is obtained by setting the value for the first month for which the moving average is available at 100 and by obtaining values for subsequent months by the formula $A(200+r) /(200-r)$, where $A$ is the Table $26 \mathrm{C}$ value for the month preceding the desired month and where $r$ is the standardized, modified rate of change (shown in Table 26B) for the desired month. This process is reversible; that is, the rates of change computed from 
Table 26C are identical with the rates of change (over corresponding periods) in the short-term moving average of the seasonally adjusted data (Table 26A) if allowance is made for the standardizing constant and for the rounding method used in the program.

The third set of tables shows the original observations with large irregularities modified and then seasonally adjusted. The modifications are made by multiplying the centered ratios of the original to the weighted fifteen-month moving average (Table 11), which contain the seasonal and modified irregular components, by the weighted fifteen-term moving average of the final seasonally adjusted series (Table 18), which is the final measure of the trend-cycle component. Table 30 shows seasonally adjusted, modified observations obtained by dividing the modified original observations (Table 29) by the final seasonal adjustment factors (Table 12).

[We have recently revised this technique so that the modified original observations are obtained by multiplying the original observations (Table 1) by the ratios of the modified ratios (Table 10) to the ratios-tomoving average (Table 9).]

If the modified observations are run through the program as original observations, the whole series of computations will not be affected by large irregularities, and better measures of the seasonal, cyclical, and irregular components and a better seasonally adjusted series may be expected.

Two revisions in technique have been made. First, extreme seasonalirregular ratios are replaced by the average of the two preceding and the two following ratios. When the extreme ratio falls at the end of the series, it is replaced by the average of the three preceding ratios. When the extreme ratio falls one position before the end, it is replaced by the average of the two preceding ratios and the end ratio. A similar procedure is followed for extremes falling at the beginning of the series. (See steps $6 \mathrm{c}$ and $11 \mathrm{c}$ above.)

Second, in order to compute the moving averages which measure the seasonal factors for the first and last years of each series, ratios are required for additional years preceding and following the actual period covered by the data. Where the average month-to-month change in the irregular factor is 2.00 or more, the average of the first four available ratios is used as the estimated value for each of the three years preceding the period covered by the series. The estimated ratios for three years following the actual period of the series are computed in a similar manner (see step $1 \mathrm{lg}$ ). 


\section{Sample Univac High-Speed Print-Out, Reduced}

I ORIGINAL SERIES PROGRAM X OCT. 9, 1959

SERIES \#3694

\begin{tabular}{|c|c|c|c|c|c|c|c|c|c|c|c|c|}
\hline YEAR & JAN & FEB & MAR & APR & MAY & JUN & JUL & AUG & SEP & OCT & NOV & OEC \\
\hline 1939 & 356 & 355 & 502 & 503 & 530 & 494 & $4>5$ & 514 & 470 & 497 & 456 & 368 \\
\hline 1940 & 289 & 371 & 524 & 629 & 636 & 574 & 629 & 614 & 605 & 624 & 450 & 402 \\
\hline 1941 & 430 & 422 & 614 & 739 & 781 & 760 & 016 & 734 & 646 & 612 & 502 & 360 \\
\hline 1942 & 394 & 426 & 572 & 504 & 245 & 224 & 248 & 259 & 259 & 217 & 174 & 151 \\
\hline 1943 & 112 & 118 & 179 & 182 & 227 & 211 & 200 & 235 & 196 & 216 & 173 & 155 \\
\hline 1944 & 146 & 140 & 101 & 154 & 176 & 181 & 149 & 133 & 113 & 116 & 108 & 86 \\
\hline 1945 & $\mathrm{BH}$ & 90 & 127 & 149 & 175 & 220 & 199 & 204 & 241 & 307 & 352 & 349 \\
\hline 1946 & 443 & 509 & 744 & 804 & 805 & 754 & 736 & 743 & 691 & 678 & 572 & 472 \\
\hline 1947 & 458 & 514 & 672 & 805 & 675 & 924 & 973 & 1033 & 1122 & 1122 & 947 & 702 \\
\hline 1948 & 630 & 587 & 916 & 1177 & 1190 & 1159 & 1124 & 1021 & 966 & 863 & 736 & 593 \\
\hline 1949 & 556 & 574 & 784 & 1020 & 1094 & 1092 & 1112 & 1159 & 1207 & 1223 & 1121 & 924 \\
\hline 1950 & 934 & 980 & 1392 & 1576 & 1748 & 1721 & 1676 & 1654 & 1393 & 1210 & 992 & 943 \\
\hline 1951 & 986 & 918 & 1082 & 1108 & 1171 & 1004 & 1042 & 1060 & 1144 & 1007 & 000 & 714 \\
\hline 1952 & 737 & 892 & 1093 & 1164 & 1212 & 1103 & 1213 & 1169 & 1190 & 1190 & 980 & B11 \\
\hline 1953 & 818 & 886 & 1153 & 1289 & 1267 & 1224 & 1157 & 1106 & 1105 & 1081 & 959 & 774 \\
\hline 1954 & 781 & 887 & 1118 & 1278 & 1289 & 1351 & 1355 & 1356 & 1361 & 1326 & 1240 & 1079 \\
\hline 1955 & 1048 & $105 s$ & 1354 & 1560 & 1621 & 1577 & 1463 & 1468 & 1363 & 1258 & 1061 & 882 \\
\hline 1950 & 884 & 924 & 1127 & 1319 & 1330 & 1255 & 1180 & 1238 & 1080 & 1094 & 924 & 755 \\
\hline 1457 & 721 & 757 & 952 & 1097 & 1163 & 1134 & 1127 & 1162 & 1082 & 1061 & 900 & 750 \\
\hline 1058 & 755 & 732 & 928 & 1130 & 1216 & 1216 & 1303 & 1375 & 1331 & 1355 & 1284 & 1074 \\
\hline 1959 & 1009 & 1122 & 1417 & 1049 & 1002 & 1573 & 1526 & 1501 & 1403 & 1226 & & \\
\hline
\end{tabular}

2 RATIOS OF ORIGINAL TO PRECEDING AND FOLLOWING

SERIES $\% 3694$

\begin{tabular}{|c|c|c|c|c|c|c|c|c|c|c|c|c|}
\hline YEAR & JAN & FEB & MaR & APR & MAY & JUN & JUL & AUG & SEP & $O C T$ & NOV & DEC \\
\hline 1939 & - & 82.8 & 117.0 & 97.5 & 106.3 & 100.3 & 90.3 & 111.1 & 93.0 & 107.3 & 1is. 4 & 98.8 \\
\hline 1940 & 78.2 & 91.3 & 104.8 & 108.4 & 105.7 & 90.8 & 105.9 & 99.5 & 97.7 & 117.4 & 89.3 & 89.7 \\
\hline 1941 & 106.3 & 00.2 & 105.8 & 105.9 & 103.6 & 90.3 & 100.6 & 100.4 & 96.0 & 106.4 & 103.3 & 86.1 \\
\hline 1942 & 85.0 & 94.0 & 123.0 & 123.4 & 67.3 & 90.9 & 102.7 & 102.2 & 108.8 & 100.2 & 94.6 & 105.6 \\
\hline 1843 & 83.3 & 01.1 & 119.3 & 89.7 & 115.5 & 98.8 & 09.7 & 118.7 & 86.9 & 117.1 & 93.0 & 97.8 \\
\hline 1944 & 98.6 & 91.2 & 209.5 & 91.4 & 105.1 & 111.4 & 94.9 & 101.5 & 90.8 & 105.0 & 106.9 & 09.6 \\
\hline 1945 & 95.5 & 85.3 & 106.3 & 98.7 & 94.9 & 117.6 & 93.9 & 92.7 & 94.3 & 103.5 & 107.3 & 97.3 \\
\hline 1946 & 103.3 & e5. 8 & 113.3 & 103.8 & 103.3 & 97.9 & 98.3 & 104.1 & 97.3 & 107.4 & 99.5 & 91.7 \\
\hline 1947 & 92.9 & 11.0 & 101.9 & 104.1 & 101.2 & 100.0 & 99.4 & 98.6 & 104.1 & 108.5 & 103.9 & 89.0 \\
\hline 1948 & 97.8 & 75.9 & 103.9 & 111.8 & 101.9 & 100.2 & 103.1 & 97.7 & 102.5 & 101.4 & 101.1 & 91.8 \\
\hline 1949 & 95.3 & 85.7 & 98.4 & 108.6 & 103.6 & 99.0 & 98.8 & 100.0 & $101 \cdot 3$ & 105.1 & 104.4 & 89.9 \\
\hline 1950 & 97.7 & 85.0 & 108.6 & 100.4 & 106.0 & 100.5 & 99.3 & 107.8 & 97.3 & 101.5 & 92.2 & $95 \cdot 3$ \\
\hline 1951 & 106.0 & 88.8 & 106.8 & 98.4 & 106.8 & 98.0 & 97.2 & 97.0 & 107.6 & 100.2 & 97.2 & 89.1 \\
\hline 1952 & 91.8 & 97.5 & 100.3 & 101.0 & 104.2 & 95.9 & 104.0 & 97.3 & 100.9 & 109.3 & 98.8 & 89.8 \\
\hline 1953 & 96.4 & 89,9 & 106.0 & 100.5 & 100.8 & 101.0 & 99.3 & 97.8 & 101.1 & 104.7 & 103.4 & 89.0 \\
\hline 1954 & 94.0 & 93.4 & 103.3 & 106.2 & 98.1 & $102 \cdot 2$ & 100.1 & 99.9 & 101.5 & 102.0 & 103.1 & 94.3 \\
\hline 1455 & 98.2 & 87.9 & 103.3 & 105.3 & 103.1 & 102.3 & 96.1 & 103.9 & 100.0 & 103.8 & 99.2 & 90.7 \\
\hline 1956 & 97.9 & 91.9 & 100.5 & 107.4 & 103.3 & 99.7 & 95.3 & 100.8 & 93.3 & 100.7 & 99.9 & 91.8 \\
\hline 1957 & 95.4 & 90.5 & 102.7 & 103.7 & 104.3 & 99.0 & 98.2 & 105.2 & 97.3 & 100.8 & 100.3 & 90.2 \\
\hline $105 \theta$ & 101.9 & 87.0 & 90.7 & 105.4 & 103.7 & 96.5 & 100.6 & 104.4 & 97.5 & 103.6 & 105.7 & 93.7 \\
\hline 1959 & 91.9 & 92.5 & 102.3 & 109.2 & 99.4 & 100.6 & 99.3 & 102.5 & 102.9 & & & \\
\hline
\end{tabular}

AVERAGES OF RATIOS
SERIES 43694 NOV DiC $100.4 \quad 92.1$ 
3 UNCENTRO 12-MONTH MOVING AVERAGE OF ORIGINAL

SERIES \#369"

\begin{tabular}{|c|c|c|c|c|c|c|c|c|c|c|c|c|}
\hline YEAR & JAN & FEB & MAA & APR & MAY & JUN & JUL & AUG & SEP & OCT & NOV & OEC \\
\hline 1939 & - & - & - & - & - & 458 & 453 & 454 & 458 & 400 & 473 & 402 \\
\hline 1940 & 496 & sos & 516 & 527 & 327 & 530 & 542 & 546 & 554 & 563 & 573 & 501 \\
\hline 1041 & 607 & 617 & 620 & 619 & 623 & 610 & 611 & 611 & 608 & 580 & 343 & 498 \\
\hline 1942 & 451 & 411 & 379 & 346 & 318 & 301 & 283 & 257 & 224 & 197 & 196 & 195 \\
\hline 1943 & 191 & 180 & 103 & 103 & 183 & 184 & 187 & 100 & 107 & 185 & 100 & 178 \\
\hline 1944 & 174 & 165 & 158 & 150 & 144 & 139 & 133 & 129 & 126 & 126 & 126 & 129 \\
\hline 1945 & 133 & 139 & 150 & 160 & 186 & 208 & 238 & 273 & 324 & 379 & 431 & 476 \\
\hline 1946 & 521 & 566 & 603 & 634 & 652 & 663 & 684 & 664 & 658 & 658 & 664 & $67 \mathrm{~B}$ \\
\hline 1947 & 690 & 722 & 758 & 795 & 826 & 846 & 860 & 066 & 886 & 917 & 944 & 963 \\
\hline 1948 & 976 & 975 & 962 & 940 & 923 & 913 & 907 & 906 & B9S & 682 & 874 & 869 \\
\hline 1949 & 860 & 670 & 990 & 929 & 961 & 989 & 1020 & I0ss & 1105 & 1152 & 1206 & 1250 \\
\hline 1950 & 1306 & 1347 & 1362 & 1361 & 1351 & 1352 & 1357 & 1351 & 1325 & 1286 & 1238 & 1185 \\
\hline 1951 & 1132 & 1082 & 1062 & 1050 & 1039 & 1020 & 990 & 997 & 998 & 1003 & 1006 & 1013 \\
\hline 1952 & 1027 & 1036 & 1040 & 1050 & 1060 & 1068 & 1075 & 1075 & 1080 & 1090 & 1095 & 1100 \\
\hline 1953 & 1095 & 1090 & 1003 & 1074 & 1071 & 1060 & 1005 & 1065 & 1062 & 1001 & 1063 & 1074 \\
\hline 1954 & 1090 & 1111 & 1,32 & 1153 & 1176 & $\$ 202$ & 1224 & 1238 & 1258 & 1282 & 1300 & 1320 \\
\hline 1955 & 1337 & 1346 & 1347 & 1341 & 1326 & 1310 & 1296 & 1285 & 1266 & 1246 & 1221 & 1194 \\
\hline 1456 & 1172 & 1152 & 1129 & 1116 & 1104 & 1094 & 1000 & 1066 & 1052 & 1033 & 1010 & 1009 \\
\hline 1057 & 1004 & 998 & 997 & 993 & 993 & 99 & 996 & 994 & 992 & 994 & 990 & 1000 \\
\hline 1958 & 1020 & 1038 & 1059 & 1083 & 1115 & 1242 & 1163 & 1195 & 1236 & 1270 & 1311 & 1341 \\
\hline 1959 & 1360 & 1370 & 1376 & 1365 & - & - & - & - & $=$ & - & & \\
\hline
\end{tabular}

4 CENTERED 12-MONTH MOVING AVERAGE OF OAIGINAL

SERIES MSAO4

\begin{tabular}{|c|c|c|c|c|c|c|c|c|c|c|c|c|}
\hline YEAR & JAN & FES & MAR & AFra & mar & JUN & JUL & Aus & sep & OCT & Nov & DEC \\
\hline 1930 & - & - & - & - & - & - & 456 & 453 & 455 & 461 & $47 !$ & 479 \\
\hline IYHO & 489 & 501 & 510 & $\$ 21$ & 527 & 528 & 536 & 544 & 350 & 358 & 569 & 383 \\
\hline 1941 & 509 & 612 & 619 & 620 & 021 & 621 & 615 & 611 & 609 & 598 & 366 & 521 \\
\hline 1942 & 474 & 431 & 395 & 362 & 332 & 310 & . $\quad 292$ & 270 & 241 & 211 & 197 & 195 \\
\hline 1943 & 193 & 190 & 180 & 183 & 183 & 104 & 185 & 188 & 180 & 186 & 202 & 170 \\
\hline 1944 & 176 & 169 & 162 & 154 & 147 & 142 & 136 & 131 & 128 & 126 & 126 & 128 \\
\hline 1945 & 131 & 136 & 143 & $15 \theta$ & 176 & 197 & 223 & 255 & 290 & 352 & 405 & 434 \\
\hline 1046 & 498 & 543 & 584 & 610 & 643 & 657 & 663 & 664 & 661 & 658 & 601 & 671 \\
\hline 1947 & 688 & 710 & 740 & 777 & 811 & 830 & 653 & 803 & 876 & 902 & 930 & 953 \\
\hline 1948 & 969 & 975 & 968 & 951 & 031 & 910 & 910 & 907 & 901 & 809 & 878 & 07! \\
\hline 1949 & 068 & 673 & 080 & 914 & $0 \quad 945$ & 975 & 1005 & 1038 & 1080 & 1120 & 1179 & 1233 \\
\hline 1950 & 1202 & 1326 & 1355 & 1362 & 1350 & 1351 & 1354 & 1354 & 1338 & 1305 & 1262 & 1211 \\
\hline 1951 & 1158 & 1107 & 1072 & 1056 & 1045 & 1030 & 1010 & 998 & 998 & 1001 & 1005 & 1010 \\
\hline 1052 & 1020 & 1032 & 1038 & 1045 & 1055 & 1060 & 1072 & 1075 & 1077 & 1005 & 1092 & 1097 \\
\hline 1953 & 1098 & 1003 & 1086 & 1078 & 1073 & 1070 & 1067 & 1065 & 1084 & 1062 & 1062 & 1069 \\
\hline 1054 & 1082 & 1101 & $\$ 122$ & 1643 & 1165 & 1189 & 1213 & 1231 & 1248 & 1270 & 1296 & 1310 \\
\hline 1953 & 1333 & 1342 & 1347 & 1344 & 1334 & 1318 & $130 y$ & 1291 & 1276 & 1256 & 1233 & 1208 \\
\hline 1056 & 1103 & 1102 & $114 d$ & 1123 & 1110 & 1099 & 1087 & 1073 & 1059 & 1043 & 1020 & 1014 \\
\hline 1957 & 1007 & 1001 & 998 & 996 & 994 & 993 & 994 & 995 & 993 & 993 & 907 & 1002 \\
\hline 1958 & 1013 & 1029 & 1048 & 1071 & 1099 & 1128 & 1152 & 1179 & 1210 & 1258 & 1295 & 1326 \\
\hline
\end{tabular}




\section{PART THREE}

5 RATIOS OF ORIGINAL TO 12-MONTH MOVING AVERAGE

\begin{tabular}{|c|c|c|c|c|c|c|c|c|c|c|c|c|}
\hline YEAR & JAN & $\mathbf{F} 8 \theta$ & MAR & APR & MaY & JUN & JUL & AUG & SEP & OCT & Nov & O:C \\
\hline 1939 & - & - & - & - & - & * & 99.8 & 113.3 & 103.3 & 107.8 & 96.8 & 76.8 \\
\hline 1940 & 59.1 & 74.1 & 102.7 & 120.7 & 120.7 & 108.7 & 117.4 & 112.9 & 110.0 & 111.8 & 80.5 & 69.0 \\
\hline 1941 & 73.1 & 69.0 & 99.2 & 119.2 & 125.8 & 123.8 & 132.7 & 120.1 & 106.1 & 102.3 & 88.7 & 09.1 \\
\hline 1942 & 70.5 & 98.8 & 144.8 & 139.2 & 73.8 & 72.3 & 84.9 & 95.9 & 107.5 & 102.8 & 88.3 & 77.4 \\
\hline 1943 & 58.0 & 62.1 & 96.2 & 99.5 & 124.0 & 114.7 & 108.1 & 125.0 & 104.3 & 116.1 & 95.1 & 87.2 \\
\hline 1944 & 83.0 & 82.8 & 99.4 & 100.0 & 119.7 & 127.5 & 109.6 & 101.5 & 88.3 & 92.1 & 85.7 & 67.2 \\
\hline 1945 & 64.1 & 86.2 & 87.6 & 94.3 & 99.4 & 111.7 & 89.2 & 80.0 & 80.6 & 87.2 & 86.9 & 76.9 \\
\hline 1946 & 89.0 & 93.7 & 127.4 & 129.9 & 125.2 & 114.8 & 111.0 & 111.9 & 104.5 & 103.0 & 86.5 & 70.3 \\
\hline 1947 & 66.6 & 72.4 & 90.8 & 103.6 & 107.9 & 110.5 & 114.1 & 119.7 & 128.1 & 124.4 & 101.8 & 73.7 \\
\hline 1940 & 65.0 & 60.2 & 94.6 & 123.8 & 127.8 & 126.3 & 123.5 & 112.6 & 107.2 & 97.1 & 83.8 & 08.1 \\
\hline 1949 & 64.1 & 65.8 & 88.2 & 111.6 & 115.8 & 112.0 & 110.6 & 111.7 & 111.8 & 108.3 & 95.1 & 74.9 \\
\hline 1950 & 72.9 & 74.5 & 102.7 & 115.7 & 128.9 & 227.4 & 123.8 & 122.2 & 104.1 & 92.7 & 78.6 & 77.9 \\
\hline 1951 & 05.1 & 82.9 & 100.9 & 104.9 & 112.1 & 105.2 & 103.2 & 106.2 & 114.6 & 106.6 & 86.2 & 70.7 \\
\hline 1952 & 72.3 & 86.4 & 105.3 & 111.4 & 114.9 & 109.3 & 113.2 & 108.7 & 110.5 & 109.7 & 90.5 & 73.9 \\
\hline 1953 & 74.5 & 81.1 & 106.2 & $1: 9.6$ & 128.1 & 114.4 & 108.4 & 103.8 & 103.9 & 101.8 & 90.3 & 72.4 \\
\hline 1954 & 72.2 & 80.6 & 99.6 & 111.0 & 110.6 & 113.6 & 111.7 & 110.2 & 109.1 & 104.4 & 95.7 & 81.8 \\
\hline 1955 & 78.6 & 78.6 & 100.5 & 116.5 & 121.5 & 119.7 & 112.3 & 113.7 & 106.8 & 100.2 & 86.1 & 73.0 \\
\hline 1936 & 74.7 & 79.5 & 98.8 & 117.5 & 119.8 & 114.2 & 109.3 & 115.4 & 102.7 & 104.9 & 90.1 & 74.5 \\
\hline 1957 & 71.6 & 75.6 & 93.4 & 110.1 & 117.0 & 114.2 & 113.4 & $116 . \theta$ & 109.0 & 106.8 & 91.1 & 74.0 \\
\hline 58 & 74.5 & 71.1 & 88.5 & 105.5 & 110.6 & 107.8 & 113.1 & 116.6 & 100.3 & 107.7 & 99.2 & 81.0 \\
\hline 1959 & 74.7 & 82.2 & 103.2 & 120.3 & & & & & & & & \\
\hline
\end{tabular}

6 PRELIMIMarY aDJustment factors

SERIES $\$ 3694$

\begin{tabular}{|c|c|c|c|c|c|c|c|c|c|c|c|c|}
\hline YEAR & JAN & $F E B$ & MAR & APR & MAY & JUN & JUL & AUG & SEP & OST & NOV & OEC \\
\hline 1939 & 61.3 & 74.4 & 103.5 & 121.9 & 122.6 & 111.6 & 108.1 & 115.2 & 107.4 & 110.0 & 90.5 & 73.7 \\
\hline 1940 & 64.1 & 73.5 & 102.6 & 120.3 & 123.2 & 114.2 & 110.2 & 113.8 & 108.0 & 108.7 & 88.6 & 72.8 \\
\hline 1941 & 67.0 & 71.5 & 101.3 & 116.8 & 124.7 & 118.0 & 110.7 & 111.4 & 108.1 & 108.0 & 89.5 & 73.1 \\
\hline 1942 & 69.8 & 72.0 & 101.0 & 111.9 & 125.6 & 121.2 & 113.3 & 106.6 & 106.7 & 107.6 & 90.6 & 73.0 \\
\hline 1943 & 71.1 & 72.6 & 100.4 & 107.1 & 124.3 & 123.3 & 111.4 & 106.8 & 105.5 & 109.3 & 93.1 & 75.2 \\
\hline 1944 & 73.5 & 75.2 & 99.6 & 104.8 & 122.3 & 124.1 & 110.4 & 109.4 & 104.4 & 108.4 & 92.5 & 75.4 \\
\hline 1995 & 72.7 & 74.8 & 97.6 & $104 \cdot 8$ & 119.1 & 122.2 & 108.7 & 115.8 & 106.6 & 109.1 & 92.2 & 76.4 \\
\hline 1946 & 71.6 & 73.3 & 96.2 & 108.4 & 120.1 & 120.9 & 112.6 & 118.1 & 107.2 & 106.1 & 90.4 & 75.2 \\
\hline 1947 & 68.7 & 70.3 & 94.8 & 112.1 & 120.1 & 119.3 & 116.2 & 110.1 & 108.7 & 105.3 & 90.6 & 74.9 \\
\hline 1948 & 67.6 & 68.3 & 94.9 & 115.8 & $122 \cdot 8$ & 120.7 & 119.4 & 117.3 & 108.3 & $102 . ?$ & 68.8 & 73.6 \\
\hline 1949 & 69.7 & 70.0 & 95.8 & 115.1 & 121.6 & 119.2 & 0117.4 & 116.0 & 109.7 & 102.6 & 08.4 & 74.4 \\
\hline 1950 & 73.0 & 74.5 & 98.8 & 113.3 & 121.0 & 117.3 & 115.4 & 114.2 & 109.7 & 102.2 & 86.3 & 74.4 \\
\hline 1951 & 76.4 & 80.1 & 101.9 & 111.6 & 117.9 & 113.2 & 111.8 & 111.1 & 110.4 & 104.4 & 87.3 & 73.0 \\
\hline 1932 & 75.8 & 82.6 & 103.7 & 112.4 & 116.2 & 112.1 & 111.0 & 108.8 & 109.2 & 104.9 & 08.9 & 74.2 \\
\hline 1953 & 75.2 & 82.2 & 103.5 & 114.2 & 115.6 & 112.6 & 110.2 & 107.8 & 108.2 & 104.6 & 90.7 & 74.8 \\
\hline 1954 & 74.3 & 80.7 & $10 ! .7$ & 115.0 & 116.0 & 114.6 & $\ln .8$ & 109.8 & 106.7 & 103.4 & 91.0 & 75.9 \\
\hline 1955 & 74.9 & 79.1 & 99.8 & 115.1 & 117.6 & 115.7 & 111.0 & 112.4 & 106.1 & 102.9 & 90.0 & 75.3 \\
\hline 1956 & 74.6 & 77.6 & 97.4 & 113.7 & 117.5 & 114.7 & 111.6 & 114.9 & 106.5 & 104.6 & 91.1 & 75.8 \\
\hline 1957 & 74.1 & 76.6 & 96.1 & 112.7 & 116.1 & 112.8 & 112.4 & 116.2 & 107.7 & 106.1 & $92: 9$ & 76.6 \\
\hline 1958 & 74.0 & 76.2 & 95.3 & 112.0 & 113.2 & 110.1 & 112.9 & 116.7 & 108.8 & 107.3 & 95.7 & 78.5 \\
\hline 1939 & 74.1 & 76.9 & 96.3 & 113.0 & 112.1 & 108.3 & 112.9 & 116.4 & 109.2 & 107.3 & & \\
\hline
\end{tabular}


7 PRELIMINARY MOJUSTED SERIES

\begin{tabular}{|c|c|c|c|c|c|c|c|c|c|c|c|c|}
\hline ECIRINAKY & MUNUSTED & SERIES & & & & & & & & & SEAIE & 09894 \\
\hline YEAR & JAN & FEB & MAR & APR & maY & JUN & JUL & AUB & SEP & OCT & NOV & OEC \\
\hline 1939 & 501 & 477 & 405 & 413 & 432 & 443 & 421 & 446 & 438 & 452 & 304 & 499 \\
\hline 1940 & 451 & 505 & 511 & 523 & 516 & 503 & 571 & 540 & 560 & 574 & 517 & 552 \\
\hline 1943 & 654 & 590 & 606 & 633 & 626 & 652 & 737 & 659 & 598 & 567 & 301 & 492 \\
\hline 1942 & 479 & 592 & 566 & 450 & 195 & 185 & 219 & 243 & 243 & 202 & 192 & 204 \\
\hline 1943 & 150 & 163 & 178 & 170 & 103 & 171 & 180 & 220 & 180 & 198 & 186 & 207 \\
\hline 1944 & 199 & 186 & 162 & 147 & 144 & 146 & 135 & 122 & 108 & 107 & 117 & 114 \\
\hline 1945 & 116 & 120 & 130 & 142 & 147 & 180 & 183 & 176 & 226 & $28_{1}$ & 382 & 457 \\
\hline 1946 & 619 & 694 & 773 & 742 & 670 & 624 & 654 & 629 & 645 & 639 & 633 & 628 \\
\hline 1947 & 667 & 731 & 709 & 718 & 729 & 775 & 837 & 867 & 1632 & 1066 & 1045 & 937 \\
\hline 1948 & 929 & 859 & 965 & 1016 & 969 & 960 & 941 & 870 & 892 & 844 & 829 & 806 \\
\hline 1949 & 798 & 820 & 818 & 986 & 900 & 916 & 947 & 999 & 1100 & 1192 & 1268 & 1242 \\
\hline 1950 & 1270 & $\$ 326$ & 1400 & 1391 & 1445 & 1467 & 1452 & 1448 & 1270 & 1184 & 1349 & 1267 \\
\hline 1951 & 1291 & 1146 & 1062 & 993 & 993 & 958 & 932 & 954 & 1036 & 1022 & 992 & 906 \\
\hline 1952 & 972 & 1080 & 1054 & 1036 & 1043 & 1037 & 1093 & 1074 & 1090 & 1134 & 1121 & 1093 \\
\hline 1953 & 1080 & 1078 & 1114 & 1129 & 1096 & 1083 & 1050 & 1026 & 1021 & 1033 & 1057 & 1035 \\
\hline 1954 & 1051 & 1099 & 1099 & 1111 & 1111 & 1179 & 1223 & 1235 & 1276 & 1282 & 1363 & 1422 \\
\hline 1955 & 1399 & 1334 & 1357 & 1361 & 1378 & 1363 & 1318 & 1300 & 1289 & 1223 & 1179 & 1171 \\
\hline 1958 & 1183 & 1191 & 1157 & 1160 & 1132 & 1094 & 1065 & 1077 & 1022 & 1046 & 1014 & 996 \\
\hline 1957 & 973 & 980 & 991 & 973 & 1002 & 1005 & 1003 & 1000 & 1005 & 1000 & 977 & 979 \\
\hline 1930 & 1020 & 901 & 974 & 1009 & 1074 & 1104 & 1154 & 1170 & 1223 & 1263 & 1342 & 1360 \\
\hline 1959 & 1362 & 1458 & 1471 & 1459 & 1442 & 1452 & 1352 & 1290 & 1285 & 1143 & & \\
\hline
\end{tabular}

B WEJGHTEO 15-MO MOVING AVERAGE OF PREL AOS

SERTES $\# 3494$

\begin{tabular}{|c|c|c|c|c|c|c|c|c|c|c|c|c|}
\hline YEAR & JAN & FEB & MAR & APR & MAY & JUN & JUL & AUG & SEP & $\mathrm{OCT}$ & NOV & DEC \\
\hline 1939 & 504 & 492 & 473 & 453 & 437 & 430 & 431 & 436 & 450 & 462 & 473 & 482 \\
\hline 1940 & 491 & 490 & 304 & 513 & 522 & 531 & 539 & 546 & 350 & 556 & 565 & 576 \\
\hline 1941 & 588 & 603 & 620 & 036 & 653 & 664 & 662 & 645 & 816 & 504 & 560 & 547 \\
\hline 1942 & 334 & 509 & 461 & 393 & 320 & 250 & 223 & 208 & 207 & 206 & 199 & 188 \\
\hline 1943 & 177 & 171 & 169 & 172 & 176 & 182 & 180 & 193 & 197 & 199 & 199 & 196 \\
\hline 1944 & 190 & 100 & 169 & 158 & 147 & 138 & 129 & 122 & 116 & 112 & 111 & 112 \\
\hline 1943 & 116 & 123 & 130 & 139 & 148 & 158 & 173 & 198 & 240 & 306 & 393 & 494 \\
\hline 1946 & 590 & 665 & 707 & 716 & 700 & 674 & 651 & 636 & 630 & 632 & 641 & 654 \\
\hline 1947 & 670 & 686 & 703 & 722 & 752 & 795 & 854 & 918 & 969 & 997 & 998 & 979 \\
\hline 1948 & 958 & 948 & 949 & 997 & 962 & 953 & 932 & 904 & 874 & 846 & 826 & 013 \\
\hline 1949 & 810 & 018 & 835 & 857 & 886 & 924 & 972 & 1031 & 1097 & 1161 & 1217 & 1265 \\
\hline 1050 & 1306 & 1344 & 1363 & 1420 & 1443 & 1444 & 1418 & 1371 & 1310 & 1269 & 1235 & 1209 \\
\hline 1931 & 1181 & 1240 & 1087 & 1032 & 988 & 965 & 962 & 970 & 982 & 901 & 998 & 1005 \\
\hline 1052 & 1014 & 1024 & 1035 & 1045 & 1052 & 1061 & 1072 & 1085 & 1097 & 1103 & 1104 & 1103 \\
\hline 1953 & 1102 & 1203 & 1104 & 2101 & 1092 & 1076 & 1058 & 1042 & 1033 & 1031 & 1038 & 1048 \\
\hline 1954 & 1062 & 1077 & 1094 & 1115 & 1141 & 1170 & 1204 & 1241 & 1281 & 1318 & 1349 & 1369 \\
\hline 1853 & 1378 & 1370 & 2374 & 1368 & 1360 & 1348 & 1328 & 1299 & 1266 & 1233 & 1207 & 1189 \\
\hline 1956 & 1178 & 1171 & 1261 & 1146 & 1126 & 1103 & 1081 & 1060 & 1042 & 1026 & 1011 & 998 \\
\hline 1957 & 989 & 984 & 984 & 989 & 994 & 999 & 1002 & 1002 & 999 & 995 & 989 & 983 \\
\hline 1958 & 980 & 984 & 998 & 1023 & 1057 & 1098 & 1142 & 1180 & 1231 & 1276 & 1320 & 1364 \\
\hline 1958 & 1404 & 1436 & 1456 & 1459 & 1442 & 1400 & 1359 & 1308 & 1267 & 1245 & & \\
\hline
\end{tabular}




\section{PART THREE}

- Ratios of original to weIGHTEd 15-mo mov aV

SERIES 43694

\begin{tabular}{|c|c|c|c|c|c|c|c|c|c|c|c|c|}
\hline YEAR & JAN & FEO & MAR & APR & MaY & JUN & JUL & AUG & SEP & OCT & Nov & DEC \\
\hline 1937 & 70.6 & 72.2 & 106.1 & 111.0 & 121.3 & 114.9 & 105.6 & $11: .4$ & 104.4 & 107.6 & 96.4 & 76.5 \\
\hline 1940 & 58.9 & 74.5 & 104.0 & 122.6 & 121.8 & 100.1 & 116.7 & 112.5 & 110.0 & 112.2 & 81.1 & 69.8 \\
\hline 1941 & 74.5 & 70.0 & 99.0 & 116.2 & 119.6 & $115 . \theta$ & 123.3 & 113.8 & 104.9 & 104.8 & 89.6 & 65.8 \\
\hline 1942 & 62.5 & 03.7 & 124.1 & 128.2 & 76.6 & 86.5 & 111.2 & 124.5 & 125.1 & 105.3 & 87.4 & 80.3 \\
\hline 1943 & 63.3 & 69.0 & 105.9 & 105.8 & 129.0 & 115.9 & 106.4 & $121 \cdot \theta$ & 99.5 & 108.5 & 86.9 & 79.6 \\
\hline 1944 & 76.8 & $77 . \theta$ & 95.3 & 97.5 & 119.7 & 131.2 & 115.5 & 109.0 & 97.4 & 103.6 & 97.3 & 76.0 \\
\hline 1945 & 72.4 & 73.2 & 97.7 & 107.2 & 118.2 & 139.2 & 115.0 & 103.0 & 100.4 & 100.3 & 89.6 & 70.6 \\
\hline 1946 & 75.1 & 76.5 & 105.2 & 112.3 & 115.0 & 111.9 & 113.1 & 116.8 & 109.7 & 107.3 & 89.2 & 72.2 \\
\hline 1947 & 68.4 & 74.9 & 95.6 & 111.5 & 116.4 & 116.2 & 113.9 & 112.5 & 115.8 & 112.5 & 94.9 & 71.7 \\
\hline 1948 & 65.8 & 01.9 & 96.5 & 123.0 & 123.7 & 121.6 & 120.6 & 112.9 & 110.3 & 102.0 & 09.1 & 72.9 \\
\hline 1949 & 68.6 & 70.2 & 93.9 & 119.0 & 123.5 & 118.2 & 114.4 & 112.4 & 110.0 & 105.3 & 92.1 & 73.0 \\
\hline 1950 & 71.5 & 73.5 & 100.7 & 111.0 & 121.1 & 119.2 & $11 \theta .2$ & 120.6 & 105.9 & 95.4 & 80.3 & 78.0 \\
\hline 1931 & AS.S & 00.5 & 99.5 & 107.4 & 118.5 & 112.3 & 108.3 & 109.3 & 116.5 & 107.7 & 06.8 & 71.0 \\
\hline 1952 & 72.7 & 07.1 & 105.6 & 111.4 & 115.2 & 109.6 & 113.2 & 107.7 & 100.5 & 107.9 & 89.5 & 73.5 \\
\hline 1953 & 74.2 & 80.3 & 104.4 & 117.1 & 116.0 & 113.8 & 109.4 & 106.1 & 107.0 & 104.0 & 92.4 & 73.9 \\
\hline 1954 & 73.5 & 82.4 & $102 \cdot 2$ & 114.6 & 113.0 & 115.5 & 112.5 & 109.3 & 106.2 & 100.6 & 91.9 & 78.8 \\
\hline 1955 & 76.1 & 76.5 & 98.5 & 114.5 & 119.2 & 117.0 & 110.2 & 113.0 & 107.7 & 102.0 & 87.9 & 74.2 \\
\hline 1956 & 75.0 & 78.9 & 97.1 & 115.1 & 118.1 & 113.8 & 109.9 & 116.8 & 104.4 & 100.6 & 91.4 & 75.7 \\
\hline 1957 & 72.9 & 76.9 & 96.7 & 110.9 & 117.0 & 113.5 & 112.5 & 116.0 & 108.3 & 106.6 & 91.8 & 76.3 \\
\hline 1958 & 77.0 & 74.4 & 93.0 & 110.5 & 115.0 & 110.7 & 114.1 & 115.9 & 100.1 & 106.2 & 97.3 & 78.7 \\
\hline 1959 & 71.9 & 70.1 & 97.3 & 113.0 & 111.1 & 111.9 & 112.3 & 114.0 & 110.7 & 90.3 & & \\
\hline
\end{tabular}

10 MODIFIED RATIOSIORIGINAL/WTO 15-MO MOV AV

\begin{tabular}{|c|c|c|c|c|c|c|c|c|c|c|c|c|}
\hline YEAA & JAN & FEB & MAR & $\triangle P R$ & MaY & JUN & JUL & AUG & SEP & OCT & NOV & DEC \\
\hline $193 \%$ & 70.6 & 72.2 & 106.1 & 111.0 & 121.3 & 114.9 & 105.6 & 117.4 & 104.4 & 107.6 & 90.4 & 76.3 \\
\hline 1940 & 58.9 & 74.5 & 104.0 & 122.6 & 121.8 & 100.1 & 116.7 & 112.5 & 110.0 & 112.2 & 81.1 & 69.8 \\
\hline 1941 & 74.5 & 70.0 & 99.0 & 116.2 & 119.6 & $115 . \theta$ & 109.9 & 113.8 & 104.9 & 104.8 & 09.6 & 76.5 \\
\hline 1942 & 62.5 & 72.9 & 101.1 & 110.6 & 122.5 & 117.8 & 111.2 & 124.5 & 103.0 & 105.3 & 07.4 & 00.3 \\
\hline 1943 & 63.3 & 00.0 & 105.9 & 105.8 & 129.0 & 115.9 & 106.4 & 121.8 & 99.5 & 108.5 & 86.9 & 79.6 \\
\hline 1944 & 76.8 & 77.8 & 95.3 & 113.4 & 119.7 & 131.2 & 115.5 & 109.0 & 97.4 & 103.6 & 97.3 & 76.8 \\
\hline 1945 & 72.4 & 73.2 & 97.7 & 107.2 & 118.2 & 139.2 & 115.0 & 115.0 & 100.4 & 100.3 & 89.6 & 70.6 \\
\hline 1946 & 75.1 & 76.5 & 105.2 & 112.3 & 115.0 & 111.9 & 113.1 & 116.8 & 109.7 & 107.3 & 09.2 & $72 \cdot 2$ \\
\hline 1947 & 68.4 & 74.9 & 95.6 & 111.5 & 116.4 & 116.2 & 113.9 & 112.5 & 115.8 & 112.5 & 94.9 & 71.7 \\
\hline 1948 & $65 . \theta$ & 73.8 & 96.5 & 123.0 & 123.7 & 121.6 & 120.6 & 112.9 & 110.5 & 102.0 & 89.1 & 72.9 \\
\hline 1949 & 68.6 & 70.2 & 93.9 & 119.0 & 123.5 & $11 \theta .2$ & 114.4 & 112.4 & 110.0 & 105.3 & 92.1 & 73.0 \\
\hline 1950 & 71.5 & 73.5 & 100.7 & 111.0 & 121.1 & 119.2 & 118.2 & 120.6 & 105.9 & 105.8 & 00.3 & 78.0 \\
\hline 1951 & 71.8 & 80.5 & 99.5 & 107.4 & 118.5 & 112.3 & 100.3 & 109.3 & 116.5 & 107.7 & 86.8 & 71.0 \\
\hline 1952 & 72.7 & 67.1 & 105.6 & 111.4 & 115.2 & 109.6 & 113.2 & 107.7 & 100.5 & 107.9 & 09.5 & 73.5 \\
\hline 1953 & 74.2 & 80.3 & 104.4 & 167.1 & 116.0 & 113.8 & 109.4 & 106.1 & 107.0 & 104.8 & 92.4 & 73.9 \\
\hline 1954 & 73.5 & 82.4 & 102.2 & 114.6 & 113.0 & 115.5 & 112.5 & 109.3 & 100.2 & 100.6 & 91.9 & $7 \theta \cdot \theta$ \\
\hline 1955 & 70.1 & 76.5 & 98.5 & 114.5 & 119.2 & 117.0 & 110.2 & 113.0 & 107.7 & 102.0 & 87.9 & 74.2 \\
\hline 1956 & 75.0 & 78.9 & 97.1 & 115.1 & 118.1 & 113.8 & 109.9 & 116.8 & 104.4 & 106.0 & 91.4 & 75.7 \\
\hline 1957 & 72.9 & 76.9 & 96.7 & 110.0 & 117.0 & 113.5 & 112.5 & 116.0 & 100.3 & 106.6 & 01.8 & 76.3 \\
\hline 1958 & 77.0 & 74.4 & 93.0 & 110.5 & 115.0 & 110.7 & 114.1 & 115.9 & 100.1 & 106.2 & 97.3 & 78.7 \\
\hline 1959 & 71.9 & 78.1 & 97.3 & 113.0 & 111.1 & 111.9 & 112.3 & 114.8 & 110.7 & 98.5 & & \\
\hline
\end{tabular}

10m STABLE-SEASONAL ADJUSTMENT FACTORS

SERIES $\# 3694$ $\begin{array}{cccccccccccc}\text { JAN } & \text { FEB } & \text { MAR } & \text { APR } & \text { MAY } & \text { NUN } & \text { JUL } & \text { AUG } & \text { SEP } & \text { OCT } & \text { NOV } & \text { DEC } \\ 711 & 759 & 990 & 1133 & 1180 & 1106 & 1125 & 1142 & 1071 & 1055 & 902 & 750\end{array}$ 
IOB STABLE-SEASONAL ADJUSTED SERIES

SERIES A3694

\begin{tabular}{|c|c|c|c|c|c|c|c|c|c|c|c|c|}
\hline & & & & & & & & & & & & \\
\hline YEAR & JAN & FEB & MAR & APR & MAY & JUN & JUL & AUG & SEP & OCT & NOV & OEC \\
\hline 1939 & SOL & 468 & sos & 444 & 446 & 424 & 404 & 450 & 439 & 471 & 506 & 491 \\
\hline 1940 & 408 & 489 & 525 & 555 & 535 & 492 & 559 & 538 & 565 & 591 & 508 & 536 \\
\hline 1041 & 616 & 556 & 619 & 652 & 657 & 600 & 725 & 643 & 603 & 580 & 397 & 480 \\
\hline 1842 & 470 & 561 & 573 & 445 & 206 & 192 & 220 & 227 & 242 & 206 & 193 & 201 \\
\hline 1943 & 158 & 155 & 179 & 161 & 191 & 181 & 178 & 206 & 183 & 205 & 192 & 208 \\
\hline 1944 & 205 & 184 & 161 & 130 & 148 & 155 & 132 & 126 & 100 & 110 & 120 & 115 \\
\hline 1945 & 118 & 119 & 127 & 132 & 147 & 180 & 177 & 179 & 225 & 291 & 390 & 465 \\
\hline 1946 & 623 & 671 & 745 & 710 & 678 & 647 & 654 & 051 & 645 & 643 & 034 & 629 \\
\hline 1947 & 844 & 677 & 673 & 711 & 737 & 792 & 865 & 905 & 1048 & 1064 & 1050 & 936 \\
\hline 1948 & 886 & 773 & 918 & 1030 & 1002 & 994 & 999 & 894 & 902 & 818 & 016 & 791 \\
\hline 1049 & $7 \theta 2$ & 750 & 786 & 900 & 921 & 937 & 988 & 1015 & 1127 & 1130 & 1243 & 1232 \\
\hline 1950 & 1314 & 1302 & 1395 & 1391 & 1471 & 1476 & 1490 & 1448 & 1301 & 1147 & 1100 & 1257 \\
\hline 1951 & 1387 & 1209 & 1084 & 978 & 986 & 930 & 926 & 928 & 1008 & 1011 & 900 & 952 \\
\hline 1892 & 1037 & 1179 & 1099 & 1027 & 1020 & 997 & 1078 & 1024 & 1111 & 1128 & 1095 & 1081 \\
\hline 1953 & 1150 & 1167 & 1155 & 1138 & 1006 & 1050 & 1028 & 908 & 1032 & 1025 & 1063 & 1032 \\
\hline 1054 & 1098 & 1160 & 1120 & 1128 & 1085 & 1159 & 1204 & 1187 & 1271 & 1257 & 1375 & 1439 \\
\hline 1955 & 1474 & 1390 & 1357 & 1382 & 1364 & 6352 & 1300 & 1285 & 1273 & 1192 & 1176 & 1176 \\
\hline 1456 & 1243 & 1217 & 1129 & 2164 & 1120 & 1076 & 1056 & 2084 & 1010 & 1037 & 1024 & 1607 \\
\hline 1957 & 1014 & 997 & 954 & 968 & 979 & 973 & 1002 & 1018 & 1010 & 1086 & 1007 & 1000 \\
\hline 1958 & 1062 & 904 & 930 & 997 & 1024 & 1043 & 1158 & 1204 & 1243 & 1284 & 1424 & 1432 \\
\hline 1059 & 1419 & 1478 & 1420 & 2455 & 1348 & 1340 & 1356 & 1314 & 1310 & 1162 & & \\
\hline
\end{tabular}

11 CENTERED RATIOSIORIGINAL/WTO 15-MO MOV AV

\begin{tabular}{|c|c|c|c|c|c|c|c|c|c|c|c|c|}
\hline YEAR & JAN & $F E B$ & MAR & APR & MAY & JUN & JUL & AUG & SEP & OCT & NOV & DEC \\
\hline 1934 & $7 \dot{v} 4$ & 720 & 1058 & 1126 & 1200 & 1245 & 1053 & 1170 & 1041 & 1073 & Yo1 & 761 \\
\hline 1940 & 393 & 750 & 1047 & 1234 & 1226 & 1088 & 1175 & 1132 & 1107 & 1129 & B16 & 703 \\
\hline 2941 & 748 & 703 & 994 & 1167 & 1201 & 1163 & 1104 & 1143 & 1054 & 1053 & 900 & 768 \\
\hline 1942 & 025 & 730 & 1012 & 1107 & 1226 & 1170 & 1113 & 1246 & 1031 & 1054 & 675 & 004 \\
\hline 1943 & 037 & 695 & 1006 & 1065 & 1200 & 1167 & 1072 & 1227 & 1002 & 1093 & 875 & 002 \\
\hline 1944 & 759 & 760 & 942 & 2121 & 1183 & 1297 & 1142 & 1078 & 963 & 1024 & 902 & 739 \\
\hline 1045 & 725 & 733 & 978 & 1073 & 1183 & 2393 & $|15|$ & 1151 & 1005 & 1004 & 897 & 707 \\
\hline 1840 & 748 & 762 & 1048 & 1119 & 1140 & 1119 & 1127 & 1264 & 1093 & 1089 & 880 & 719 \\
\hline 1947 & 682 & 746 & 953 & 1111 & 1100 & 1158 & 1135 & 1121 & 1154 & 1121 & 946 & 714 \\
\hline 1048 & 651 & 730 & 955 & 1217 & 1224 & 1204 & 1194 & 1117 & 1094 & 1010 & 882 & 722 \\
\hline 1949 & 686 & 702 & 939 & 1189 & 1234 & 1181 & 1143 & 1123 & 1099 & 1052 & 921 & 730 \\
\hline 1450 & 712 & 731 & 1002 & 1105 & 1205 & 1186 & 1170 & 1200 & 1054 & 1053 & 799 & 776 \\
\hline 1951 & 724 & 812 & 1004 & 1083 & 1295 & 1133 & 1092 & 1103 & 1173 & 1080 & 876 & 710 \\
\hline 1092 & 726 & 870 & 1054 & 1112 & 1150 & 1094 & 1130 & 1075 & 1083 & 1077 & 694 & 734 \\
\hline 1053 & 742 & Bos & 1045 & 1172 & 1161 & 1239 & 1095 & 1082 & 1071 & 1049 & 924 & 739 \\
\hline 1954 & 735 & 824 & 1022 & 1646 & 1130 & 1155 & 1225 & 1093 & 1062 & 1000 & 919 & 788 \\
\hline 1455 & 763 & 707 & 988 & 1248 & 1295 & 1173 & 1103 & 1133 & 1080 & 1023 & 881 & 744 \\
\hline 1456 & 748 & 787 & 969 & 1148 & 1178 & 1135 & 1096 & 1205 & 1042 & 1064 & 912 & 755 \\
\hline 1057 & 720 & 700 & 967 & 1110 & 1171 & 1136 & 1120 & 2161 & 1084 & 1067 & 918 & 763 \\
\hline 1958 & 769 & 743 & 929 & 1104 & 1149 & 1100 & 1240 & 1158 & 1080 & 1081 & 972 & 786 \\
\hline 1059 & 722 & 784 & 977 & 1134 & 1115 & 1123 & 1127 & 1152 & 1111 & 989 & & \\
\hline
\end{tabular}




\section{PART THREE}

12 FINAL SEASONAL AOJ FACYORS, $3 * 5$ MO MOV AVS

\begin{tabular}{|c|c|c|c|c|c|c|c|c|c|c|c|c|}
\hline YEAR & JAN & FEB & MAR & APR & MAY & JUN & JUL & AUG & SEP & OCT & Nov & OEC \\
\hline 1939 & 60.8 & 72.7 & 103.2 & 115.9 & 121.5 & 113.8 & 111.2 & 116.5 & 106.2 & 108.2 & 88.9 & 75.2 \\
\hline 1940 & 66.8 & 72.3 & 103.1 & 115.1 & 122.0 & 114.3 & 110.9 & 117.1 & 105.6 & 108.0 & $\theta 8 . \theta$ & 75.9 \\
\hline 1941 & 66.7 & 72.5 & 102.5 & 114.3 & 122.5 & 115.7 & 111.2 & 117.4 & 104.6 & 107.6 & 08.6 & 76.5 \\
\hline 1942 & 67.8 & 72.5 & 101.5 & 112.7 & 122.6 & 118.9 & 111.4 & 117.3 & 103.0 & 106.6 & 09.1 & 76.8 \\
\hline 1943 & 69.0 & 73.1 & 100.7 & 111.4 & 121.8 & 121.6 & 112.0 & 116.9 & 102.0 & 105.3 & 89.6 & 76.4 \\
\hline 1944 & 70.3 & 73.5 & 100.2 & 110.0 & 120.7 & 123.2 & 112.1 & 116.3 & 102.4 & 105.2 & 90.5 & 75.5 \\
\hline 1905 & 70.7 & 74.2 & 99.4 & 110.8 & 19.4 & 123.0 & 113.2 & 114.9 & 104.1 & 105.2 & 91.0 & 74.1 \\
\hline 1946 & 70.7 & 74.6 & 98.2 & 112.3 & 118.8 & 122.3 & 114.2 & 113.7 & 100.5 & 105.3 & 91.2 & 72.8 \\
\hline 1947 & 70.2 & 73.9 & 97.6 & 113.9 & 118.7 & 120.4 & 113.2 & 113.3 & 108.3 & 105.3 & 90.3 & 72.5 \\
\hline 1948 & 69.5 & 73.0 & 97.5 & 114.4 & 119.6 & 110.4 & 115.1 & 113.8 & 110.1 & 105.9 & 89.3 & 72.7 \\
\hline 1949 & 69.6 & 74.9 & 98.0 & 114.3 & 120.0 & 116.7 & 115.0 & 113.4 & 110.5 & 106.0 & 88.2 & 73.3 \\
\hline 1950 & 70.3 & 76.6 & 99.0 & 113.8 & 119.0 & 116.0 & 114.1 & 112.3 & 110.4 & 106.1 & 68.1 & 73.5 \\
\hline 1951 & 71.5 & 70.7 & 100.8 & 113.2 & 118.6 & 114.9 & 113.3 & 111.4 & 109.5 & 205.8 & 88.0 & 74.2 \\
\hline 1952 & 72.8 & 80.2 & 101.9 & 112.9 & 117.4 & 114.2 & 112.0 & 110.4 & 109.3 & 105.5 & $8 \theta \cdot 8$ & 74.5 \\
\hline 1953 & 73.6 & 01.1 & 102.1 & 113.4 & 116.6 & 114.0 & 111.4 & 110.2 & 108.4 & 104.9 & 89.6 & 74.9 \\
\hline 1954 & 74.1 & 80.5 & 101.2 & 124.1 & 116.5 & 114.2 & 111.0 & 110.7 & 107.7 & 104.5 & 90.5 & 75.1 \\
\hline 1955 & 74.5 & 79.3 & 99.6 & 114.0 & 116.5 & 114.3 & 111.3 & 112.3 & 106.8 & 104.3 & 91.2 & 75.9 \\
\hline 1956 & 74.6 & 77.9 & 90.0 & 123.5 & 116.5 & 114.1 & 111.6 & 114.0 & 107.3 & 104.2 & 91.7 & 76.2 \\
\hline 1957 & 74.6 & 77.3 & 96.8 & 112.9 & 110.0 & 113.4 & 112.0 & 115.2 & 107.7 & 104.4 & 92.3 & 76.5 \\
\hline 1958 & 74.4 & 77.0 & 96.3 & 112.5 & 115.5 & 112.9 & 112.4 & 115.8 & 108.3 & 104.3 & 92.7 & 76.5 \\
\hline 1959 & 74.3 & 76.9 & 96.0 & 112.3 & 115.0 & 112.4 & 112.7 & 115.9 & 108.5 & 104.2 & & \\
\hline
\end{tabular}

ESTIMATEO SEASONAL FACTORS ONE YEAR AHEAD

SERIES \#3694 JAN FEB MAR

Ave
1959

1960

$12 A$ MONTHLY SEASONAL FACTORS AS PERCENT OF YEAR

\begin{tabular}{|c|c|c|c|c|c|c|c|c|c|c|c|c|}
\hline YEAR & JAN & FEB & MAR & APR & MAY & JUN & JUL & AUG & SEP & OCT & NOV & DEC \\
\hline 1939 & 5.6 & 0.1 & 0.6 & 9.7 & 10.1 & 9.5 & 9.3 & 9.7 & 0.0 & 9.0 & 7.4 & 6.3 \\
\hline 1940 & 5.6 & 0.0 & 8.6 & 9.6 & 10.2 & 9.5 & 9.2 & 9.8 & $\theta . \theta$ & 9.0 & 7.4 & 0.3 \\
\hline 1941 & 5.6 & 6.0 & 8.5 & 9.5 & 10.2 & 9.6 & 9.3 & 9.8 & 0.7 & 9.0 & 7.4 & 6.4 \\
\hline 1942 & 5.6 & 6.0 & 8.5 & 9.4 & 10.2 & 9.9 & 9.3 & $9 \cdot \theta$ & 8.6 & 0.9 & 7.4 & 6.4 \\
\hline 1943 & 5.7 & 0.1 & 0.4 & 9.3 & 10.1 & 10.1 & 9.3 & 9.7 & 0.5 & 0.8 & 7.5 & 6.4 \\
\hline 1944 & 5.0 & 6.1 & 8.3 & 9.2 & 10.1 & 10.3 & 9.3 & 9.7 & 0.5 & 8.0 & 7.5 & 6.3 \\
\hline 1945 & 3.9 & 6.2 & 8.3 & .0 .2 & 9.9 & 10.2 & 9.4 & 9.6 & 8.7 & 8.8 & 7.6 & 6.2 \\
\hline 1946 & 5.9 & 6.2 & 0.2 & 9.4 & 9.9 & 10.2 & 9.5 & 9.5 & 8.9 & $\theta, 8$ & 7.6 & 6.1 \\
\hline 1047 & 5.8 & 0.2 & 8.1 & 9.5 & 9.9 & 10.0 & 9.6 & 9.5 & 9.0 & $\theta . \theta$ & 7.5 & 6.0 \\
\hline 1948 & 5.8 & 6.1 & 0.1 & 9.5 & 10.0 & 9.9 & 9.6 & 9.5 & 9.2 & 8.8 & 7.4 & 6.1 \\
\hline 1949 & 5.8 & 6.2 & $B \cdot 2$ & 9.5 & 10.0 & 9.7 & 9.6 & 9.4 & 9.2 & 8.0 & 7.3 & 6.1 \\
\hline 1950 & 5.9 & 6.4 & 0.2 & 9.5 & 10.0 & 9.7 & 9.5 & 9.4 & 9.2 & $\theta .8$ & 7.3 & 0.1 \\
\hline 1951 & 6.0 & 6.6 & 0.4 & 9.4 & 9.9 & 9.6 & 9.4 & 9.3 & 9.1 & B. 8 & 7.3 & 6.2 \\
\hline 1952 & 6.1 & 6.7 & 0.5 & 9.4 & $9 . \theta$ & 9.5 & 9.3 & 0.2 & 9.1 & $0 . \theta$ & 7.4 & 6.2 \\
\hline 1953 & 0.1 & 6.8 & 0.5 & 9.4 & 9.7 & 9.5 & 9.3 & 9.2 & 9.0 & 6.7 & 7.5 & 6.2 \\
\hline 1954 & 6.2 & 6.7 & 8.4 & 9.5 & 9.7 & 9.5 & 9.2 & 9.2 & 9.0 & 0.7 & 7.5 & 6.3 \\
\hline 1955 & 6.2 & 0.6 & 0.3 & 9.5 & 9.7 & 9.5 & 9.3 & 9.4 & 8.9 & B.7 & 7.6 & 6.3 \\
\hline 1956 & 6.2 & 6.5 & 8.2 & 9.5 & 9.7 & 9.3 & 9.3 & 9.5 & 0.9 & 8.7 & 7.6 & 6.3 \\
\hline 1957 & 0.2 & 6.4 & a.1 & 9.4 & 9.7 & 9.4 & 0.3 & 9.6 & 9.0 & 0.7 & 7.7 & 6.4 \\
\hline 1958 & 6.2 & 0.4 & 8.0 & 9.4 & 9.6 & 9.4 & 9.4 & 9.6 & 9.0 & 0.7 & 7.7 & 6.4 \\
\hline & .2 & .4 & 1.0 & 9.4 & 9.6 & 9.4 & 9.4 & 9.7 & 0.0 & 0.7 & & \\
\hline
\end{tabular}

ESTIMATEO SEASONAL FACTORS ONE YEAR AHEAD

SERIES $\$ 3694$ JAN FEO MAR APR mar un
JUL AUG
NOV OEC
7.7 B.4

1960 
228 QUARTERLY SEASONAL FACTORS AS PCT OF YEAR

SERTES $\$ 3694$

\begin{tabular}{|c|c|c|c|c|c|c|c|c|c|c|c|c|}
\hline PEAR & JAN & FEB & MAR & $A P R$ & MAY & JUN & JUL & AUG & SEP & OCT & NOV & DEC \\
\hline 1939 & - & 20.3 & - & - & 29.3 & - & - & 27.8 & - & - & 22.7 & - \\
\hline 1940 & - & 20.2 & - & - & 29.3 & - & $=$ & 27.8 & - & - & 22.7 & - \\
\hline 1941 & - & 20.1 & - & - & 29.3 & - & - & 27.8 & n & - & 22.8 & - \\
\hline 1942 & - & 20.1 & - & - & 29.5 & - & - & 27.7 & $=$ & - & 22.7 & - \\
\hline 1943 & - & 20.2 & $=$ & - & 29.5 & - & - & 27.5 & - & - & 22.7 & - \\
\hline 1944 & - & 20.3 & - & - & 29.6 & - & - & 27.5 & - & - & 22.6 & - \\
\hline 1945 & - & 20.4 & - & - & 29.3 & - & - & 27.7 & - & - & 22.6 & - \\
\hline 2946 & - & 20.3 & $=$ & - & 29.5 & - & - & 27.9 & - & - & 22.5 & - \\
\hline 1947 & - & 20.1 & $=$ & - & 29.4 & - & - & 28.1 & 9 & - & 22.3 & - \\
\hline 1948 & - & 20.0 & - & - & 29.4 & - & $=$ & 28.3 & - & - & 22.3 & - \\
\hline 1949 & - & 20.2 & - & - & 29.2 & - & - & 28.2 & - & - & 22.2 & - \\
\hline 1950 & - & 20.5 & - & - & 29.2 & - & - & 28.1 & - & - & 22.2 & $=$ \\
\hline 1951 & - & 2100 & - & - & 28.9 & - & - & 27.8 & - & - & 22.3 & - \\
\hline 1952 & - & 21.3 & - & - & 28.7 & - & - & 27.6 & - & - & 22.4 & - \\
\hline 2953 & - & 21.4 & - & - & 28.0 & - & - & 27.5 & $v$ & - & 22.4 & - \\
\hline 1954 & - & 21.3 & - & - & 28.7 & - & - & 27.4 & $a$ & - & 22.5 & - \\
\hline 1955 & - & 21.1 & - & - & 28.7 & - & - & 27.6 & - & - & 22.6 & - \\
\hline 1936 & - & 20.9 & - & - & 28.7 & - & - & 27.7 & - & - & 22.6 & - \\
\hline 1957 & - & 20.7 & - & - & 28.5 & $=$ & - & 27.9 & - & - & $22 . \theta$ & - \\
\hline 1958 & - & 20.6 & - & - & 28.4 & - & - & 28.0 & - & - & 22.0 & - \\
\hline 1950 & - & 20.6 & - & - & 28.4 & - & $=$ & 28.1 & - & - & & \\
\hline
\end{tabular}

Estimated SEASONAL factors ONE YEAR AMEAD

SERIES 13694 JAN FEB MAR APR MAY JUN JUL AUG SEP OCT MOV DEC 1939

1960

13 FINAL SEASONALLY AOJUSTEO SERIES

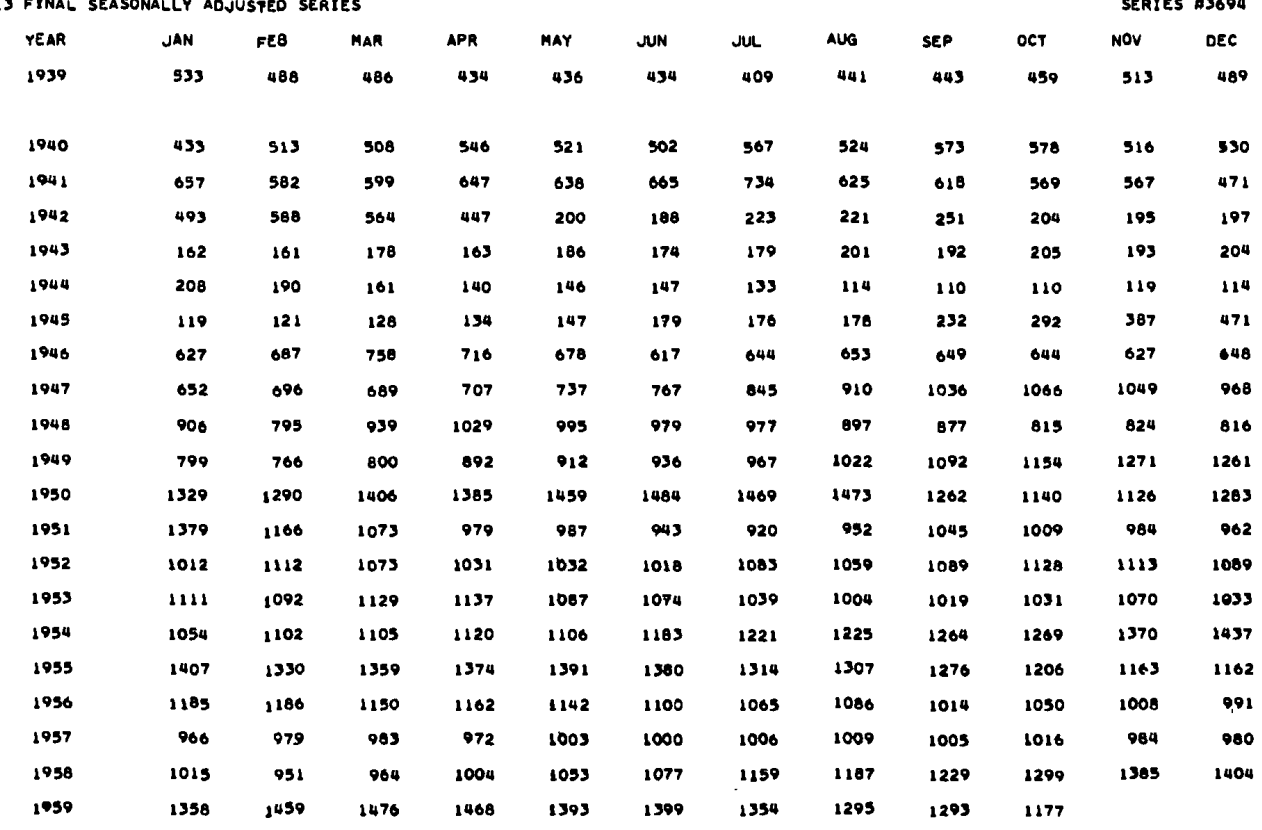


PART THREE

14 RATIOS, FINAL ADJ TO PRECEDING AND FOLLOWING

SERIES $\$ 3694$

\begin{tabular}{|c|c|c|c|c|c|c|c|c|c|c|c|c|}
\hline YEAR & JAN & FEB & MAR & $A P R$ & MAY & JUN & JUL & AUG & SEP & OCT & Nor & OEC \\
\hline 1934 & - & 95.8 & 105.4 & 94.1 & 100.5 & 102.7 & 93.5 & 103.5 & 98.4 & 96.0 & 108.2 & 103.4 \\
\hline 1940 & 86.4 & 109.0 & 95.9 & 106.1 & 99.4 & 92.3 & 110.5 & 91.9 & 104.0 & 106.2 & 93.1 & 90.4 \\
\hline 194. & 118.2 & 92.7 & 97.5 & 104.6 & 97.3 & 96.9 & 113.8 & 92.5 & 103.5 & 96.0 & 109.0 & 08.9 \\
\hline 1442 & 93.1 & 111.3 & 109.0 & 117.0 & 63.0 & 88.9 & 109.0 & 93.2 & 118.1 & 91.5 & 97.3 & 110.4 \\
\hline 1943 & 90.5 & 94.7 & 109.9 & 89.6 & 110.4 & 95.3 & 95.5 & 108.4 & 94.6 & 106.5 & 94.4 & 101.7 \\
\hline 1944 & 105.6 & 103.0 & 97.6 & 91.2 & 101.7 & 105.4 & 101.9 & 93.8 & $9 B .2$ & 96.1 & 106.3 & 95.8 \\
\hline 1945 & 101.3 & 98.0 & 100.4 & 97.5 & 93.9 & 110.8 & 98.6 & 87.3 & 98.7 & 94.3 & 101.4 & 92.9 \\
\hline 1946 & 108.3 & 99.2 & $108 \cdot 1$ & 99.7 & 101.7 & 93.3 & 101.4 & 101.0 & 100.1 & 100.9 & 97.1 & 101.3 \\
\hline 1947 & 97.0 & 103.8 & 98.2 & 99.2 & 100.0 & 97.0 & 100.8 & 96.8 & 104.9 & 102.3 & 103.1 & 99.0 \\
\hline 1948 & 102.8 & 86.2 & 103.0 & 106.4 & 99.1 & 99.3 & 104.2 & 96.8 & 102.5 & 95.8 & 101.0 & 100.0 \\
\hline 1949 & 101.0 & 95.0 & 90.5 & 104.2 & 99.8 & 99.6 & 98.8 & 99.3 & 100.4 & 97.7 & 105.3 & 97.0 \\
\hline 1950 & 104.2 & 94.3 & 105.1 & 96.7 & 101.7 & 101.4 & 99.4 & 107.9 & 96.6 & 95.5 & 92.9 & 102.4 \\
\hline 1951 & 112.6 & 95.1 & 100.0 & 95.0 & 102.7 & 98.9 & 97.1 & 96.9 & 106.6 & 99.5 & 99.8 & 96.4 \\
\hline 1952 & 97.6 & 106.7 & 100.1 & 98.0 & 100.7 & 90.3 & 104.3 & 97.5 & 99.6 & 102.5 & 100.4 & 97.9 \\
\hline 1953 & 101.9 & 97.5 & 101.3 & 102.6 & 98.3 & 101.0 & 100.0 & 97.6 & 100.1 & 98.7 & 103.7 & 97.3 \\
\hline 1954 & 98.7 & 102.1 & 99.5 & 101.3 & 96.0 & 101.7 & 101.4 & 98.6 & 101.4 & 96.4 & 101.3 & 103.5 \\
\hline 1455 & 101.7 & 96.2 & 100.5 & 99.9 & 101.0 & 102.0 & 97.8 & 100.9 & 101.6 & 98.9 & 98.2 & 99.0 \\
\hline 1956 & 100.9 & 101.6 & 98.0 & 101.4 & 101.0 & 99.7 & 97.4 & 104.5 & 94.9 & 103.9 & 98.8 & 100.4 \\
\hline 1957 & 98.1 & 100.5 & 100.8 & 97.9 & 101.7 & 99.6 & 100.1 & 100.3 & 99.3 & 102.2 & 98.0 & 98.0 \\
\hline 1958 & 105.1 & 96.1 & 98.6 & 99.6 & 101.2 & 97.4 & 102.4 & 99.4 & 98.9 & 99.4 & 102.5 & 102.4 \\
\hline 1959 & 94.9 & 103.0 & 100.9 & 102.3 & 97.2 & 101.9 & 100.5 & 97.8 & 104.6 & & & \\
\hline
\end{tabular}

AVERAGES

$\begin{array}{clcccccccccc}\text { JAN } & \text { FEB } & \text { MAR } & \text { APR } & \text { MAY } & \text { JUN } & \text { JUL } & \text { AUG } & \text { SEP } & \text { OCT } & \text { NOV } & \text { DEC } \\ 101.0 & 99.2 & 101.3 & 100.2 & 98.5 & 99.1 & 101.4 & 98.4 & 101.3 & 99.0 & 100.6 & 98.9\end{array}$

15 UNCENTERED 12-MO MOVING AVERAGE FINAL ADJ

SERIES H 3694

\begin{tabular}{|c|c|c|c|c|c|c|c|c|c|c|c|c|}
\hline YEAR & JAN & FEQ & MAR & $A P R$ & MAY & JUN & JUL & AUG & SEP & OCT & NOV & OEC \\
\hline 1937 & - & - & - & - & - & 464 & 435 & 457 & 459 & 469 & 476 & 481 \\
\hline 1940 & 495 & 501 & 512 & 522 & 522 & 526 & 545 & 550 & 558 & 566 & 576 & 590 \\
\hline 1041 & 604 & 612 & 016 & 615 & 619 & 614 & 601 & 601 & 598 & 582 & 545 & 505 \\
\hline 1942 & 463 & 429 & 398 & 368 & 337 & 314 & 287 & 251 & 219 & 195 & 194 & 193 \\
\hline 1943 & 189 & 188 & 183 & 183 & 183 & 183 & 187 & 189 & 188 & 186 & 103 & 180 \\
\hline 1944 & 177 & 169 & 163 & 155 & 148 & 141 & 134 & 128 & 125 & 125 & 125 & 127 \\
\hline 1945 & 131 & 136 & 146 & 162 & 184 & 214 & 256 & 303 & 356 & 404 & 448 & 485 \\
\hline 1946 & 524 & 563 & 598 & 628 & 648 & 662 & 664 & 605 & 659 & 659 & 664 & 676 \\
\hline 1947 & 693 & 714 & 746 & 782 & 817 & 843 & 065 & 873 & 894 & 921 & 942 & 960 \\
\hline 1948 & 971 & 970 & 956 & 935 & 917 & 904 & 895 & 893 & 881 & B70 & 063 & 659 \\
\hline 1940 & 858 & 869 & 887 & 915 & 952 & 989 & 1033 & 1077 & 1128 & 1169 & 1214 & 1260 \\
\hline 1950 & 1302 & 1339 & 1354 & 1332 & 1340 & 1342 & 1346 & 1336 & 1308 & 1274 & 1233 & 1190 \\
\hline 1951 & 1144 & 1101 & 1083 & 1072 & 1000 & 1033 & 1003 & 998 & 998 & 1002 & 1006 & 1012 \\
\hline 1052 & 1026 & 1035 & 1039 & 1049 & 1059 & 1070 & 1078 & 1076 & 1081 & 1090 & 1095 & 1099 \\
\hline 1953 & 1096 & 1091 & 1085 & 1077 & 1073 & 1089 & 1064 & 1065 & 1003 & 1061 & 1083 & 1072 \\
\hline 1954 & 1087 & 1106 & 1126 & 1146 & 1171 & 1205 & 1234 & 1253 & 1274 & 1293 & 1319 & 1336 \\
\hline 1955 & 1343 & 1350 & 1351 & 1346 & 1329 & 1306 & 1287 & 1275 & 1258 & 1240 & 1219 & 1196 \\
\hline 1956 & 1175 & 1157 & 1135 & 1122 & 1109 & 1095 & 1077 & 1059 & 1045 & 1030 & 1018 & 1010 \\
\hline 1957 & 1005 & 998 & 998 & 993 & 993 & 992 & 996 & 994 & 992 & 995 & 999 & 1005 \\
\hline 1858 & 1018 & 1033 & 1052 & 1075 & 1109 & 1144 & 1172 & 1215 & 1257 & 1296 & 1324 & 1351 \\
\hline & & 377 & 1382 & & & & & & & & & \\
\hline
\end{tabular}




\section{AIDS TO THE CURRENT USE OF INDICATORS}

16 RATIOS, 12-MO MOV AYS, FINAL AOJ TO ORIGINAL

SERIES 3694

\begin{tabular}{|c|c|c|c|c|c|c|c|c|c|c|c|c|}
\hline YEAR & JAN & FEB & MAR & APR & MaY & JUN & JUL & AUG & SEP & OCT & NOV & OEC \\
\hline 1934 & - & - & - & - & - & 101.3 & 100.4 & 100.7 & 100.7 & 100.6 & liv̄. 2 & 99.8 \\
\hline 1940 & 99.8 & 99.2 & 99.2 & 99.1 & 99.1 & 99.2 & 100.6 & 100.7 & 100.7 & 100.5 & 100.2 & 99.8 \\
\hline 1941 & 99.5 & 99.2 & 99.4 & 99.4 & 99.4 & 99.2 & 98.4 & 98.4 & 98.4 & 99.0 & $100 \cdot 4$ & 101.4 \\
\hline 1942 & 102.7 & 104.4 & 105.0 & 106.4 & 106.0 & 104.3 & 101.4 & 97.7 & 97.8 & 99.0 & 99.0 & 99.0 \\
\hline 1943 & 99.0 & 99.5 & 100.0 & 100.0 & 100.0 & 99.3 & 100.0 & 200.3 & 100.5 & 100.5 & 101.7 & 101.1 \\
\hline 1944 & 101.7 & 102.4 & 103.2 & 103.3 & 102.8 & 101.4 & 100.8 & 99.2 & 99.2 & 99.2 & 99.2 & 98.4 \\
\hline 1945 & 98.5 & 97.8 & 97.9 & 97.6 & 98.9 & 102.9 & 107.6 & 111.0 & 109.9 & 106.6 & 103.9 & 101.9 \\
\hline 1946 & 100.6 & 99.5 & 99.2 & 99.1 & 99.4 & 99.8 & 100.0 & 100.2 & 100.2 & 100.2 & 100.0 & 99.7 \\
\hline 1947 & 99.3 & 98.9 & 98.4 & 98.4 & 98.9 & 99.6 & 100.6 & 100.8 & 100.9 & 100,4 & 90.8 & 99.7 \\
\hline 1948 & 99.5 & 99.5 & 90.4 & 99.5 & 99.3 & 99.0 & 98.7 & 98.6 & 98.4 & 98.6 & 98.7 & 98.8 \\
\hline 1949 & 98.8 & 98.9 & 98.7 & 98.5 & 99.1 & 100.0 & 101.3 & 102.1 & 102.1 & 101.5 & 100.7 & 100.1 \\
\hline 1950 & 99.7 & 99.4 & 99.4 & 99.3 & 99.2 & 99.3 & 99.2 & 98.9 & 98.7 & 99.1 & 99.8 & 100.4 \\
\hline 1951 & 101.1 & 101.8 & 102.0 & 102.1 & 102.0 & 102.3 & 100.4 & 100.1 & 100.0 & 99.9 & 100.0 & 99.9 \\
\hline 1952 & 99.9 & 99.9 & 99.9 & 99.9 & 99.9 & 100.2 & 100.3 & 100.1 & 100.1 & 100.0 & 100.0 & 99.9 \\
\hline 2953 & 100.1 & 100.1 & 100.2 & 100.3 & 100.2 & 100.1 & 99.9 & 100.0 & 100.1 & 100.0 & 100.0 & 99.8 \\
\hline 1954 & 99.7 & 99.5 & 99.3 & 99.4 & 99.6 & 100.2 & 100.8 & 101.2 & 101.3 & 101.0 & 100.8 & 100.6 \\
\hline 1955 & 100.4 & 100.3 & 100,3 & 100.4 & 100.2 & 99.7 & 99.3 & 99.2 & 99.4 & 99.5 & 99.8 & 100.2 \\
\hline 1950 & 100.3 & 100.4 & 100.5 & 100.5 & 100.5 & 100.1 & 99.7 & 99.3 & 99.3 & 99.7 & 99.9 & 100.1 \\
\hline 1957 & 100.1 & 100.0 & 100.1 & 100.0 & 100.0 & 99.9 & 100.0 & 100.0 & 100.0 & 100.1 & 100.0 & 99.9 \\
\hline 1958 & 99.8 & 99.5 & 99.3 & 99.3 & 99.5 & 100.2 & 100.8 & 101.7 & 101.7 & 101.3 & 101.0 & 100.7 \\
\hline 1959 & 100.6 & 100.3 & 100.4 & 100.5 & - & - & - & - & - & - & & \\
\hline
\end{tabular}

17 RATIOS. EACH MO TO PREEEOING JAN, FINAL AOJ

SERIES $\# 3694$

\begin{tabular}{|c|c|c|c|c|c|c|c|c|c|c|c|c|}
\hline YEAR & JAN & FEB & MAR & APR & MAY & JUN & JUL & AUG & SEP & OCT & NOY & OEC \\
\hline 1939 & - & 916 & 912 & 814 & 828 & 814 & 767 & 827 & 831 & 861 & 962 & 917 \\
\hline 1940 & 812 & 1185 & 1173 & 1261 & 1203 & 1239 & 1309 & 1210 & 1323 & 1335 & 1192 & 1224 \\
\hline 1941 & 1517 & 886 & 912 & 985 & 971 & 1012 & 1117 & 991 & 941 & 866 & 863 & 717 \\
\hline 2042 & 730 & 1193 & 2144 & 907 & 400 & 381 & 452 & 448 & 509 & 414 & 396 & 400 \\
\hline 1943 & 329 & 994 & 1099 & 1006 & 1248 & 1074 & 1105 & 1241 & 1185 & 1265 & 1191 & 1250 \\
\hline 1944 & 1284 & 913 & 774 & 673 & 702 & 707 & 639 & 348 & 529 & 329 & 572 & 548 \\
\hline 1945 & 372 & 1017 & 1076 & 1126 & 1233 & 1504 & 2479 & 1496 & 1950 & 2434 & 3252 & 3950 \\
\hline 1946 & 3269 & 1096 & 1209 & 1142 & 1081 & 984 & 1027 & 1041 & 1035 & 1027 & 1000 & 1033 \\
\hline 1947 & 1040 & 1067 & 1057 & 1084 & 1130 & 1170 & 1290 & 1396 & 1589 & 1635 & 1609 & 1485 \\
\hline 1948 & 1390 & 877 & 1036 & 1136 & 1098 & 1081 & 1078 & 990 & 968 & 900 & 909 & 901 \\
\hline 1949 & 882 & 959 & 1002 & 1116 & 2242 & 2171 & 1210 & 1279 & 1367 & 1444 & 1591 & 1578 \\
\hline 1950 & 2663 & 971 & 1058 & 1042 & 1098 & 1117 & 1105 & 1108 & 950 & 658 & 847 & 965 \\
\hline 1931 & 1038 & 840 & 778 & 710 & 716 & 684 & 667 & 690 & 758 & 732 & 714 & 698 \\
\hline 1952 & 734 & 1099 & 1060 & 1019 & 1020 & 1006 & 1070 & 1046 & 1076 & 1115 & 1100 & 1076 \\
\hline 1953 & 1098 & 983 & 1016 & 1023 & 978 & 967 & 935 & 904 & 917 & 928 & 963 & 930 \\
\hline 1954 & 949 & 1046 & 1048 & 1063 & 1049 & 1122 & 1158 & 1162 & 1199 & 1204 & 1300 & 1363 \\
\hline 1955 & 1335 & 945 & 906 & 977 & 989 & 981 & 934 & 929 & 907 & 857 & 827 & 826 \\
\hline 1956 & 842 & 1001 & 970 & 981 & 964 & 928 & 899 & 916 & 850 & 886 & 651 & 836 \\
\hline 1957 & 815 & 1013 & 1018 & 1006 & 1038 & 1035 & 1041 & 1045 & 1040 & 1052 & 1019 & 1014 \\
\hline 1958 & 1051 & 937 & 950 & 989 & 1037 & 1061 & 1142 & 1169 & 1211 & 1280 & 1365 & 1383 \\
\hline 1959 & 1338 & 1074 & 1087 & 1081 & 1020 & 1030 & 997 & 954 & 992 & 867 & & \\
\hline
\end{tabular}




\section{PART THREE}

18 WEIGHTED 1S-MO MOVING AVERAGE OF FINAL ADJ

SERIES M3694

\begin{tabular}{|c|c|c|c|c|c|c|c|c|c|c|c|c|}
\hline YEAR & JAN & FEB & MAR & APR & MaY & JUN & JUL & AUG & SEP & OCT & NOY & DEC \\
\hline 1939 & 496 & 487 & 473 & 455 & 430 & 430 & 429 & 437 & 440 & 462 & 472 & 481 \\
\hline 1940 & 490 & 498 & 508 & 517 & 527 & 534 & 540 & 345 & 548 & S53 & $\$ 61$ & B70 \\
\hline 1941 & 583 & 601 & 621 & 640 & 658 & 667 & 663 & 644 & 624 & 583 & 559 & 546 \\
\hline 1942 & 534 & 508 & 401 & 393 & 320 & 250 & 221 & 207 & 205 & 205 & 199 & 180 \\
\hline 1943 & 177 & 170 & 168 & 170 & 175 & $1 \theta 0$ & 206 & 191 & 197 & 201 & 203 & 200 \\
\hline 1944 & 193 & 283 & 170 & 157 & 245 & 136 & 127 & 121 & 116 & 123 & 112 & 114 \\
\hline 1945 & 117 & 122 & 129 & 136 & 145 & 156 & 172 & 200 & 246 & 314 & 402 & 500 \\
\hline 1046 & 591 & 861 & 699 & 706 & 692 & 671 & 652 & 641 & 638 & 638 & 642 & 649 \\
\hline 1947 & 650 & 671 & 687 & 711 & 747 & 800 & 865 & 933 & 985 & 1000 & 1000 & 971 \\
\hline 1948 & 942 & 929 & 936 & 956 & 973 & 973 & 952 & 918 & 878 & 842 & 815 & 199 \\
\hline 1949 & 794 & 804 & 025 & 856 & 893 & 936 & 984 & 1030 & 1099 & 1261 & 1219 & 1268 \\
\hline 1050 & 1309 & 1348 & 1386 & 1425 & 1452 & 2454 & 1426 & 1372 & 1313 & 1265 & 2238 & 1223 \\
\hline 1951 & 1203 & 1163 & 1103 & 1037 & 984 & 955 & 951 & 981 & 976 & 990 & 2003 & 1016 \\
\hline 1952 & 1030 & 1042 & 1048 & 1049 & 1048 & 1050 & 1059 & 1073 & 1088 & 1100 & 1107 & 1110 \\
\hline 1953 & 1213 & 1125 & 1213 & 1105 & 1089 & 1068 & 1047 & 1032 & 1026 & 1029 & 1039 & 1052 \\
\hline 1954 & 1086 & 1082 & 1099 & 1119 & 1142 & 1160 & 1199 & 1235 & 1273 & 1315 & 1349 & 1372 \\
\hline 1955 & 1384 & 1386 & 1382 & 1377 & 1369 & 1355 & 1331 & 1297 & 1258 & 1222 & 1195 & 1179 \\
\hline 1956 & 1171 & 1167 & 1261 & 1148 & 1230 & 1100 & 1083 & 2063 & 1043 & 1024 & 1007 & 993 \\
\hline 1957 & 982 & 978 & 979 & 984 & 992 & 999 & 1005 & 1007 & 1006 & 1001 & 994 & 085 \\
\hline 1958 & 977 & 977 & 987 & 1009 & 1043 & 1088 & 1130 & 2194 & 1249 & 1302 & 1348 & 1389 \\
\hline 1959 & 1421 & 2442 & 1440 & 1442 & 1420 & 1386 & 1345 & 1300 & 1276 & 1200 & & \\
\hline
\end{tabular}

19 PERCENT CHANGe fRom PRECEDING Mo, ORIgINAL

SERIES M 3694

\begin{tabular}{|c|c|c|c|c|c|c|c|c|c|c|c|c|}
\hline YEAR & JAN & FEB & MAR & APR & MAY & JUN & JUL & Avs & SEP & OCT & NOV & DEC \\
\hline 1930 & •. & . & 41.4 & .2 & 5.4 & $=6.8$ & -7.9 & 13.0 & $=8.6$ & 3.7 & $=8.2$ & -19.3 \\
\hline 1940 & -21.5 & 28.4 & 41.2 & 20.0 & 1.1 & -9.7 & 9.6 & -2.4 & -1.5 & 3.1 & -26.6 & -12.2 \\
\hline 1941 & 9.0 & -3.7 & 45.5 & 20.4 & 3.7 & -1.5 & 6.1 & -10.0 & -12.0 & -5.3 & -18.0 & -28.3 \\
\hline 1942 & -7.2 & 27.5 & 34.3 & -11.9 & -51.4 & -8.6 & 10.7 & 4.4 & .0 & -16.2 & -19.8 & -13.2 \\
\hline 1943 & -25.8 & 5.4 & 91.7 & 1.7 & 24.7 & $=7.0$ & -3.2 & 17.5 & -16.6 & 10.2 & -19.9 & -9.8 \\
\hline 1944 & -6.4 & $=4.1$ & 15.0 & -4.3 & 14.3 & 2.8 & $=17.7$ & -10.7 & -15.0 & 2.7 & -6.9 & -20.4 \\
\hline 1945 & -2.3 & 7.1 & 41.1 & 17.3 & 17.4 & 25.7 & -9.5 & 2.5 & 18.1 & 27.4 & 14.7 & $=09$ \\
\hline 1946 & 26.9 & 14.9 & 46.2 & 0.1 & .1 & -6.3 & $-2,4$ & 1.0 & -7.0 & -1.9 & -15.6 & -17.5 \\
\hline 1947 & -3.0 & 12.2 & 30.7 & 19.8 & 0.7 & 5.6 & 5.3 & 6.2 & 0.6 & .0 & -15.6 & -28.0 \\
\hline 1948 & -10.3 & -6.8 & 56.0 & 20.5 & 1.1 & -2.6 & -3.0 & -0.2 & -5.4 & -10.7 & -14.7 & -19.4 \\
\hline 1949 & -6.2 & 3.2 & 36.6 & 30.1 & 7.3 & .2 & 1.8 & 4.2 & 4.1 & 1.3 & -0.3 & -17.6 \\
\hline 1950 & 1.1 & 5.6 & 40.9 & 13.2 & 10.9 & -1.5 & -2.6 & -1.3 & -15.8 & -13.1 & -28.0 & - 4.9 \\
\hline 1951 & 4.6 & -6.9 & 17.9 & 2.4 & 5.7 & $=7.4$ & -3.9 & 1.7 & 7.9 & $=6.7$ & -18.8 & -17.6 \\
\hline 1952 & 3.2 & 21.0 & 22.5 & 0.5 & 4.1 & -4.0 & $4 \cdot 3$ & -3.6 & 1.0 & .0 & -17.0 & -17.9 \\
\hline 1953 & $\cdot 9$ & 8.3 & 30.1 & 11.8 & $=1.7$ & -3.4 & $=5.5$ & $=4.4$ & .1 & -2.2 & -11.3 & -10.3 \\
\hline 1954 & .9 & 13.6 & 26.0 & 14.3 & $\bullet 9$ & 4.8 & $\cdot 3$ & $\cdot 1$ & .4 & -2.6 & -6.5 & -13.0 \\
\hline 1955 & -2.9 & .7 & 28.3 & 15.7 & 3.5 & $=2.7$ & -7.2 & .3 & -7.2 & $=7.7$ & -15.7 & -16.9 \\
\hline 1956 & .2 & 4.5 & 22.0 & 17.0 & $\cdot 8$ & -3.6 & -5.3 & 4.2 & -12.1 & .6 & -15.5 & -18.3 \\
\hline 1957 & -4.5 & 5.0 & 25.8 & 15.2 & 6.0 & -2.5 & .6 & 3.1 & -6.9 & -1.9 & -14.4 & -17.4 \\
\hline 1958 & .7 & -3.0 & 26.8 & 21.8 & 7.6 & .0 & 7.2 & 5.5 & -3.2 & 1.0 & -5.2 & -16.4 \\
\hline 1959 & -0.1 & 21.2 & 26.3 & 16.4 & 2.9 & -1.8 & -3.0 & -1.6 & -6.5 & -12.6 & & \\
\hline
\end{tabular}


20 PERCENT CMANGe from PReCEOING MO, SEASONAL

SERIES \#3694

\begin{tabular}{|c|c|c|c|c|c|c|c|c|c|c|c|c|}
\hline YEAR & JAN & PEB & MAR & APR & MAY & UN & JUL & AUs & SEP & OCT & Nov & DEC \\
\hline 1939 & $\bullet$ & 0.8 & 42.0 & 12.3 & 4.6 & -0.3 & -2.3 & 4.8 & -8.8 & 1.0 & -17.8 & -15.4 \\
\hline 1940 & $=11.2$ & 8.2 & 42.6 & 21.6 & 0.0 & -0.3 & -3.0 & 5.6 & -9.8 & 2.3 & -17.8 & -14.5 \\
\hline 1941 & -12.1 & 8.7 & 41.4 & 21.9 & 7.2 & -5.6 & -3.9 & 3.6 & -10.0 & 2.9 & -17.7 & -13.7 \\
\hline 1942 & -11.4 & 6.9 & 40.0 & 11.0 & 8.8 & -3.0 & -6.3 & 3.3 & -12.2 & 3.3 & -16.4 & -13.8 \\
\hline 1943 & -10.2 & 5.9 & 37.8 & 10.0 & 9.3 & $-\quad .2$ & -7.9 & 4.4 & -12.7 & 3.4 & -15.2 & -24.7 \\
\hline 1944 & -0.0 & 4.6 & 36.3 & 9.8 & 9.7 & 2.1 & -9.0 & 3.7 & -12.0 & 2.7 & -24.0 & -16.6 \\
\hline 2945 & -6.4 & 5.0 & 34.0 & 11.5 & 7.8 & 3.0 & -8.0 & 1.5 & -0.4 & 1.1 & -13.5 & -18.6 \\
\hline 1946 & -4.6 & 4.8 & 32.5 & 14.4 & 5.8 & 2.9 & $=6.0$ & $-\quad .4$ & -6.3 & -2.1 & $=13.4$ & -20.2 \\
\hline 1947 & -3.6 & 5.3 & 32.1 & 16.7 & 4.2 & 1.4 & -4.3 & -1.5 & -4.6 & -2.8 & -14.2 & -19.7 \\
\hline 1948 & -4.1 & 6.2 & 32.1 & 27.3 & 4.5 & -1.0 & -2.0 & -1.1 & -3.3 & -3.8 & -13.7 & -18.6 \\
\hline 1949 & -4.3 & 7.6 & 30.8 & 16.6 & 5.0 & -2.0 & -1.5 & -1.4 & -2.6 & -4.1 & -16.8 & -16.0 \\
\hline 1950 & -4.1 & 9.0 & 29.2 & 14.9 & 9.3 & -3.2 & -2.0 & -1.6 & -1.7 & -3.9 & -17.0 & -10.6 \\
\hline 1951 & -2.7 & 10.1 & 28.1 & 12.3 & 4.8 & -3.1 & -2.4 & -1.7 & -1.7 & -3.4 & -16.8 & -15.7 \\
\hline 1952 & -1.0 & 10.2 & 27.1 & 10.8 & 4.0 & -2.7 & -1.9 & -1.4 & -1.0 & -3.5 & -13.8 & -16.1 \\
\hline 1853 & -2.2 & 10.2 & 25.0 & 21.1 & 2.8 & -2.2 & -2.3 & -1.1 & -1.6 & -3.2 & -14.6 & -16.4 \\
\hline 1954 & -1.1 & 8.6 & 25.7 & 12.7 & 2.1 & -2.0 & -2.8 & $-\quad .3$ & -2.7 & -3.0 & -13.4 & -17.0 \\
\hline 1953 & $-\quad .8$ & 6.4 & 25.6 & 24.5 & 2.2 & -1.9 & -2.6 & .9 & -4.9 & -2.3 & -12.0 & -16.8 \\
\hline 1956 & -1.7 & 4.4 & 23.8 & 15.8 & 2.6 & -2.1 & -2.2 & 2.2 & -5.9 & -2.0 & -12.0 & -16.0 \\
\hline 2957 & -2.1 & 3.6 & 25.2 & 10.6 & 2.7 & -2.2 & -1.2 & 2.0 & -6.5 & -3.1 & -11.6 & -27.1 \\
\hline 1938 & -2.7 & 3.5 & 23.1 & 16.8 & 2.7 & -2.3 & $-\quad .4$ & 3.0 & -6.5 & -3.7 & -11.1 & -17.5 \\
\hline 1050 & -2.8 & 3.5 & 24.8 & 17.0 & 2.4 & -2.3 & .3 & 2.8 & -6.4 & -4.0 & & \\
\hline
\end{tabular}

21 percent change from paeceoing mo, final adJ

SERIES "9694

\begin{tabular}{|c|c|c|c|c|c|c|c|c|c|c|c|c|}
\hline EAR & JAN & FEB & MAR & $\triangle P P R$ & MAY & WN & JUL & AUG & SEP & OCT & NOV & DEC \\
\hline 939 & .. & -8.4 & -.4 & -10.7 & . & .5 & -5.8 & 7.8 & .5 & 3.6 & 11.0 & -4.7 \\
\hline 940 & -11.5 & 18.5 & -1.0 & 7.5 & -4.6 & -3.6 & 12.9 & -7.6 & 9.4 & .9 & -10.7 & 2. \\
\hline 1941 & 24.0 & -11.4 & 2.9 & 0.0 & -1.4 & 4.2 & 10.4 & -14.9 & -1.1 & -7.9 & -.4 & -10. \\
\hline 1942 & 4.7 & 10.3 & -4.1 & -20.7 & -85.3 & -6.0 & 18.6 & $-\quad \cdot \bullet$ & 13.6 & -18.7 & -4.4 & 2.0 \\
\hline 1043 & -17.0 & -.0 & 10.6 & -8.4 & 14.1 & -6.5 & 2.0 & 12.3 & -4.5 & 6.8 & -3.0 & 3. \\
\hline 2944 & 2.0 & -0.7 & -15.3 & -13.0 & 4.3 & .7 & -0.5 & -14.3 & -3.5 & .0 & 0.2 & \\
\hline 1045 & 0.4 & 1.7 & 9.8 & 4.7 & 0.7 & 21.8 & -1.7 & 1.1 & 30.3 & 25.0 & 32.5 & 21. \\
\hline 1946 & 33.1 & 9.6 & 10.3 & -5.5 & -5.3 & -9.0 & 4.4 & 1.4 & -.6 & -.8 & -2.6 & 3. \\
\hline 1947 & .6 & 0.7 & -1.0 & 2.6 & 4.2 & 4.1 & 10.2 & 7.7 & 13.8 & 2.0 & -1.0 & - \\
\hline 1948 & -6.4 & -12.3 & 18.1 & 9.6 & -3.3 & -1.6 & $-\quad .2$ & -8.2 & -2.2 & -7.1 & 1.1 & - \\
\hline 1940 & -2.1 & -4.1 & $4 \cdot 4$ & 21.5 & 2.2 & 2.6 & 3.3 & 5.7 & 0.8 & 3.7 & 10.1 & \\
\hline 1950 & 5.4 & -2.0 & 9.0 & -1.5 & 3.3 & 1.7 & -1.0 & .3 & -14.3 & -0.7 & -1.2 & \\
\hline 1991 & 7.5 & -15.4 & -8.0 & -8.8 & .0 & -4.5 & -2.4 & 3.5 & 9.8 & -3.4 & -2.5 & - \\
\hline 1952 & 3.2 & 9.9 & -3.5 & -3.9 & .1 & $=1.4$ & 6.4 & -2.2 & 2.8 & 3.6 & -1.3 & - \\
\hline 1853 & 2.0 & -1.7 & 3.4 & .7 & -4.4 & -1.2 & -3.3 & -3.4 & 1.5 & 1.2 & 3.8 & -3. \\
\hline 1954 & 2.0 & 4.6 & .3 & 1.4 & -1.3 & 7.0 & 3.2 & . & 3.2 & .4 & 0.0 & 40 \\
\hline 1053 & -2.1 & -5.5 & 2.2 & 1.1 & 1.2 & - & -4.8 & .3 & -2.4 & -3.5 & -3.0 & \\
\hline 1956 & 2.0 & .1 & -3.0 & 1.0 & -1.7 & -3.7 & -3.2 & 2.0 & -6.6 & 3.6 & -4.0 & - \\
\hline 957 & -2.5 & 1.3 & .4 & -2.1 & 3.2 & $-\quad .3$ & .6 & .3 & -.4 & 1.1 & -3.1 & 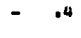 \\
\hline 95 & 3.6 & -0.3 & 1.4 & 4.1 & 4.9 & 2.3 & 7.6 & 2.4 & 3.5 & 5.7 & 0.0 & \\
\hline 230 & 3.3 & 7.4 & 2.2 & .5 & 5.1 & .4 & 3.2 & 4.4 & .2 & -0.0 & & \\
\hline
\end{tabular}


22 PERCENT CHANGE FROM PRECEDING MO, S-I RATIOS

\begin{tabular}{|c|c|c|c|c|c|c|c|c|c|c|c|c|}
\hline YEAR & JAN & FEB & MAR & APR & MAY & JUN & JUL & AUG & SEP & OCT & NOV & DEC \\
\hline 1930 & 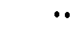 & 2.3 & 47.0 & 4.6 & 9.3 & -5.3 & -8.1 & 11.2 & -11.1 & 3.1 & -10.4 & -20.9 \\
\hline 1940 & -22.8 & 26.5 & 39.6 & 17.9 & .7 & -11.2 & 8.0 & -3.6 & -2.2 & $2 \cdot 0$ & -27.7 & -13.9 \\
\hline 1941 & 6.7 & $=6.0$ & 41.4 & 17.4 & 2.9 & -3.2 & 6.5 & -7.7 & -7.8 & $\cdot 1$ & -14.5 & -26.6 \\
\hline 1942 & -5.0 & 33.9 & 48.3 & 3.3 & -40.2 & 12.9 & 28.6 & 12.0 & .5 & -15.0 & -17.0 & $=8.1$ \\
\hline 1943 & -21.2 & 9.0 & 53.5 & $\cdot 1$ & 21.9 & -10.2 & -0.2 & 14.5 & -18.3 & 9.0 & -19.9 & -8.4 \\
\hline 1944 & -3.5 & 1.3 & 22.5 & 2.3 & 22.8 & 9.6 & $=12.0$ & -5.0 & -10.6 & 6.4 & -0.1 & -21.1 \\
\hline 1945 & -5.7 & 1.1 & 33.5 & 9.7 & 10.3 & 17.8 & +17.4 & -10.4 & -2.5 & .1 & -10.7 & -21.2 \\
\hline 1946 & 6.4 & 1.9 & 37.5 & 6.7 & 2.4 & -2.7 & 1.1 & 3.3 & $=0.1$ & -2.2 & -16.9 & -19.1 \\
\hline 1947 & -5.3 & 9.5 & 27.6 & 16.6 & 4.4 & .2 & -2.0 & -1.2 & 2.9 & -2.8 & -15.6 & $=24.4$ \\
\hline 1948 & -8.2 & -5.9 & 55.9 & 27.5 & .6 & -1.7 & .8 & -6.4 & -2.1 & -7.7 & -12.6 & -18.2 \\
\hline 1949 & -5.9 & 2.3 & 33.8 & 26.7 & 3.8 & -4.3 & $=3.2$ & -1.7 & -2.1 & -4.3 & -12.5 & -20.7 \\
\hline 1950 & -2.1 & $2 \cdot 8$ & 37.0 & 10.2 & 9.1 & -1.6 & .8 & 2.0 & -12.2 & -9.0 & -15.8 & -2.9 \\
\hline 1951 & $7 \cdot 1$ & -3.6 & 23.6 & 7.9 & 10.3 & -5.2 & $=3.6$ & .9 & 6.6 & $=7.6$ & -10.4 & -18.2 \\
\hline 1952 & 2.4 & 19.8 & 21.2 & 5.5 & 3.4 & $=4.0$ & 3.3 & -4.0 & .7 & .6 & -17.1 & -17.9 \\
\hline 1953 & 1.0 & 8.2 & 30.0 & 12.2 & .9 & -1.9 & -3.9 & -3.0 & .8 & -2.1 & -11.8 & $=20.0$ \\
\hline 1954 & .5 & 12.1 & 24.0 & 12.1 & -1.4 & $2 \cdot 2$ & -2.6 & -2.8 & -2.8 & -5.3 & -8.6 & -14.3 \\
\hline 1955 & -3.4 & .5 & 28.8 & 16.2 & 4.1 & -1.8 & -5.8 & 2.5 & -4.7 & -5.3 & -13.0 & -15.6 \\
\hline 1956 & 1.1 & 5.2 & 23.1 & 18.5 & 2.6 & -3.6 & -3.4 & 6.3 & -10.6 & 2.1 & -14.3 & -17.2 \\
\hline 1957 & -3.7 & 5.5 & 25.7 & 14.7 & 5.5 & -3.0 & .9 & 3.1 & -0.6 & -1.6 & -13.9 & -16.9 \\
\hline 1998 & $\bullet 9$ & -3.4 & 25.0 & 18.8 & 4.1 & -3.7 & 3.1 & 1.6 & -6.7 & -1.0 & -8.4 & -10.1 \\
\hline 1950 & -8.6 & 8.6 & 24.6 & 16.1 & -1.7 & .7 & .4 & 2.2 & 3.6 & -11.0 & & \\
\hline
\end{tabular}

23 IRREGULAR COMPONENT

\begin{tabular}{|c|c|c|c|c|c|c|c|c|c|c|c|c|}
\hline 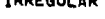 & 6 & & & & & & & & & & SERIE & $\$ 3694$ \\
\hline YEAR & JAN & PEB & MAR & APR & MAY & JUN & JUL & AUG & SEP & OCT & NOV & DEC \\
\hline 1930 & 107.5 & 100.2 & 102.7 & 95.4 & 99.3 & 100.9 & 95.3 & 100.9 & 98.7 & 99.4 & 108.7 & 101.7 \\
\hline 1940 & 88.4 & 103.0 & 100.0 & 105.6 & 98.9 & 94.0 & 105.0 & 96.1 & 104.6 & 104.5 & 92.0 & 93.0 \\
\hline 1941 & 112.7 & 96.8 & 96.5 & 101.1 & 97.0 & 99.7 & 110.7 & 97.0 & 100.7 & 97.6 & 101.4 & 86.3 \\
\hline 1942 & 92.3 & 115.7 & 122.3 & 113.7 & 62.5 & 72.6 & 100.9 & 106.8 & 122.4 & 90.5 & 98.0 & 104.8 \\
\hline 1943 & 91.5 & 94.7 & 106.0 & 95.9 & 106.3 & 96.7 & 96.2 & 105.2 & 97.5 & 102.0 & 95.1 & 102.0 \\
\hline 1944 & 107.8 & 103.8 & 94.7 & 89.2 & 100.7 & 108.1 & 104.7 & 94.2 & 94.8 & 97.3 & 106.3 & 100.0 \\
\hline 1945 & 101.7 & 99.2 & 99.2 & 98.5 & 101.4 & 114.7 & $102 \cdot 3$ & 89.0 & 94.3 & 93.0 & 96.3 & 94.2 \\
\hline 1946 & 106.1 & 103.9 & 108.4 & 101.4 & 98.0 & 92.0 & 98.8 & 101.9 & 101.7 & 100.9 & 97.7 & 99.8 \\
\hline 1047 & 98.9 & 103.7 & 100.3 & 99.4 & 98.7 & 95.9 & 97.7 & 97.5 & 105.2 & 105.8 & 104.9 & 99.7 \\
\hline 1948 & 96.2 & 85.6 & $100 \cdot 3$ & 107.6 & 102.3 & 100.6 & 102.6 & 97.7 & 99.9 & 96.8 & 101.1 & 102.1 \\
\hline 1949 & 100.6 & 95.3 & 97.0 & 104.2 & 102.1 & 100.0 & 98.3 & 98.4 & 99.4 & 99.4 & 104.3 & 99.4 \\
\hline 1950 & 101.5 & 95.7 & 101.4 & 97.2 & 100.5 & 102.1 & 103.0 & 107.4 & 98.1 & 90.1 & 01.0 & 104.9 \\
\hline 1951 & 114.6 & 100.3 & 97.3 & 94.4 & 100.3 & 98.7 & 96.7 & 99.1 & 107.1 & 101.9 & 98.1 & 94.7 \\
\hline 1952 & 98.3 & 106.7 & 102.4 & 98.3 & 98.5 & 97.0 & 102.3 & 98.7 & $10 n .1$ & 102.5 & 100.5 & 98.1 \\
\hline 1953 & 99.8 & 97.9 & 101.4 & 102.9 & 99.8 & 100.6 & 99.2 & 97.3 & 99.3 & 100.2 & 103.0 & 98.2 \\
\hline 1954 & 98.9 & $101 \cdot \theta$ & 100.5 & 100.1 & 96.8 & 101.3 & 101.8 & 99.2 & 99.1 & 96.5 & 101.6 & 104.7 \\
\hline 1955 & 101.7 & 96.0 & 98.3 & 99.8 & 101.6 & 101.8 & 98.7 & 100.8 & 101.4 & 98.7 & 97.3 & 98.6 \\
\hline 1956 & 101.2 & 101.6 & 90.1 & 101.2 & 101.1 & 99.3 & 98.2 & 102.2 & 97.2 & 102.5 & 100.1 & 99.8 \\
\hline 1957 & 98.4 & 100.1 & 100.4 & 98.8 & 101.1 & 100.1 & 100.1 & 100.2 & 99.9 & 101.5 & 99.0 & 99.5 \\
\hline 1958 & 103.9 & 97.3 & 97.7 & 99.5 & 101.0 & 99.0 & 101.8 & 99.4 & 98.4 & 99.8 & 102.7 & 101.1 \\
\hline 1959 & 95.6 & 101.2 & 101.9 & 101.8 & 98.1 & 100.9 & 100.7 & 99.2 & 101.3 & 93.4 & & \\
\hline
\end{tabular}




\section{AIDS TO THE CURRENT USE OF INDICATORS}

24 PERCENT CHANGE FROM PRECEOING MO, IRREGULAR

\begin{tabular}{|c|c|c|c|c|c|c|c|c|c|c|c|c|}
\hline YEAR & JAN & FEG & MAR & APR & MAY & JUN & JUL & AUG & SEP & OCT & Nov & DEC \\
\hline 1439 & $\because$ & -6.8 & 2.5 & -7.1 & 4.1 & 1.6 & -5.6 & 5.9 & $-\quad 2.2$ & .7 & 9.4 & -6.4 \\
\hline 1940 & -13.1 & 16.5 & $=2.9$ & 5.6 & $=0.3$ & $=5.0$ & 11.7 & $=8.5$ & 8.8 & .1 & -12.0 & 1.1 \\
\hline 194$]$ & 23.2 & $=14.1$ & $\cdot 3$ & 4.8 & -4.1 & 2.8 & 11.0 & -12.4 & 3.8 & -3.1 & 3.9 & $=14.9$ \\
\hline 1942 & 7.0 & 25.4 & 5.7 & -7.0 & -45.0 & 16.2 & 39.0 & 5.8 & 14.6 & -18.7 & -1.5 & 6.9 \\
\hline 1943 & -12.7 & 3.5 & 11.9 & -0.5 & 10.8 & $=9.0$ & .5 & 9.4 & -7.3 & 4.6 & -6.8 & 7.3 \\
\hline 1944 & 5.7 & -3.7 & -8.8 & -5.8 & 12.9 & 7.3 & -3.1 & -10.0 & .6 & 2.6 & 9.2 & -5.9 \\
\hline 1945 & 1.7 & -2.9 & .0 & .7 & 2.9 & 13.1 & -10.8 & -13.0 & 6.0 & $=1.4$ & 3.5 & -2.2 \\
\hline 1940 & 12.0 & -2.1 & $4 \cdot 3$ & -0.5 & -3.4 & $=0.1$ & 7.4 & 3.1 & $\cdot 2$ & .8 & -3.2 & 2.1 \\
\hline 1947 & -.9 & 4.9 & -3.3 & .9 & .7 & -2.0 & 1.9 & .2 & 7.9 & .6 & .9 & $=5.0$ \\
\hline 1948 & -3.5 & $=11.0$ & 17.2 & 7.3 & $=4.9$ & -1.7 & 2.0 & -4.8 & $2 \cdot 3$ & -3.1 & 4.4 & 1.0 \\
\hline 1949 & -1.5 & $=5.3$ & 1.8 & 7.4 & -2.0 & $=2.1$ & $=1.7$ & .1 & 1.0 & .0 & 4.9 & -4.7 \\
\hline 1950 & $2 \cdot 1$ & $=5.7$ & 6.0 & -4.1 & 3.4 & 1.0 & .9 & 4.3 & -10.5 & $=0.2$ & 1.0 & 15.3 \\
\hline 1951 & 9.2 & -12.5 & -3.0 & $=3.0$ & 6.3 & -1.6 & -2.0 & 2.5 & 8.1 & $=4.0$ & $-\quad 3.7$ & -3.5 \\
\hline 1452 & 3.8 & 8.5 & $=4.0$ & -4.0 & .2 & -1.5 & 5.5 & -3.5 & 1.4 & 2.4 & -2.0 & -2.4 \\
\hline 1453 & 1.7 & $=1.9$ & 3.6 & 1.5 & $=3.0$ & .8 & -1.4 & -1.9 & $2 \cdot 1$ & .9 & 2.8 & $=4.7$ \\
\hline 1454 & .7 & 2.9 & -1.3 & .4 & -3.3 & 4.6 & .5 & -2.6 & .1 & -2.6 & 5.3 & 3.1 \\
\hline 1455 & -2.9 & -5.6 & 2.4 & 1.5 & $1 . \theta$ & .2 & -3.0 & 2.1 & .6 & -2.7 & -1.4 & 1.3 \\
\hline 1996 & 2.6 & .4 & -2.5 & 2.1 & .1 & $=1.8$ & -1.1 & 4.1 & $=4.9$ & 5.5 & -2.3 & .3 \\
\hline 1957 & $=1.4$ & 1.7 & $\cdot 3$ & -1.0 & 2.3 & $=1.0$ & .0 & .1 & $\cdot 3$ & 1.6 & -2.5 & .5 \\
\hline 1958 & 4.4 & $=6.4$ & .4 & 1.8 & 1.5 & $=2.0$ & 2.8 & -2.4 & -1.0 & 1.4 & 2.9 & -1.6 \\
\hline 1959 & -5.4 & 5.9 & .7 & .1 & -3.6 & 2.0 & .2 & -1.5 & 2.1 & -7.0 & & \\
\hline
\end{tabular}

25 PERCENT CMANGE FROM PRECEDING MO, CYCLICAL

SERIES $\$ 3694$

\begin{tabular}{|c|c|c|c|c|c|c|c|c|c|c|c|c|}
\hline YEAR & JAN & FEB & MAR & APR & MAY & JUN & JuL & AUG & SEP & OCT & Nov & DEC \\
\hline 1939 & $\cdots$ & $=1.0$ & -2.9 & -3.8 & -3.5 & -2.1 & .2 & 1.9 & 2.7 & 2.9 & 2.2 & 1.9 \\
\hline 1940 & 1.9 & 1.6 & 2.0 & 1.8 & 1.9 & $1 . y$ & 1.1 & .9 & .6 & .9 & 1.4 & 1.6 \\
\hline 1941 & $2 \cdot 3$ & 3.1 & 3.3 & 3.1 & 2.8 & 1.4 & .6 & -2.9 & -4.7 & -5.0 & -4.1 & -2.3 \\
\hline 1942 & -2.2 & $=4.9$ & -9.3 & -14.8 & -28.6 & -19.1 & -14.7 & -6.3 & -1.0 & .0 & -2.9 & -5.5 \\
\hline 1943 & -5.9 & -4.0 & -1.2 & 1.2 & 2.9 & 2.9 & 3.3 & 2.7 & 3.1 & $2 . n$ & 1.0 & -1.5 \\
\hline 1944 & -3.5 & -5.2 & -7.1 & -7.0 & -7.6 & -0.2 & -6.0 & $=4.7$ & -4.1 & -2.6 & .9 & 1.8 \\
\hline 1945 & 2.6 & 4.3 & 5.7 & 5.4 & 0.6 & 7.6 & 10.3 & 10.3 & 23.0 & 27.6 & 28.0 & 24.4 \\
\hline 1946 & 18.2 & 11.8 & 5.7 & 1.0 & -2.0 & -3.0 & -2.8 & -1.7 & .5 & .0 & .6 & $1 \cdot 1$ \\
\hline 1947 & 1.5 & 1.0 & 2.4 & 3.5 & 5.1 & 7.1 & $\theta .1$ & 7.0 & 5.6 & 2.3 & .8 & -2.9 \\
\hline 1948 & -3.0 & -1.4 & $\bullet$ & 2.1 & $1 . \theta$ & .0 & -2.2 & -3.6 & -4.4 & -4.1 & -3.2 & -2.0 \\
\hline 1949 & .0 & 1.3 & 2.6 & 3.8 & 4.3 & 4.8 & 5.1 & 5.6 & 5.8 & 5.6 & 5.0 & 4.0 \\
\hline 1950 & 3.2 & 3.0 & $2 \cdot 8$ & 2.8 & 1.9 & $\cdot 1$ & -1.9 & $=3.8$ & -4.3 & $=3.7$ & -2.1 & -1.2 \\
\hline 1951 & -1.0 & -3.3 & -5.2 & $=0.0$ & -5.1 & -2.9 & .4 & 1.1 & 1.6 & 1.4 & 1.3 & 1.3 \\
\hline 1952 & 1.4 & 1.2 & .6 & $\cdot 1$ & .1 & .2 & .9 & 1.3 & 1.4 & 1.1 & .6 & .3 \\
\hline 1953 & $\cdot 3$ & .2 & $\cdot 2$ & .7 & $=1.4$ & -1.9 & -2.0 & $=1.4$ & .6 & .3 & 1.0 & 1.3 \\
\hline 1954 & 1.3 & 1.5 & 1.6 & $1 \cdot \theta$ & 2.1 & 2.3 & 2.7 & 3.0 & $3 \cdot 2$ & 3.1 & 2.6 & 1.7 \\
\hline 1955 & .9 & .1 & $\cdot 3$ & .4 & .6 & -1.0 & -1.8 & -2.6 & -3.0 & -2.0 & -2.2 & $=1.3$ \\
\hline 1956 & .7 & .3 & .5 & -1.1 & $=1.6$ & -1.9 & -2.1 & -2.0 & $=1.9$ & -1.8 & -1.7 & -1.4 \\
\hline 1957 & $=1.1$ & .4 & .1 & .5 &.$\theta$ & .7 & .6 & .2 & .1 & .5 & .7 & .9 \\
\hline 1958 & -.8 & .0 & 1.0 & 2.2 & 3.4 & 4.3 & 4.7 & 4.8 & 4.6 & 4.2 & 3.6 & 3.0 \\
\hline 1959 & 2.3 & 1.4 & .6 & .5 & $=1.5$ & -2.4 & $=3.0$ & -2.9 & -2.3 & -1.3 & & \\
\hline
\end{tabular}




\section{PART THREE}

26 2-MO MOVING AVERAGE. FINAL AOJUSTEO SEAIES

SERIES 13694

\begin{tabular}{|c|c|c|c|c|c|c|c|c|c|c|c|c|}
\hline YEAR & JAN & PEA & MAR & APR & MaY & NN & JUL & AUS & SEP & OCT & Nov & OEC \\
\hline 1939 & 511 & 487 & 460 & 435 & 435 & 422 & 425 & 442 & 451 & 466 & SOl & 461 \\
\hline 1940 & 473 & 511 & 527 & 534 & 512 & 535 & 546 & 540 & 576 & 547 & 523 & 594 \\
\hline 1941 & 020 & 591 & 023 & 643 & 652 & 700 & 680 & 622 & 594 & SGR & 510 & 482 \\
\hline 1942 & 541 & 376 & 506 & 324 & 194 & 206 & 222 & 236 & 228 & 200 & 196 & 180 \\
\hline 1943 & 162 & 170 & 171 & 175 & 180 & 177 & 190 & 197 & 199 & 199 & 199 & 206 \\
\hline 1944 & 199 & 176 & 151 & 143 & 147 & 140 & 124 & 112 & 110 & 115 & 117 & 117 \\
\hline 1945 & 120 & 125 & 131 & 141 & 163 & 178 & 177 & 205 & 262 & 340 & 429 & 549 \\
\hline 1946 & 657 & 723 & 737 & 697 & 648 & 631 & 649 & 651 & 647 & 636 & 038 & 650 \\
\hline 1947 & 674 & 693 & 698 & 722 & 752 & 806 & 878 & 973 & 1051 & 1058 & 1009 & 937 \\
\hline 1948 & $85_{1}$ & 867 & 984 & 1012 & 987 & 978 & 937 & 887 & 846 & 820 & 820 & 808 \\
\hline 1949 & 783 & 783 & 846 & 902 & 924 & 952 & 995 & 1057 & 1123 & 1213 & 1266 & 1295 \\
\hline 1950 & 1310 & 1348 & 1396 & 1422 & 1472 & 1477 & 1471 & 1368 & 1201 & 1133 & 1205 & 1331 \\
\hline 1951 & 1273 & 1120 & 1026 & $9 B 3$ & 965 & 932 & 936 & 999 & 1027 & 997 & 973 & 987 \\
\hline 1952 & 1062 & 1093 & 1052 & 1032 & 1025 & 1051 & 1071 & 1074 & 1109 & 1121 & 1101 & 1100 \\
\hline 1453 & 1102 & 1111 & 1133 & 1112 & 1081 & 1057 & 1022 & 1012 & 1025 & 1051 & 1052 & 1044 \\
\hline 1954 & 1078 & 1104 & 1113 & 1113 & 1145 & 1202 & 1223 & 1245 & 1267 & 1320 & 1404 & 1422 \\
\hline 1955 & 1309 & 1345 & 1367 & 1383 & 1386 & 1347 & 1311 & 1292 & 1241 & 1185 & 1163 & 1170 \\
\hline 1456 & 1186 & 1168 & 1156 & 1152 & 1121 & 1083 & 1076 & 1050 & 1032 & 1029 & 1000 & 979 \\
\hline 1957 & 973 & 981 & 978 & 988 & 1002 & 1003 & 1008 & 1007 & 1011 & 1000 & 982 & 998 \\
\hline 1958 & 983 & 958 & 984 & 1029 & 1065 & 1118 & 1173 & 1208 & 1264 & 1342 & 1395 & 1381 \\
\hline 1959 & 1409 & 1468 & 1472 & 1431 & 1390 & 1377 & 1325 & 1294 & 1235 & & & \\
\hline
\end{tabular}

26A SYM * GHANGE FROM PRECEOING MO. IN TABLE 26

SERIES MS694

\begin{tabular}{|c|c|c|c|c|c|c|c|c|c|c|c|c|}
\hline YEAR & JAN & FEO & MAR & APR & MAY & JUN & JUL & AUS & SEP & & & DEC \\
\hline 1939 & $\cdots$ & -4.8 & -5.7 & -5.6 & .0 & $=3.0$ & .7 & 3.9 & 2.0 & 7.5 & 3.0 & -8.3 \\
\hline 1940 & 2.6 & 7.7 & 3.1 & 1.3 & -4.2 & 4.4 & 2.0 & .5 & 4.8 & -5.2 & -4.5 & 12.7 \\
\hline 1941 & 4.3 & -4.8 & 5.3 & 3.2 & 1.4 & 7.1 & -2.9 & $=8.9$ & -4.6 & -4.5 & -0.0 & -7.4 \\
\hline 1942 & 11.5 & 6.3 & -12.9 & -43.9 & - 50.2 & 6.0 & 7.5 & 6.1 & -3.4 & -13.1 & -2.0 & -8.5 \\
\hline 1943 & -10.5 & 4.8 & .6 & 2.3 & 2.8 & -1.7 & 7.1 & 3.6 & 1.0 & .0 & .0 & 3.5 \\
\hline 1944 & -3.5 & $=12.3$ & -15.3 & -3.4 & 2.8 & $=4.9$ & -12.1 & -10.2 & -1.8 & 4.4 & 1.7 & .0 \\
\hline 1945 & 2.5 & 4.1 & 4.7 & 7.4 & 14.5 & 6.8 & $=.6$ & 34.7 & 24.4 & 25.9 & 23.1 & 24.5 \\
\hline 1946 & 17.9 & 9.6 & 1.9 & -5.6 & -7.3 & -2.7 & 2.0 & .3 & .6 & -1.7 & .3 & 1.9 \\
\hline 1947 & 3.6 & 2.8 & .7 & 3.4 & 4.1 & 6.9 & 8.6 & 10.3 & 7.7 & .7 & -4.7 & -7.4 \\
\hline 1948 & $-9,0$ & 1.9 & 12.6 & 2.8 & -2.5 & .9 & -4.3 & -5.5 & -4.7 & -3.1 & .0 & -1.5 \\
\hline 1049 & -3.1 & .0 & 7.7 & 6.4 & $2 \cdot 4$ & 3.0 & 4.4 & 0.0 & 6.1 & 7.7 & 4.3 & 2.3 \\
\hline 1950 & 1.2 & 2.9 & 3.5 & 1.8 & 3.5 & .3 & .4 & -7.3 & -13.0 & $-5 . A$ & 6.2 & 9.9 \\
\hline 1951 & -4.5 & -12.8 & -8.8 & -4.3 & -1.8 & $=3.5$ & .4 & 6.5 & 2.8 & $=3.0$ & -2.4 & 1.4 \\
\hline 1952 & 7.3 & 2.9 & -3.8 & -1.9 & .7 & 2.5 & 1.9 & .3 & 3.2 & 1.1 & -1.8 & .1 \\
\hline 1953 & .2 & .8 & $2 \cdot 0$ & -1.9 & $=2.8$ & -2.2 & $=3.4$ & -1.0 & 1.3 & 2.5 & .1 & - $\theta$ \\
\hline 1954 & 3.2 & 2.4 & .8 & .0 & 2.8 & 4.9 & 1.7 & 1.8 & 1.8 & 4.1 & 6.2 & 1.3 \\
\hline 1955 & -3.8 & -1.8 & 1.6 & 1.2 & .2 & -2.9 & - 2.7 & -1.5 & -4.0 & $=4.6$ & -1.9 & .9 \\
\hline 1950 & 1.0 & -1.5 & -1.0 & .3 & -2.7 & -3.4 & .6 & $=2.4$ & -1.7 & .3 & -2.9 & -2.1 \\
\hline 1957 & -.6 & .8 & .3 & 1.0 & 1.4 & .1 & .5 & .1 & .4 & $=1.1$ & -1.8 & 1.6 \\
\hline 1958 & -1.5 & -2.6 & 2.7 & 4.5 & 3.4 & 4.9 & 4.8 & 2.9 & 4.5 & 0.0 & 3.8 & -1.0 \\
\hline 1959 & 2.0 & 4.1 & .3 & -2.0 & - 2.5 & $=1.4$ & -3.6 & -2.4 & -4.7 & & & \\
\hline
\end{tabular}




\section{AIDS TO THE GURRENT USE OF INDICATORS}

\begin{tabular}{|c|c|c|c|c|c|c|c|c|c|c|c|c|}
\hline 268 STAND & SYM $\triangle C H$ PRE & C NO T. & & 4.54 & & & & & & & \multicolumn{2}{|c|}{ SERIES $\# 3694$} \\
\hline reAR & JAN & FEB & MAR & APR & MAY & JUN & JUL & AUG & SEP & OCT & NOV & DEC \\
\hline 1930 & $\cdots$ & -1.1 & -1.3 & -1.2 & .0 & .7 & .2 & .9 & .4 & 1.7 & .7 & -1.8 \\
\hline 1040 & .6 & 1.7 & .7 & $\cdot 3$ & .9 & 1.0 & .4 & .1 & 1.1 & -1.1 & -1.0 & 2.8 \\
\hline 1941 & .9 & $=1.1$ & 1.2 & .7 & .3 & 1.6 & .6 & -2.0 & -1.0 & -1.0 & -2.0 & -1.6 \\
\hline 1942 & 2.5 & 1.4 & -2.8 & - 9.7 & -11.1 & 1.3 & 1.7 & 1.3 & .7 & -2.9 & .4 & -1.9 \\
\hline 1943 & -2.3 & 1.1 & .1 & .5 & .6 & .4 & 1.6 & -8 & .2 & $-\quad .0$ & .0 & .8 \\
\hline 1944 &.$\theta$ & -2.7 & -3.4 & -1.2 & .6 & -1.1 & -2.7 & -2.2 & .4 & 1.0 & .4 & -.0 \\
\hline 1943 & .0 & $\bullet 9$ & 1.0 & 1.6 & 3.2 & 1.9 & .1 & 3.2 & 3.4 & 3.7 & 5.1 & 3.4 \\
\hline 1946 & 3.9 & 2.1 & .4 & -1.2 & -1.6 & .6 & .6 & .1 & .1 & .4 & .1 & .4 \\
\hline 1947 & $\bullet \theta$ & .0 & .2 & .7 & .9 & 1.5 & 1.9 & 2.3 & 1.7 & .2 & -1.0 & -1.0 \\
\hline 1948 & -2.1 & .4 & 2.8 & .6 & .6 & .2 & .9 & -1.2 & -1.0 & $-\quad .7$ & .0 & -.3 \\
\hline 1949 & .7 & .0 & 1.7 & 1.4 & .5 & .7 & 1.0 & 1.3 & 1.5 & 1.7 & .9 & .5 \\
\hline 1950 & .3 & .6 & $\cdot 8$ & .4 & $\cdot 8$ & .1 & .1 & -1.6 & -2.9 & -1.3 & 1.4 & 2.2 \\
\hline 1951 & -1.0 & -2.0 & -1.9 & .9 & .4 & .8 & .1 & 1.4 & .6 & $-\quad .7$ & .3 & .3 \\
\hline 1952 & 1.6 & .6 & $\cdot \theta$ & $\cdot 4$ & .2 & .6 & .4 & .1 & .7 & .2 & .4 & - \\
\hline 1953 & .0 & .2 & .4 & .4 & .6 & .5 & .7 & .2 & .3 & .6 & .0 & - \\
\hline 1934 & .7 & .5 & .2 & .0 & .6 & 1.1 & .4 & .4 & .4 & .9 & 1.4 & .3 \\
\hline 1953 & $-\quad . \theta$ & -.4 & .4 & .3 & .0 & -.6 & -.6 & $\cdot 3$ & .9 & -2.0 & $=.4$ & .2 \\
\hline 1936 & $\cdot 2$ & .9 & .2 & .1 & .6 & $=.7$ & $\bullet 1$ & .5 & .4 & $-\quad .1$ & -.6 & -.5 \\
\hline 1997 & $-\quad .1$ & .2 & .2 & .2 & .3 & .0 & $\bullet 1$ & .0 & $\cdot 1$ & -.2 & -.4 & .4 \\
\hline 1958 & -.3 & -.6 & .6 & 1.0 & .7 & 1.1 & 1.1 & .6 & 1.0 & 1.3 & $\bullet 9$ & - \\
\hline 1939 & .4 & .9 & .1 & .6 & .6 & $=.3$ & - $\quad \theta$ & .5 & $=1.0$ & & & \\
\hline
\end{tabular}

2OC STANO SHORT term MOVING aVERAGE InOEX

SERIES $\$ 3694$

\begin{tabular}{|c|c|c|c|c|c|c|c|c|c|c|c|c|}
\hline YEAAR & JAN & FEB & MAR & APR & MAY & WN & JUL & AUS & SEP & OCT & NOV & OEC \\
\hline 1930 & 100.0 & 98.9 & 97.6 & 96.4 & 96.4 & 93.7 & 95.9 & 96.8 & 97.2 & 98.9 & 99.6 & 97.8 \\
\hline 1940 & 98.4 & 100.1 & 100.8 & 101.1 & 100.2 & 101.2 & 101.6 & 101.7 & 102.8 & 101.7 & 100.7 & 103.6 \\
\hline 1941 & 104.5 & 103.4 & 104.6 & 105.3 & 105.6 & 107.3 & 100.7 & 104.6 & 103.0 & 102.6 & 100.6 & 99.0 \\
\hline 1942 & 101.5 & 102.9 & 100.1 & 90.8 & 81.3 & 82.4 & 83.8 & 84.9 & 64.3 & 81.0 & B1.6 & 80.1 \\
\hline 1943 & 78.3 & 79.2 & 79.3 & 79.7 & 80.2 & 79.0 & 81.2 & 81.9 & 82.1 & 82.1 & 82.1 & 82.8 \\
\hline 1944 & 02.1 & 79.9 & 77.2 & 76.3 & 76.8 & 76.0 & 74.0 & 72.4 & 72.1 & 72.8 & 73.1 & 73.1 \\
\hline 1945 & 73.5 & 74.2 & 74.9 & 76.1 & 78.6 & 80.1 & 80.0 & 82.6 & 87.2 & 92.3 & 97.1 & .5 \\
\hline 1946 & 106.0 & 108.9 & 109.3 & 108.0 & 106.3 & 105.7 & 106.3 & 100.4 & 106.3 & 105.9 & 106.0 & 106.4 \\
\hline 1947 & 107.3 & 107.9 & 100.1 & 108.9 & 109.9 & 111.0 & 113.7 & 110.3 & 118.3 & 118.5 & 117.3 & 115.4 \\
\hline 1948 & 113.0 & 113.5 & 116.7 & 117.4 & 116.7 & 116.5 & 115.5 & 114.1 & 113.0 & 112.2 & 112.2 & 1.9 \\
\hline 1949 & 111.1 & 111.1 & 113.0 & 114.6 & 115.2 & 116.0 & 117.2 & 128.7 & 120.3 & 122.4 & 123.5 & 124.1 \\
\hline 1950 & 124.5 & 125.2 & 126.2 & 126.7 & 127.7 & 127.8 & 127.7 & 125.7 & 122.1 & 120.5 & 122.2 & 4.9 \\
\hline 1951 & 123.7 & 120.3 & 118.0 & 116.9 & 116.4 & 115.5 & 115.6 & 117.2 & 117.9 & 117.1 & 116.5 & 16.9 \\
\hline 1952 & 118.0 & 119.5 & 118.5 & 118.0 & 117.8 & 118.5 & 119.0 & 119.1 & 119.9 & 120.1 & 119.6 & 119.6 \\
\hline 1953 & 110.6 & 110.8 & 120.3 & 119.8 & 110.1 & 118.5 & 117.7 & 117.5 & 117.9 & 118.6 & $\$ 18.6$ & 118.4 \\
\hline 1954 & 119.2 & 119.8 & 120.0 & 120.0 & 120.7 & 122.0 & 122.5 & 123.0 & 123.5 & 124.6 & 126.4 & 126.8 \\
\hline 1955 & 125.8 & 125.3 & 125.8 & 126.2 & 126.2 & 123.4 & 124.6 & 124.2 & 123.1 & 121.9 & 121.4 & 8000 \\
\hline 1956 & 121.0 & 121.4 & 121.2 & 121.1 & 120.4 & 119.6 & 119.5 & 118.9 & 118.4 & 118.3 & 117.6 & A1700 \\
\hline 1957 & 110.9 & 117.1 & 117.0 & 117.2 & 117.6 & 117.6 & 117.7 & 117.7 & 117.8 & 117.6 & 117.1 & .6 \\
\hline 1958 & 117.2 & 116.3 & 117.2 & 118.4 & 119.2 & 120.5 & 121.0 & 122.5 & 123.7 & 125.3 & 126.4 & 126.1 \\
\hline 1030 & 126.6 & 127.7 & 127.8 & 127.0 & 126.2 & 125.8 & 124.8 & 124.2 & 123.0 & & & \\
\hline
\end{tabular}




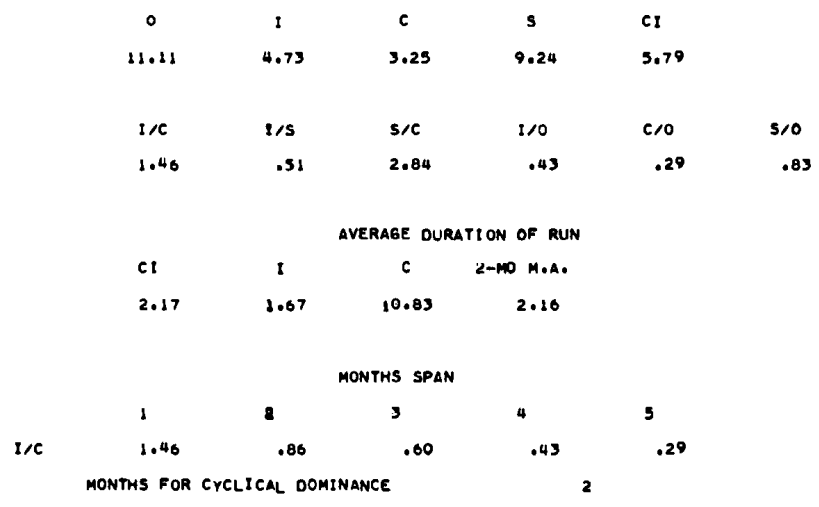

28 RATIUS, 12-MO MOV AVS MT IPR:C * CYCLE AYCPS

SERIES $\$ 3694$

\begin{tabular}{|c|c|c|c|c|c|c|c|c|c|c|c|c|}
\hline YEAR & JAN & FEB & MAR & APR & MAY & JUN & JUL & AUG & SEP & OCT & NoV & $D E C$ \\
\hline 1030 & - & - & - & - & - & $=$ & 2353 & 2721 & 2828 & 2996 & 3200 & 3570 \\
\hline 1940 & 3694 & 3977 & 4721 & 5210 & 5601 & 5388 & 5730 & 5148 & 4688 & 4367 & 4094 & 3078 \\
\hline 1941 & 4036 & 3063 & 3,21 & 2817 & 2367 & 2708 & 2315 & 2507 & 2284 & 1830 & 2000 & 1756 \\
\hline 1442 & 1788 & 1068 & 1834 & 2088 & 2089 & 1942 & 1927 & 1730 & 1945 & 2305 & 2335 & 2967 \\
\hline 1943 & 2841 & 3254 & 2857 & 2330 & 2602 & 2943 & 2945 & 2836 & 2291 & 1802 & 1722 & 1577 \\
\hline 1044 & 1529 & 1485 & 1342 & 1293 & 1337 & 1306 & 1256 & 1255 & 1120 & 1076 & 903 & 989 \\
\hline 1945 & 1060 & 924 & 785 & 599 & 442 & 357 & 387 & 360 & 393 & 434 & 449 & 420 \\
\hline 1946 & 418 & 393 & 417 & 527 & 724 & 1070 & 1265 & 1977 & 2277 & 1737 & 1400 & 1078 \\
\hline 1947 & 743 & 553 & 662 & 626 & 574 & 612 & 646 & 772 & 1085 & 1253 & 1443 & 1492 \\
\hline 1948 & 2019 & 2521 & 2419 & 2331 & 2278 & 2210 & 2336 & 2126 & 1437 & 1358 & 1168 & 1022 \\
\hline 1049 & 940 & 782 & 727 & 633 & 019 & 670 & 648 & 634 & 718 & 662 & 722 & 786 \\
\hline 1950 & 827 & 970 & 1255 & 1490 & 1503 & 1984 & 2336 & 2342 & 2257 & 2020 & 1927 & 1796 \\
\hline 1951 & 1891 & 1981 & 2067 & 2176 & 2318 & 1933 & 1771 & 1701 & 2136 & 2875 & 3493 & 43364 \\
\hline 1952 & 4482 & 4491 & 3973 & 3853 & 3951 & 4261 & 4580 & 4296 & 4493 & 3781 & 3535 & 2883 \\
\hline 1953 & 2246 & 2087 & 2308 & 2343 & 2330 & 2327 & 2057 & 1034 & 1600 & 1422 & 1381 & 1570 \\
\hline 1954 & 1458 & 1374 & 1122 & 1064 & 1094 & 1019 & 1117 & 1287 & 1403 & 1540 & 1579 & 1459 \\
\hline 1955 & 1663 & 1072 & 1718 & 1743 & 1560 & 1491 & 1491 & 1170 & 1162 & 1150 & 1000 & 1035 \\
\hline 1950 & 926 & 1056 & 1351 & 1598 & 1698 & 1629 & 1523 & 1589 & 1497 & 1521 & 1739 & 1828 \\
\hline 1957 & 1954 & 1011 & 1787 & 1593 & 1845 & 2015 & 2587 & 3550 & 3103 & 2506 & 1847 & 1463 \\
\hline 1958 & 1293 & 1137 & 978 & 898 & 797 & 781 & 777 & 737 & 752 & 741 & 839 & 914 \\
\hline 1959 & 881 & 907 & 1022 & 1390 & & & & & & & & \\
\hline
\end{tabular}




\section{AIDS TO THE CURRENT USE OF INDICATORS}

29 MODIFIED ORIGINAL OESERVATIONS (T.11X T.18)

\begin{tabular}{|c|c|c|c|c|c|c|c|c|c|c|c|c|}
\hline YEAR & JAN & FEB & MAR & APR & MAY & NN & JUL & AUG & SEP & $O C F$ & NOV & DEC \\
\hline 1939 & 349 & 351 & 500 & 503 & 531 & 492 & 452 & 511 & 467 & 496 & 454 & 366 \\
\hline 1040 & 291 & 374 & 532 & 630 & 646 & 581 & 635 & 617 & 607 & 624 & 458 & 401 \\
\hline 1941 & 436 & 423 & 617 & 747 & 790 & 776 & 732 & 736 & 647 & 614 & 503 & 419 \\
\hline 1942 & 334 & 371 & 467 & 435 & 392 & 305 & 246 & $25 \theta$ & 211 & 216 & 174 & 151 \\
\hline 1943 & 113 & 118 & 179 & 181 & 227 & 210 & 199 & 234 & 197 & 220 & 178 & 160 \\
\hline 1944 & 146 & 141 & 160 & 176 & 172 & 176 & 145 & 130 & 112 & 116 & 100 & 87 \\
\hline 1945 & 85 & 89 & 126 & 146 & 172 & 217 & 190 & 230 & 247 & 315 & 361 & 354 \\
\hline 1946 & 442 & 504 & 733 & 790 & 793 & 748 & 735 & 746 & 697 & 682 & 571 & 467 \\
\hline 1947 & 449 & 501 & 655 & 790 & 867 & 926 & 982 & 1046 & 1137 & 1130 & 946 & 693 \\
\hline 1948 & 613 & 678 & 894 & 1163 & 1191 & 1171 & 1137 & 1025 & 961 & eso & 719 & 577 \\
\hline 1949 & 545 & 504 & 775 & 1018 & 1102 & 1103 & 1125 & 1167 & 1208 & 1221 & 1123 & 926 \\
\hline 1950 & 932 & 985 & 1389 & 1575 & 1750 & 1724 & 1677 & 1646 & 1384 & 1332 & 989 & 949 \\
\hline 1951 & 871 & 944 & 1107 & 1123 & 1176 & 1082 & 1038 & 1060 & 1147 & 1075 & 879 & 727 \\
\hline 1952 & 748 & 907 & 1105 & 1166 & 1205 & 1149 & 1197 & 1153 & 1178 & 1185 & 990 & 015 \\
\hline 1993 & 826 & 893 & 1163 & 1295 & 1264 & 1216 & 1146 & 1096 & 1099 & 1079 & 960 & 777 \\
\hline 1954 & 784 & 892 & 1123 & 1282 & 1290 & 1349 & 1349 & 1330 & 1354 & 1323 & 1240 & 1081 \\
\hline 1953 & 1056 & 1063 & 1365 & 1581 & 1636 & 1589 & 1471 & 1470 & 1359 & 1250 & 1053 & 677 \\
\hline 1956 & 076 & 918 & 1125 & 1318 & 1331 & 1258 & 1189 & 1238 & 1087 & 1090 & 918 & 750 \\
\hline 1957 & 716 & 752 & 947 & 1092 & 1162 & 1135 & 1132 & 1169 & 1091 & 1068 & 912 & 752 \\
\hline 1958 & 731 & 726 & 917 & 1114 & 1198 & 1203 & 1298 & 1383 & 1349 & 1380 & 1310 & 1092 \\
\hline 1959 & 1026 & 1130 & 1416 & 1635 & 1583 & 1596 & 1516 & 1505 & 1418 & 1246 & & \\
\hline
\end{tabular}

30 MOO SEASONALLY ADJUSTEO SERJES $(T .20, T, 12)$

\begin{tabular}{|c|c|c|c|c|c|c|c|c|c|c|c|c|}
\hline & & & & ग्र & & & & & & & SER I & $\# 3694$ \\
\hline YEAR & JAN & FEB & MAR & APR & MaY & JUN & LL JU & AUG & SEP & OCT & NOV & DEC \\
\hline 1939 & 522 & 482 & 484 & 433 & 437 & 432 & 406 & 438 & 439 & 458 & 510 & 486 \\
\hline 1940 & 435 & 517 & 516 & 354 & 529 & 500 & 572 & 526 & 574 & 577 & 515 & 520 \\
\hline 1041 & 653 & 583 & 601 & 653 & 644 & 670 & 658 & 626 & 618 & 570 & 567 & 547 \\
\hline 1942 & 492 & 511 & 460 & $3 e 5$ & 319 & 256 & 220 & 219 & 204 & 202 & 195 & 196 \\
\hline 1043 & 163 & 161 & 177 & 162 & 186 & 172 & 177 & 200 & 193 & 200 & 198 & 209 \\
\hline 1944 & 207 & 191 & 159 & 160 & 142 & 142 & 129 & 111 & 109 & 110 & 119 & 115 \\
\hline 1945 & 120 & 119 & 126 & 131 & 144 & 176 & 174 & 200 & 237 & 299 & 396 & 477 \\
\hline 1946 & 625 & 680 & 746 & 703 & 667 & 611 & 643 & 656 & 654 & 647 & 626 & 641 \\
\hline 1947 & 630 & 677 & 671 & 693 & 730 & 769 & 852 & 921 & 1049 & 1073 & 1047 & 955 \\
\hline 1040 & 082 & 918 & 916 & 1016 & 995 & 989 & 987 & 900 & 872 & 002 & 605 & 793 \\
\hline 1949 & 783 & 753 & 790 & 090 & 918 & 946 & 978 & 1029 & 1093 & 1151 & 1273 & 1263 \\
\hline 1950 & 1325 & 1285 & 1403 & 1384 & 1460 & 1486 & 1469 & 1465 & 1253 & 1255 & 1122 & 1291 \\
\hline 1951 & 1218 & 1199 & 1098 & 992 & 991 & 941 & 916 & 991 & 1047 & 1016 & 998 & 979 \\
\hline 1952 & 1027 & 1130 & 1004 & 1032 & 1026 & 1006 & 1068 & 1044 & 1077 & 1123 & 1114 & 1093 \\
\hline 1953 & 1122 & 1103 & 1139 & 1141 & 1084 & 1066 & 1028 & 994 & 1013 & $102 \theta$ & 1071 & 1037 \\
\hline 1954 & 1058 & 1108 & 1109 & 1123 & 1107 & 1181 & 1215 & 1219 & 1257 & 1266 & 1370 & 1439 \\
\hline 1955 & 1417 & 1340 & 1370 & 1386 & 1404 & 1390 & 1321 & 1300 & 1272 & 1198 & 1154 & 1155 \\
\hline 1956 & 1174 & 1178 & 1147 & 1161 & 1242 & 1102 & 1065 & 1085 & 1013 & 1046 & 1001 & 984 \\
\hline 1957 & 959 & 972 & 978 & 967 & 1001 & 1000 & 1010 & 1014 & 1013 & 1022 & 988 & 983 \\
\hline 1958 & 1009 & 942 & 952 & 990 & 1037 & 1065 & 1154 & 1194 & 1243 & 1323 & 1413 & 1427 \\
\hline 1050 & 1380 & 1469 & 1479 & 1455 & 1376 & 1384 & 1345 & 1298 & 1306 & 1195 & & \\
\hline
\end{tabular}


PART THREE

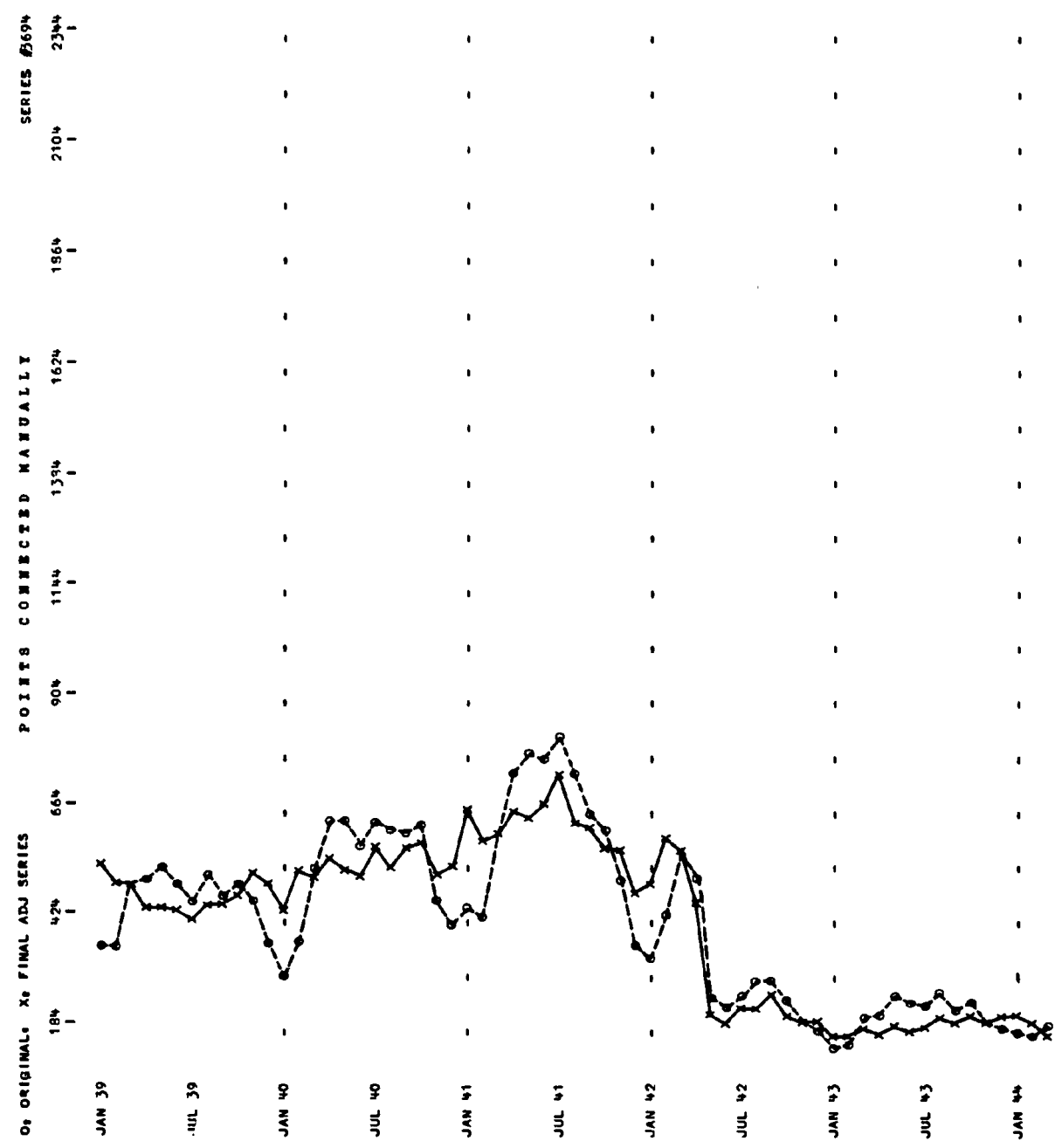


AIDS TO THE CURRENT USE OF INDICATORS

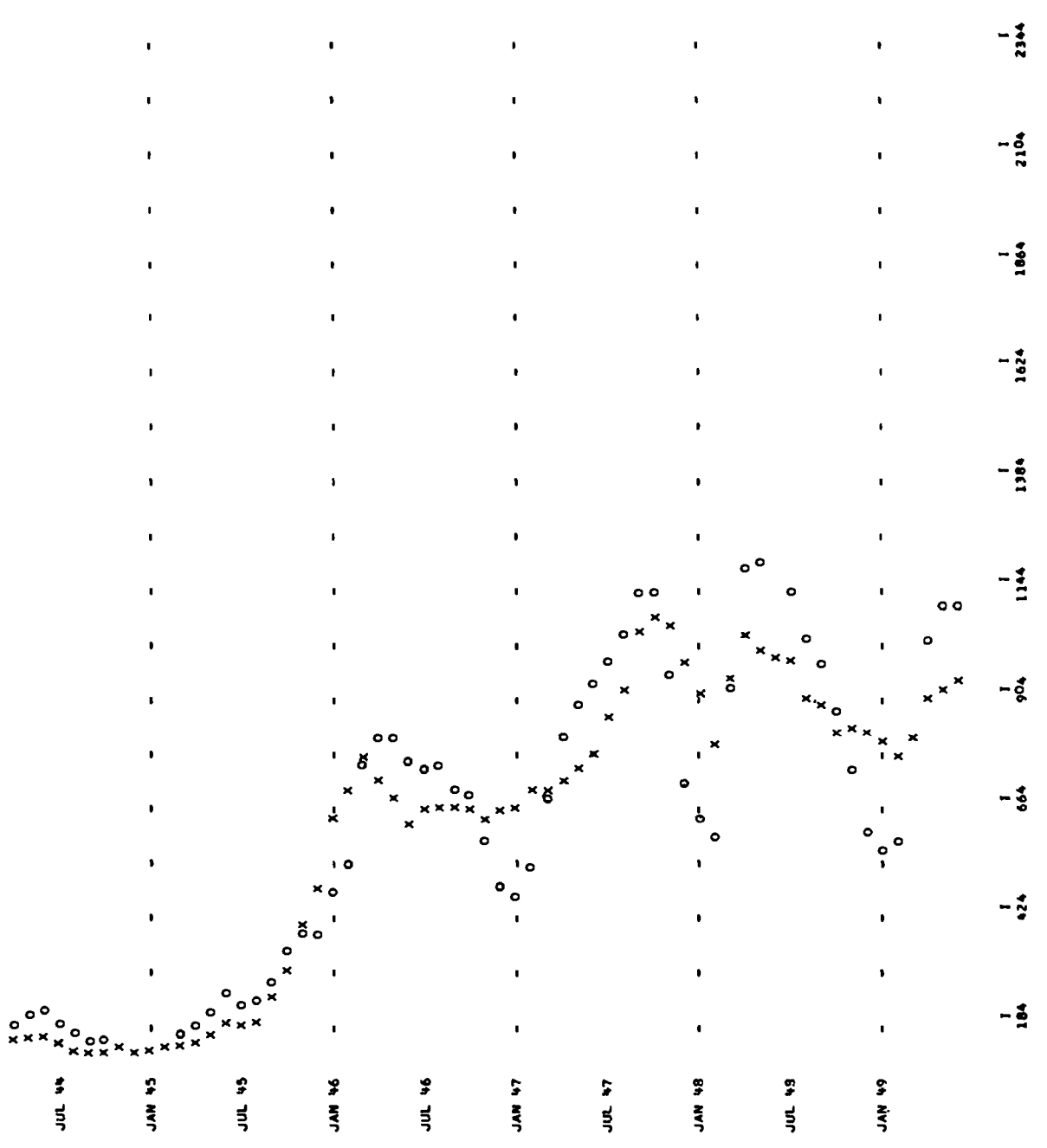


PART THREE

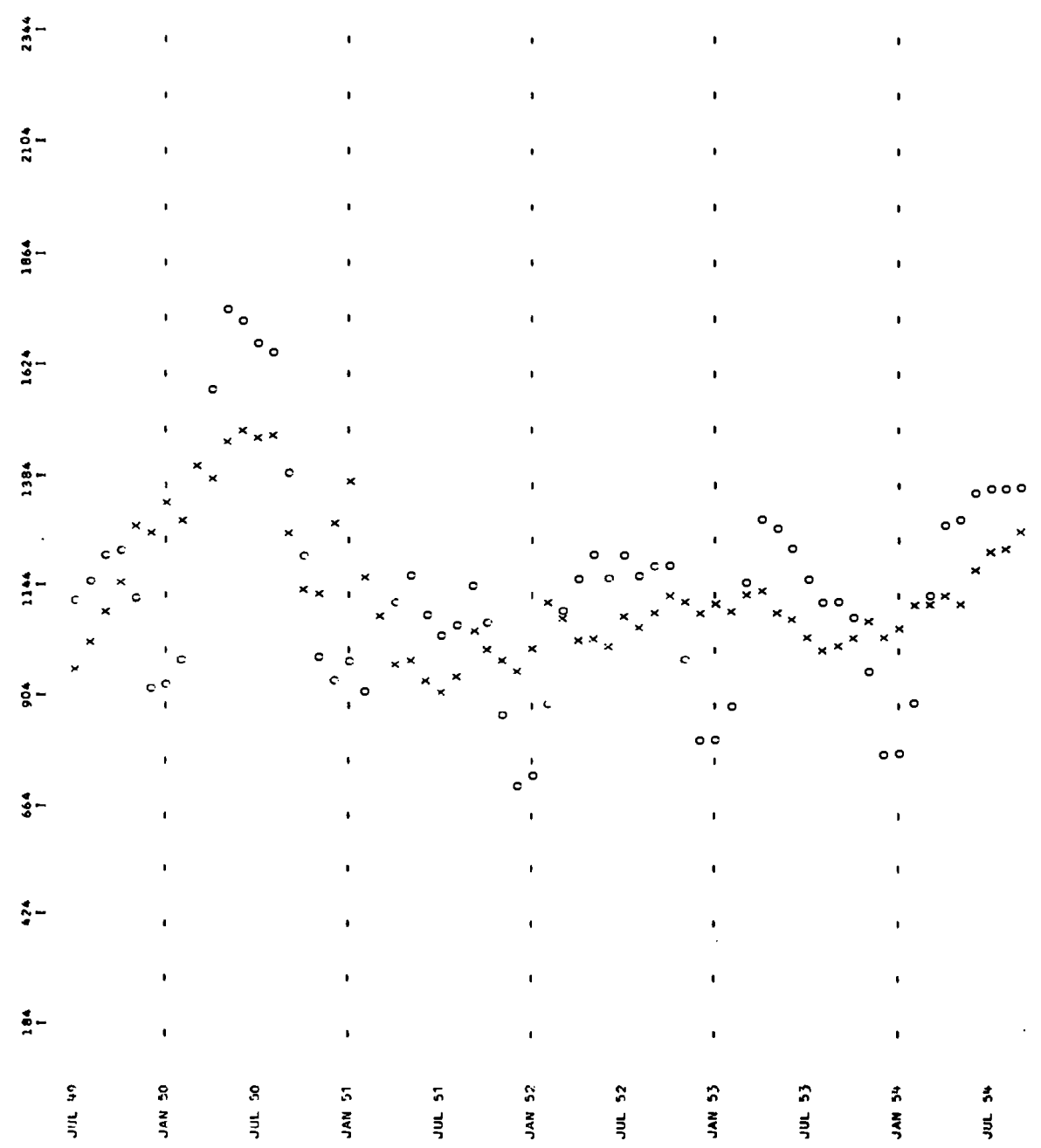


AIDS TO THE CURRENT USE OF INDICATORS

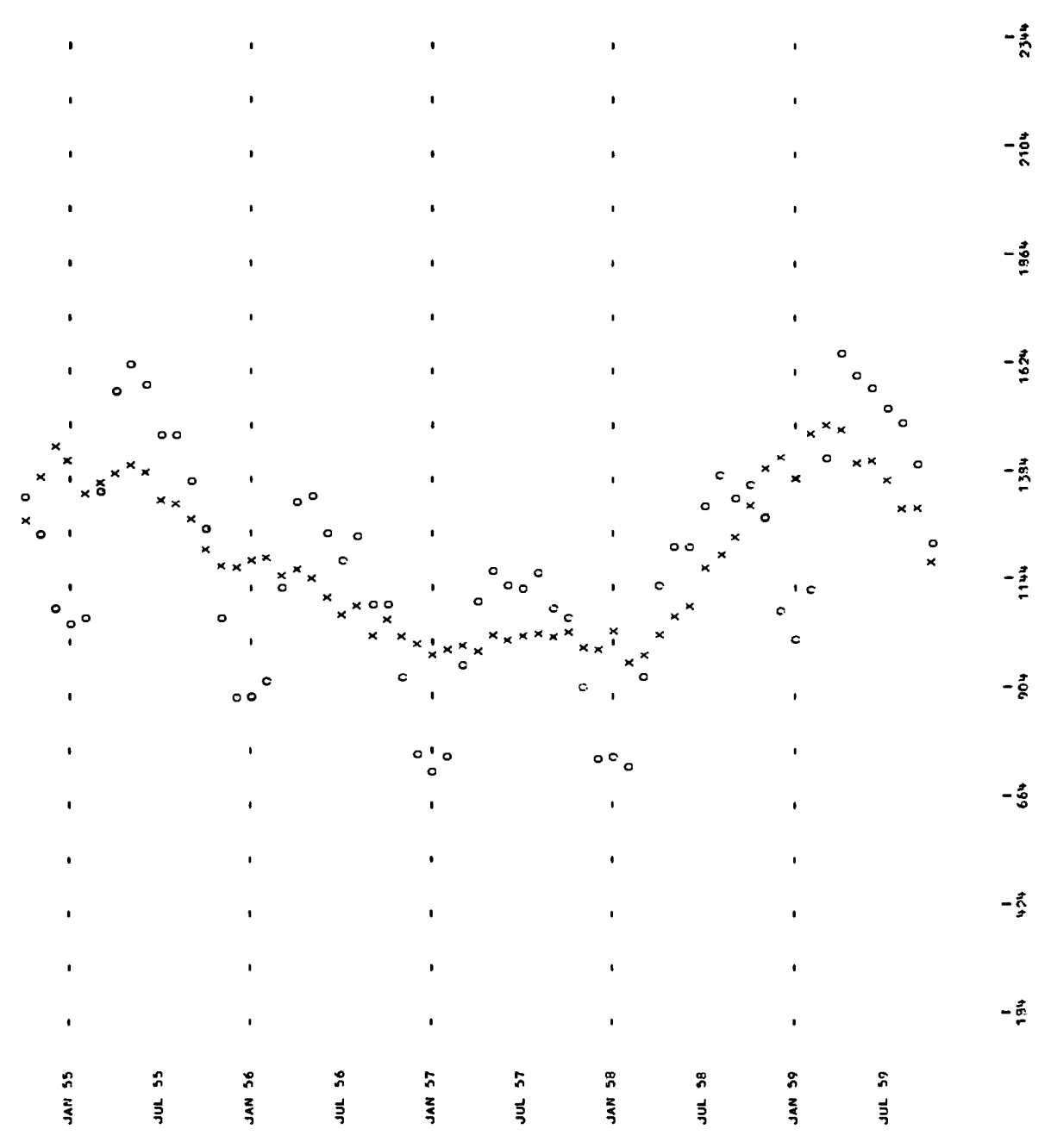


PART THREE

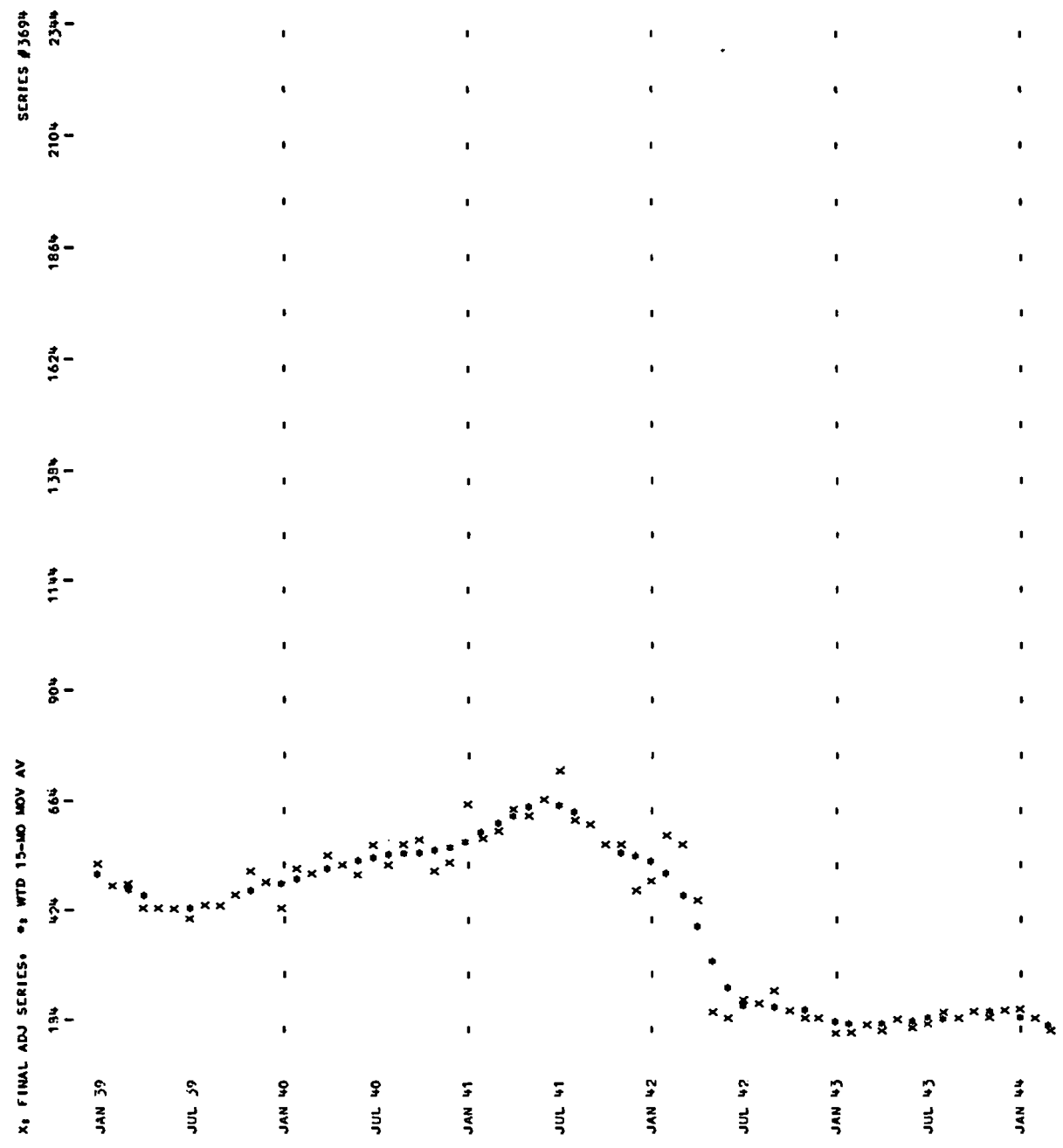


AIDS TO THE CURRENT USE OF INDICATORS

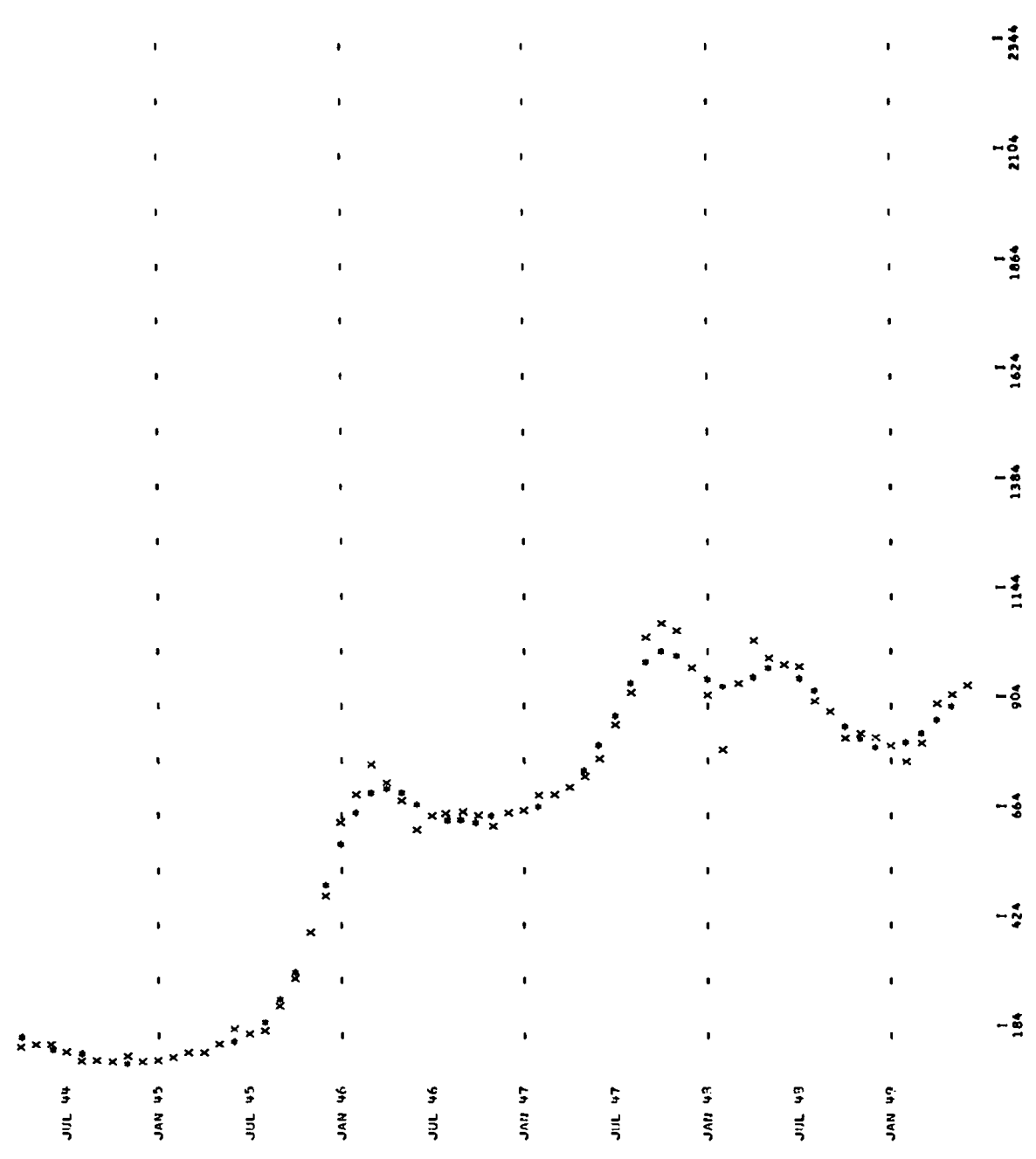


PART THREE

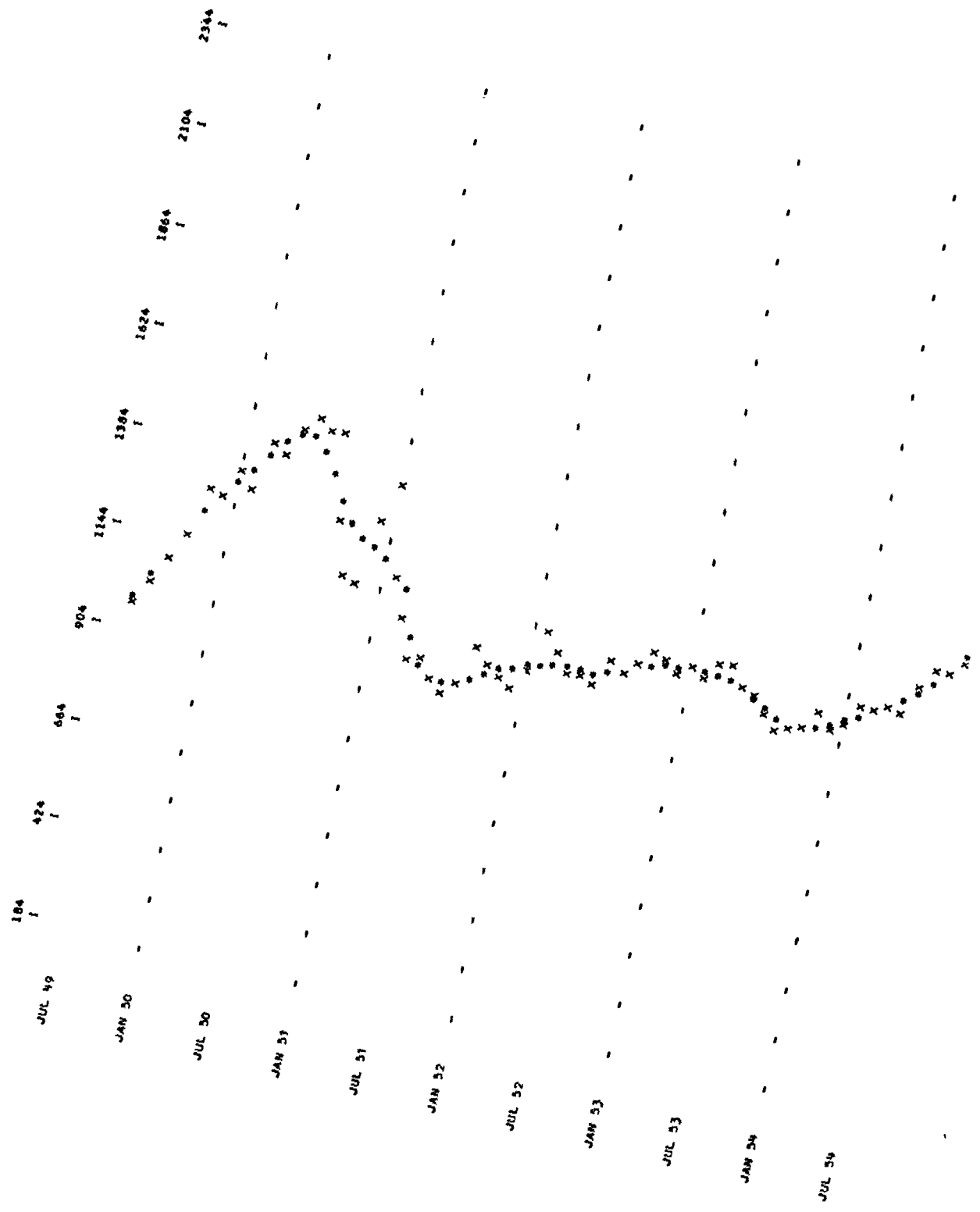

586 
AIDS TO THE CURRENT USE OF INDICATORS

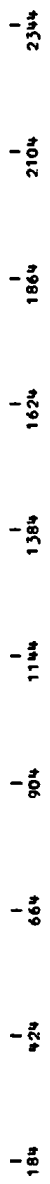

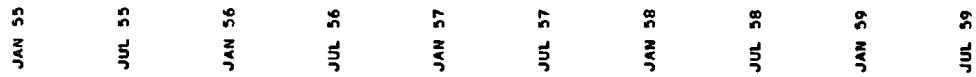




\section{PART THREE}

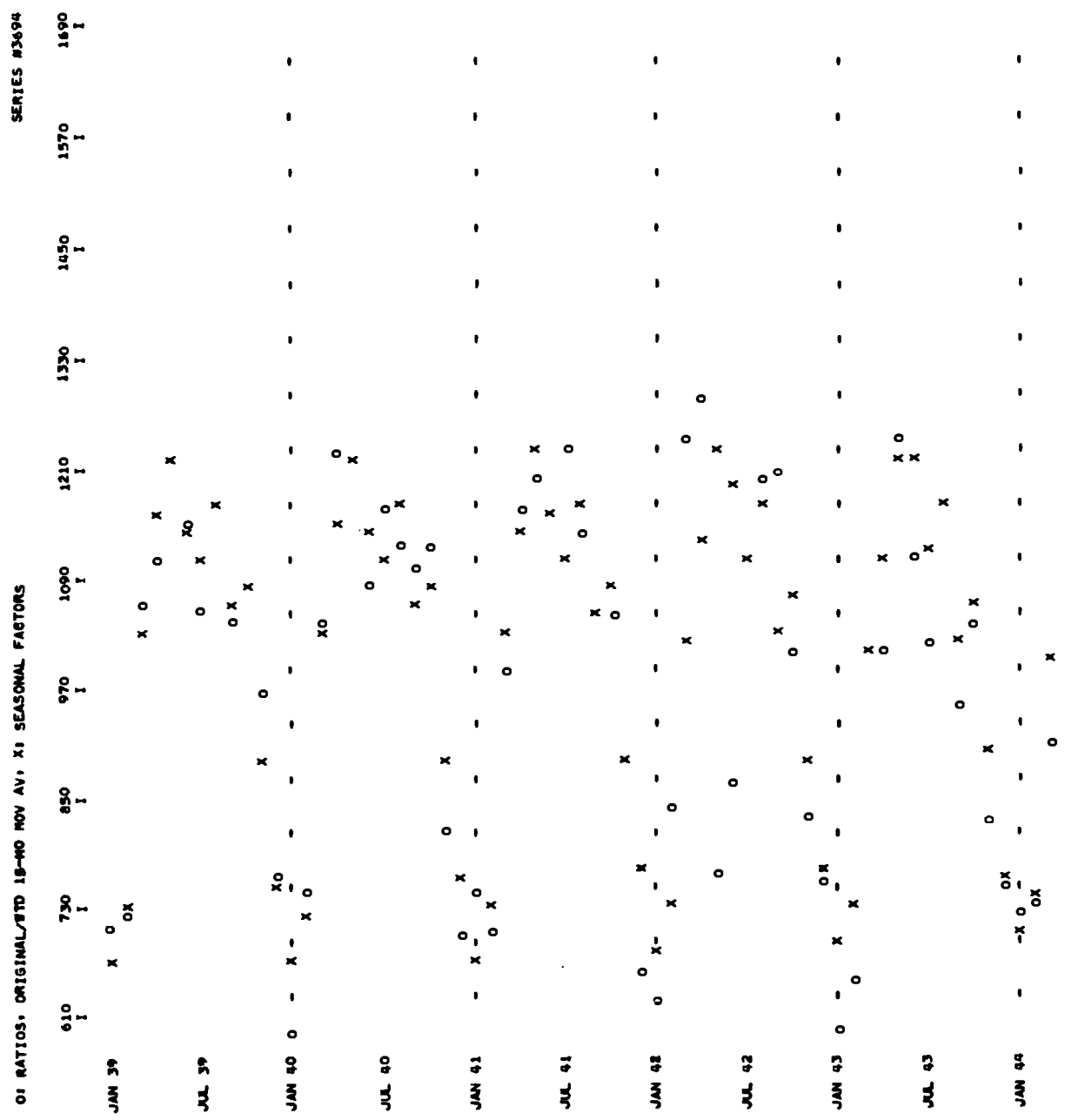


AIDS TO THE CURRENT USE OF INDICATORS

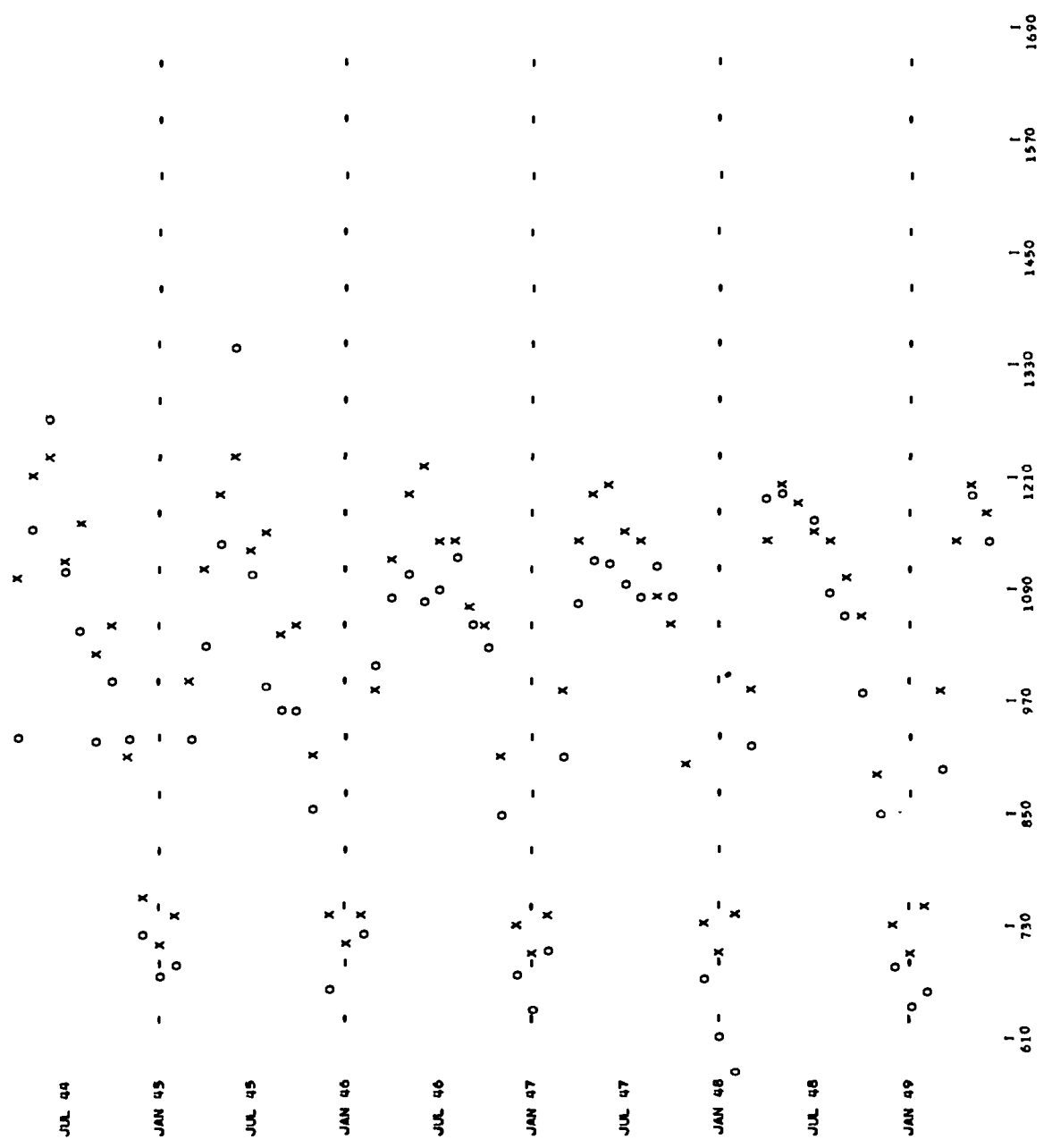


PART THREE

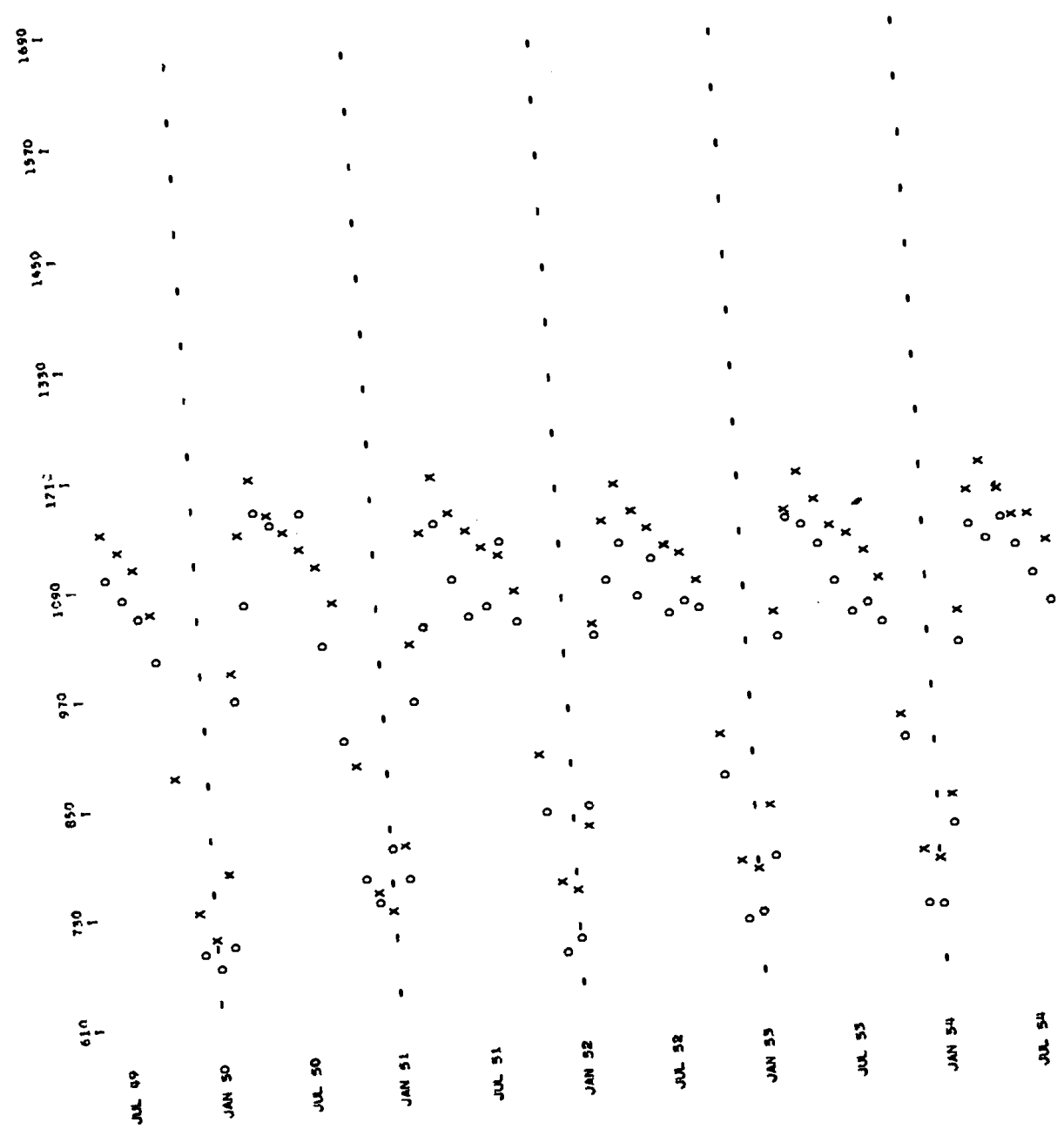

590 
AIDS TO THE CURRENT USE OF INDICATORS

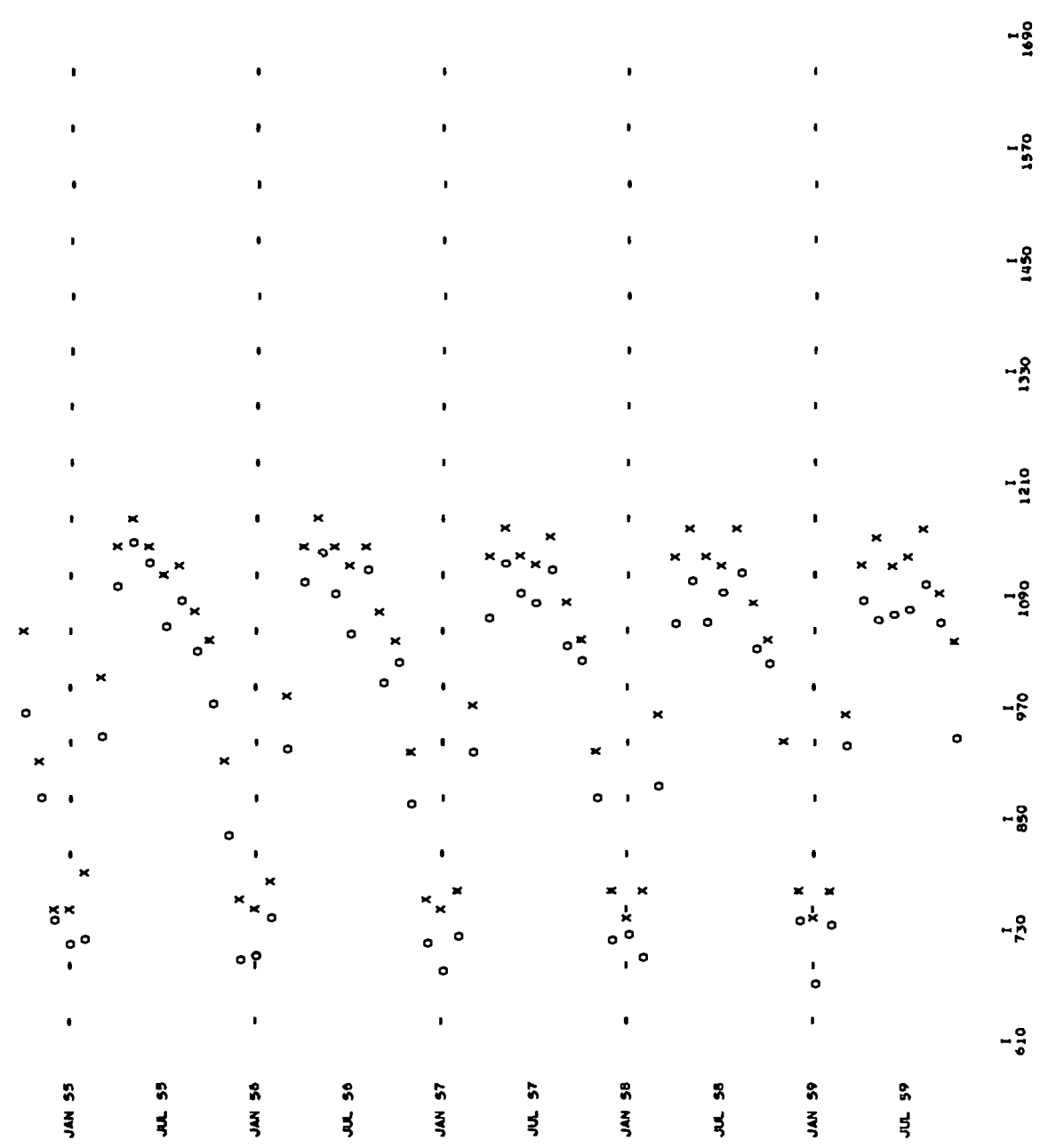




\section{PART THREE}

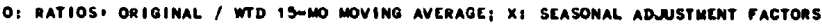
SCALE 10

\section{JAMUARY}

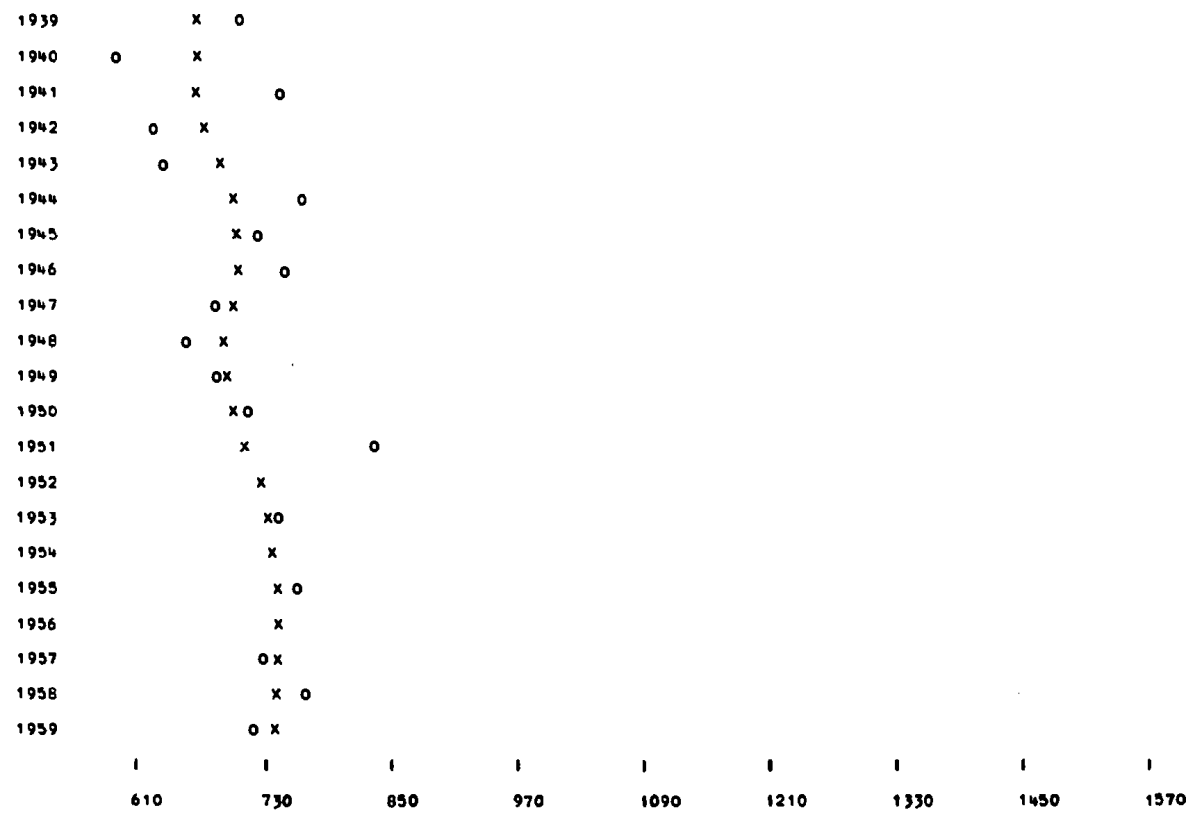

O: RATIOS, ORIGINAL / WTD IS-NO WOVING AVERAGE; $X$ : SEASONAL ADUUSTMENT FACTORS SCALE 10

\section{FenUakY}

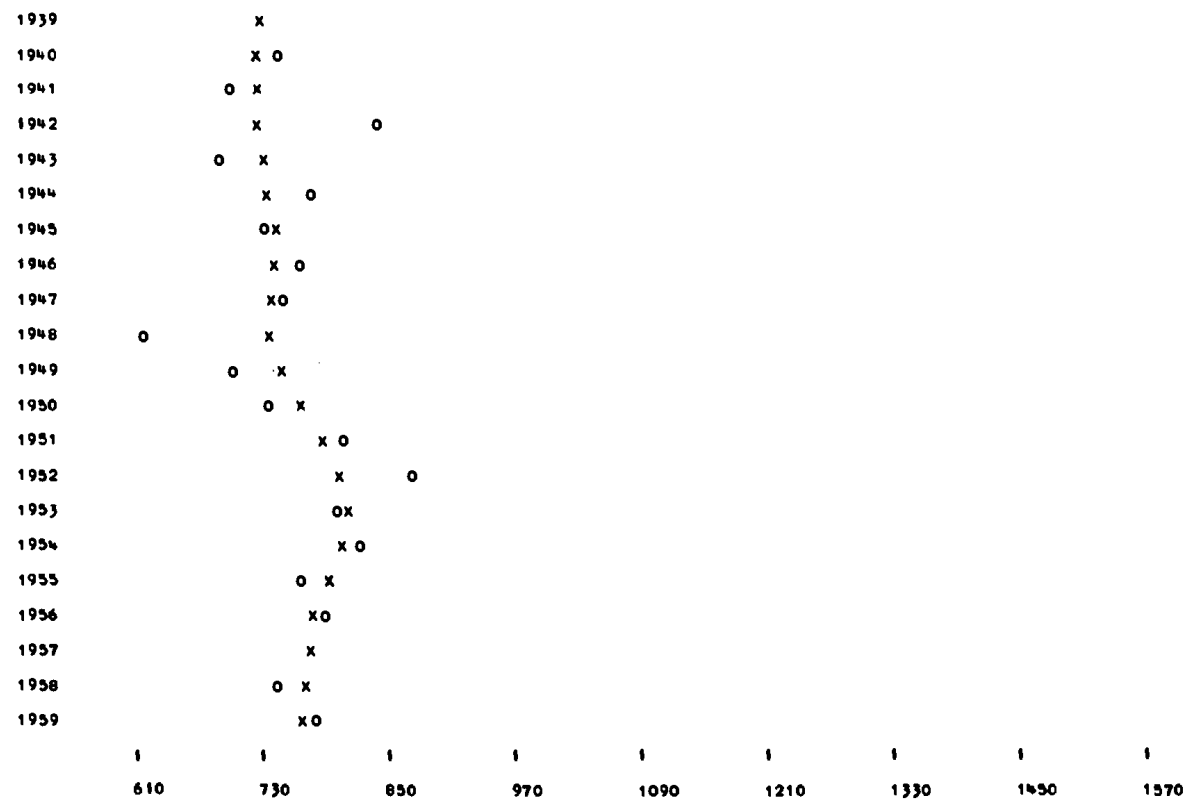




\section{AIDS TO THE CURRENT USE OF INDICATORS}

O: RATIOS, ORIOINAL / WD 19-WO mOVING AVERAGC: $X$ : SEASONAL ADNUSTMENT FACTORS SCALE 10

1939

1940

1941

1942

1943

1944

1945

1946

1947

1948

1949

1950

1991

1952

1953

1954

1953

1996

1997

1958

1999

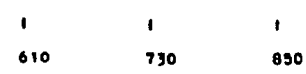

MARCH

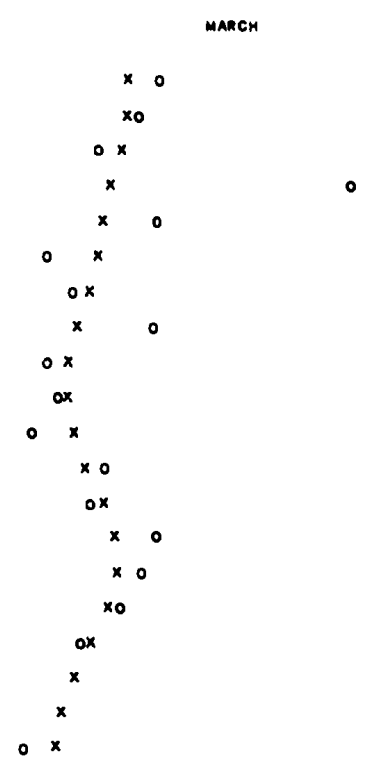

$1 \quad 1 \quad 1101$

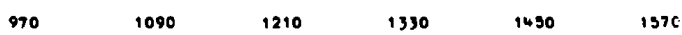

O: RATIOS, ORIQINAL / WTD 15-MO mOVING AVERAGE; $x_{3}$ SEASOMAL ADJUSTMENT FACTORS SCALE 10

\begin{tabular}{l}
1939 \\
1940 \\
1941 \\
1942 \\
1943 \\
1944 \\
1945 \\
1946 \\
1947 \\
1946 \\
1949 \\
1950 \\
1951 \\
1952 \\
1993 \\
1954 \\
1955 \\
1956 \\
1959 \\
1958 \\
1999 \\
\hline
\end{tabular}

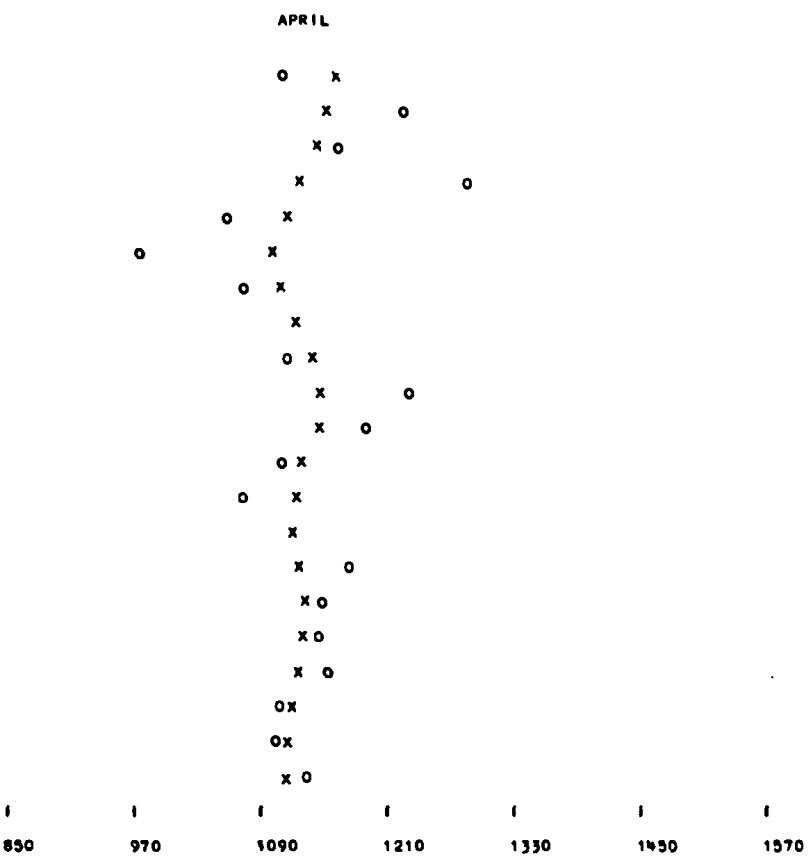




\section{PART THREE}

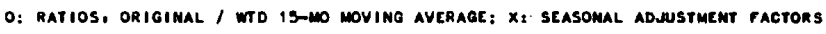
SCALE 10

MAY

1939

1940

1941

1942

1943

1944

1945

1946

1947

1948

1949

1950

1951

1952

1953

1954

1955

1956

1957

1958

1959

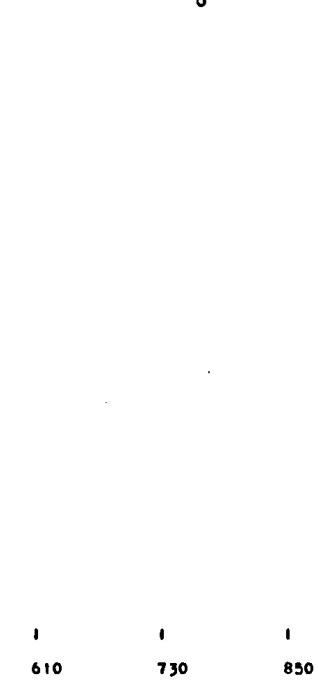

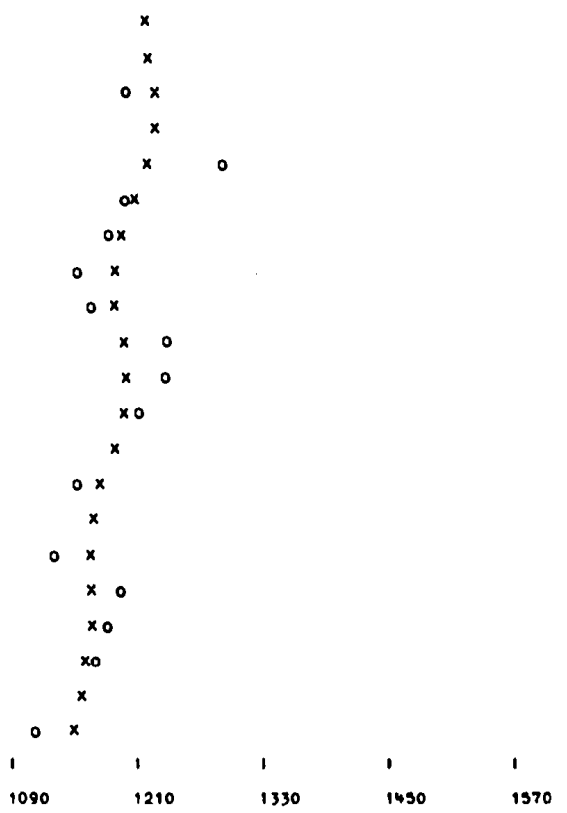

O: RATIOS, ORIGINAL / WT D IS-MO MOVING AVERAGE; $x$ : SEASONAL aDJUSTMENT Factons SCALE 10

1939

1940

1949

1942

1943

1944

1945

1946

1947

1948

1949

1950

1951

1952

1953

1954

1955

1956

1957

1958

1959
JUNE
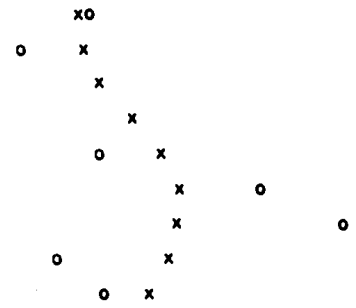

$\times 0$

$\times 0$

$\times 0$

$0 x$

$0 x$

$x$

xo

$\times 0$

$x$

$0 x$

$x$

1

1090

1

$610 \quad 730 \quad 850$




\section{AIDS TO THE GURRENT USE OF INDICATORS}

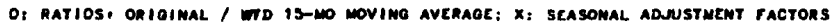
SCALC 10

1939

1940

1941

1942

1943

1944

1945

1946

1947

1948

1949

1950

1951

1932

1953

1954

1955

1956

1957

1958

1959

$\begin{array}{lll}1 & 1 & 1 \\ 610 & 730 & 650\end{array}$

NLY

- $\quad x$

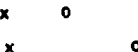

$x$

- $x$

$\times 0$

$\times 0$

ox

$\times \quad 0$

$\times \quad 0$

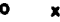

$\times 0$

$0 \times$

$\times 0$

ox

o $x$

$x$

$\times 0$

$x$

$\begin{array}{ll}1 & 1 \\ 1090 & 1210\end{array}$

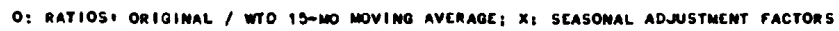
SCALE 10

1939

1940

194

1942

194

1944

1945

1946

190

1948

194

1950

1951

1952

1953

1934

1999

1956

1937

1958

1959
Auoust

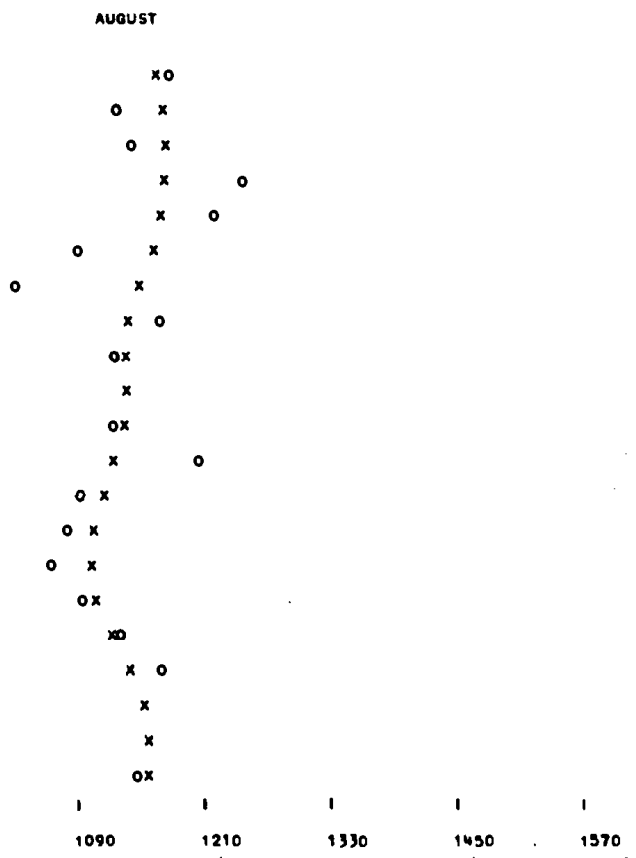




\section{PART THREE}

O: RATIOS. ORIGINAL / WTD 15-MO MOVING AVLRAGC: $X$ : SEASONAL ADJUSTMENT FACTORS SCALE 10

SLPT CMBER

1939

1940

1941

$\sin 2$

1943

1944

1945

1946

1947

1948

1949

1950

1951

1952

1933

1954

1955

1956

1957

1958

1959

$\begin{array}{ll}1 & 1 \\ 610 & 730\end{array}$

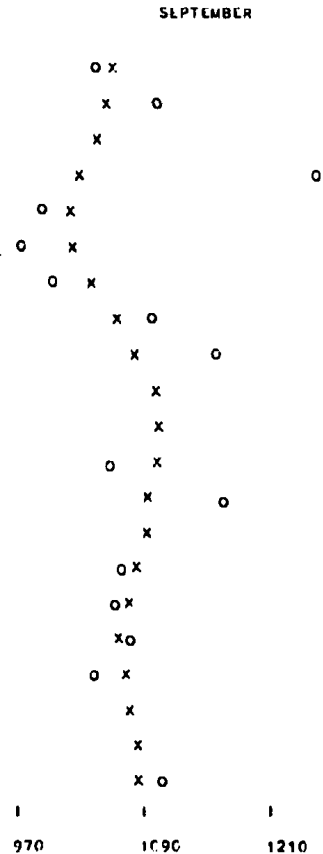




\section{AIDS TO THE CURRENT USE OF INDICATORS}

O: RATIOS ORIGINAL / WTV I5-MO MOVING AVERAGL; X: SZASONAL ADJUSTMENT FACTORS SCALC 10

NOVEMECR

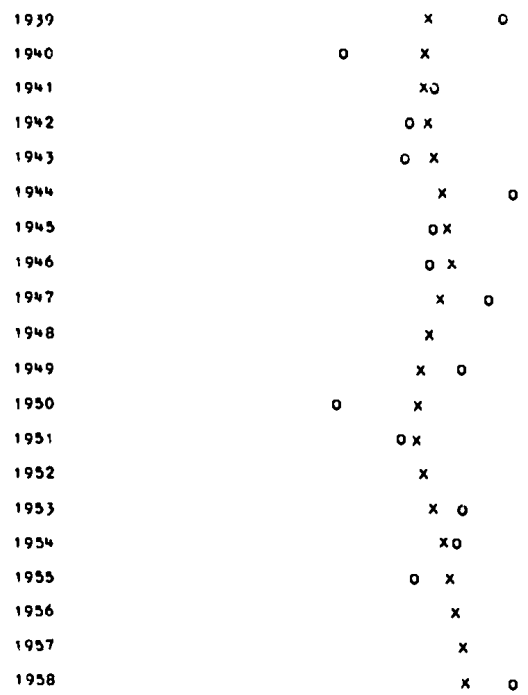

$\begin{array}{lllllllll}1 & 1 & 1 & 1 & 1 & 1 & 1 & 1 \\ 610 & 730 & 650 & 970 & 1090 & 1210 & 1330 & 1450 & 1570\end{array}$

O: RATIOS, ORIGINAL / ITD 13-MO MOVING AVERAGL: X: ILASONAL AUJUSTMENT FACTORS SCALC 10

DECEMBLR

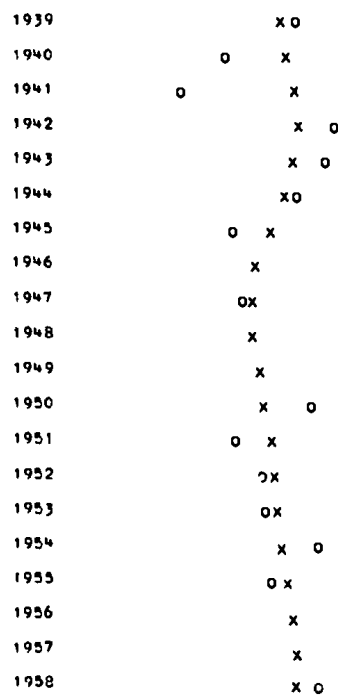

$\begin{array}{llll}1 & 1 & 1 & 1 \\ 610 & 730 & 050 & 970\end{array}$

1090

